\title{
Les dernières sociétés du Tardiglaciaire et des tout débuts de l'Holocène en France
}

\section{Bilan d'une trentaine d'années de recherche}

\author{
Nicolas Naudinot ${ }^{1}$, Jean-Pierre Fagnart ${ }^{2}$, Mathieu Langlais ${ }^{3}$, \\ Ludovic Mevel ${ }^{4}$, Boris Valentin ${ }^{5}$
}

Article reçu le 12 novembre 2018 - Accepté le 5 janvier 2019 - Mis en ligne le 9 avril 2019

\begin{abstract}
Mots clés. Alpes, art mobilier, Bassin aquitain, Bassin parisien, façade atlantique, Ouest de la France, Paléolithique récent, paléoéconomie, Tardiglaciaire, technologie lithique
\end{abstract}

Résumé. Depuis le milieu des années 1980, une importante dynamique de recherche bénéficie aux derniers temps du Paléolithique supérieur en France. Cet article propose un bilan de cette trentaine d'années de recherche. Bien qu'organisée autour des quatre grandes unités géographiques, chacune structurante dans la connaissance de ces sociétés, cette synthèse vise à mettre en lumière, à l'échelle de la France, les grandes dynamiques de recomposition des systèmes techniques, économiques, symboliques et probablement socioculturels. Entre la fin du Magdalénien et les premiers temps du Mésolithique, I'histoire des chasseurs-collecteurs évoluant sur ce territoire connait en effet trois grandes inflexions dont les rythmes restent flous. La compréhension des moteurs à l'origine de ces basculements demeure très délicate, même si plusieurs scénarios mobilisant le contexte climatique et environnemental, très instable de cette période, sont régulièrement avancés. Quoi qu'il en soit, ce Tardiglaciaire ne constitue plus aujourd'hui l'antichambre du Mésolithique - un «Épipaléolithique » disait-on - surtout étudié pour contextualiser l'avènement des sociétés complexes, attribuées à tort au seul Néolithique. Ces derniers temps du Pléistocène, du fait de nombreuses transformations culturelles des techno-complexes et traditions aux schémas évolutifs complexes, sont en réalité particulièrement riches en problématiques de recherches propres.
Keywords. Alpes, mobile art, Aquitain basin, Paris basin, Atlantic façade, Western France, Upper Paleolithic, paleo-economy, Lateglacial, lithic technology

Abstract. Since the middle of the 1980s, a lot of research has focused on the end of the Upper Palaeolithic in France. This article presents an overview of these thirty years of research, organized around four main geographic units which structure our knowledge of these societies. However, this overview aims to bring to light the main dynamics driving the composition of the technical, economic, symbolic and probably socio-cultural systems in France as a whole. Between the end of the Magdalenian and the first stages of the Mesolithic, the history of the hunter-gatherers on this territory underwent three major changes. The rhythms of these changes are still unclear and understanding the forces driving these changes is still difficult, although scenarios based on the very unstable climatic and environmental context are often advanced. This Lateglacial is no longer merely considered to be the antechamber of the Mesolithic -an "EpiPalaeolithic", as it was called-studied in particular to contextualize the emergence of complex societies, wrongly solely attributed to the Neolithic. These last Pleistocene periods, with their abundant cultural changes and complex evolutionary techno-complexes and traditions, comprise their own research issues and constitute a subject in their own right.

1. Université Nice Sophia-Antipolis, UMR 7264 CEPAM, UMR 6566 CReAAH, Bâtiment 24-25, Campus de Beaulieu, 35000 Rennes | nicolas. naudinot@cepam.cnrs.fr

2. Association pour l'étude du Paléolithique de la Somme, 18 rue Dufour, 80000 Amiens | jp.fagnart@wanadoo.fr

3. UMR 5199 PACEA, Bâtiment B8, Allée Geoffroy Saint-Hilaire, 33600 Pessac | mathieu.langlais@u-bordeaux.fr

4. UMR 7041 ArScAn - Ethnologie préhistorique, Maison Archéologie et Ethnologie René-Ginouvès, 21 allée de l'université, 92000 Nanterre | ludovic.mevel@cnrs.fr

5. Université Paris 1 Panthéon-Sorbonne, 3 rue Michelet, 75006 Paris | boris.valentin@univ-paris1.fr 


\title{
The last Lateglacial and Early Holocene societies in France
}

\author{
Overview of thirty years of research
}

Since the middle of the 1980s, a lot of research has focused on the end of the Upper Palaeolithic in France. During this period of marked climatic instability, phases of climate warming were followed by phases of deterioration over a relatively short period of time (Rasmussen et al. 2014) and technical, economic, symbolic and probably socio-cultural systems underwent several cycles of reconfiguration. This article aims to assess the knowledge acquired over the past thirty years, and is divided into four parts focusing on macroregional geographic units (fig. 1).

Based on the exploration of these units, we describe the different stages underlying the construction of present-day scenarios:

1. The overall chrono-stratigraphic framework of the period based on sites in the North of France, which is a pioneering region from this point of view;

2. An overview of seminal research in the Paris Basin from the 1990s onwards;

3. More recent developments on the chronology, technical choices, economic organization of societies and their symbolic practices on the Atlantic coast;

4. Similar developments in the East of France.

This overview of the final French Palaeolithic yields a homogeneous picture throughout the country. This uniformity is undoubtedly related to the generalization of technological approaches, but it also underlines the strong links between human communities in France at the end of the Palaeolithic. Between the end of the Magdalenian and the first stages of the Mesolithic, groups of hunter-gatherers in France underwent three major changes. The rhythms of these changes are still unclear, but they are marked by important transformations in the technical systems, and also more generally in economic and perhaps social organization.

The first of these episodes is perceptible at the end of GIle, when the standards structuring the Magdalenian gradually give way to new technical solutions during the Early Azilian (fig. 8). The latter seems to maintain several Magdalenian characters, but many choices also differentiate it from the preceding period: abandonment of bladelet productions, exclusive use of axial points rather than backed bladelets or the systematic use of stone hammers (Valentin 2008, Fat Cheung et al. 2014, Mevel 2017, Naudinot et al. 2017a). The osseous industry also seems to be modified with a drastic reduction of these productions and a clear decrease in typological categories. On the other hand, graphical representations show clear Magdalenian-type stylistic elements (Lorblanchet 1985, Naudinot et al. 2017a, 2018a, 2018b). This arrhythmia in cultural changes during this period raises questions regarding the causes of these transformations. The estimation of the overall rhythm of this transition still raises problems as the dates of these two complexes (Recent Magdalenian and Early Azilian) sometimes overlap. Is this the consequence of the high plateau in the radiocarbon calibration curve or does this overlap indicate the cohabitation of groups with different technical baggage? Stratigraphic data now point towards the first hypothesis, but this question, and more generally the tempo and the transition between the Magdalenian and Azilian, still require more research.

The technical changes initiated during the early phase of the Azilian became increasingly clear from the beginning of GIld-c-b-a onwards, although, again, it is difficult to pinpoint the exact timing of this shift. The lithics from this recent phase of the Azilian are often produced on materials collected from limited procurement areas with less standardized and regular production aims than previously (fig. 8). Blades (or often elongated flakes) are obtained with simple operating schemes (reduced or even inexistent shaping of volumes, percussion with a stone hammer set back from striking platform edges with inconstant preparation for extraction and even the use of bipolar percussion on an anvil in some regions). In the Early Azilian, and during the Magdalenian, we observe important maintenance, reuse and recycling strategies for toolkits (with in particular the resharpening of laminar cutting edges with flat scalar retouch in the Early Azilian; Bodu and Mevel 2008), whereas during the recent Azilian, groups opt for less technical investment, with lower expenditure and more ephemeral use (Valentin 2008, Naudinot 2010, Fat Cheung et al. 2014, Mevel 2017). These choices reflect more general changes affecting the economic organization and mobility of these societies (Coudret and Fagnart 1997, Floss 2000, Valentin 2008, Naudinot 2010, Naudinot and Jacquier 2014). Equipment in osseous materials is typologically different from productions from the preceding period, but undergoes less important changes at this time, as the rupture with the Magdalenian occurred at an earlier stage. Conversely, art undergoes a major change during this recent phase with the disappearance of figurative expressions and the emergence of engraved or painted geometric outlines on pebbles (Couraud 1985, D'Ericco 1994). This change occurs much later than previously thought (Naudinot et al. 2017a). Nonetheless, the timing and extent of this artistic mutation still need to be better defined. 
We now know that the Recent Azilian lasted, at least in the Pyrenees (Fat Cheung 2015, Tomasso et al. 2018), during the first half of the GS1 climatic deterioration. The second half of this period and the first part of the Preboreal are marked by the last episode of the French Palaeolithic. Contrary to common belief, in most of France, what we consider as the end of the Palaeolithic does not coincide with the beginning of the Holocene. Indeed, it is only during the second half of the Preboreal that the Mesolithic develops fully. Until the end of the first half of the Preboreal, industries with abundant geometric microlithics are observed in the North of France, but with similar laminar productions to those of the last Palaeolithic groups (Ducrocq et al. 2008, Ducrocq forthcoming). From this viewpoint, only the extreme southeast of the territory shows signs of earlier development, as the terminal phase of the Epigravettian, dated from GS1, presents most of the characteristics of the Mesolithic (Tomasso et al. 2014, Naudinot et al. 2017b). Elsewhere, the first lithic industries of these last Palaeolithic communities from the beginning of the Holocene do not show early signs of mesolithisation in terms of debitage, but rather a reorganization of technical systems in pursuit of the systematic production of regular and standardized blades and bladelets (fig. 8; Fagnart 1997, Valentin 2005, 2008, Naudinot 2010, 2013, Langlais et al. 2014a, 2014b, forthcoming). In addition to the regularity of blanks, operative schemes also aimed to produce sharp cutting edges, and these two purposes structured production (Naudinot 2010, 2013). In the Paris basin, some assemblages from the "Belloisian" facies aimed towards the production of long blades (Fagnart 1997, Valentin 2008). This type of debitage is also known in the South of England (Barton et al. 2003), in sectors with abundant good quality flint, and seems to have been driven by rather specific activities, such as butchery, for example (Jacquier 2015). We also observe an important transformation of paleo-economic organization with the spatio-temporal segmentation of activities, some of which are quite specialized, in contrast with Recent Azilian sites, which are often described as polyfunctional (Valentin 2008, Naudinot 2010, Naudinot and Jacquier 2014). Renewed interest for blades results in a new change in raw material acquisition strategies with a significant extension of lithic procurement areas, and also leads to a profound restructuring of operative schemas with high-investment debitage and careful shaping and maintenance phases. This trend seems to be common to a zone extending from the Pyrenees (and perhaps even to the Iberian Atlantic coast) to the South of Scandinavia. This increased technical investment does not seem to apply to the osseous industry, as currently available data show that the osseous toolkit is rather sparse and monotonous, as in the preceding Azilian phases, although some typological changes exist (Langlais et al. forthcoming). The art of these last Palaeolithic societies is still rather poorly known and is only present in the Early Laborian in France on the Atlantic coast (Paillet and Man-Estier 2014,
Paillet et al. 2018). However, this reduced corpus is particularly interesting, as unlike the Azilian where discrepancies exist between technical and artistic change, during the Laborian we observe a totally unique figurative style at the same time as the emergence of new blade production requirements (even though some emblematic Azilian engraved pebbles with geometric patterns seem to persist; Pasty et al. 2002). We also note that a cultural mosaic underlies this large-scale cohesion, based on the typology of projectile points (early/recent Laborian, Ahrensbourgian/Epiahrensbourgian). In the South of France, the situation seems to be even more complex at the interface of cultures preceding the Epigravettian (during which industries seem to follow a process of technical simplification initiated during the Early Dryas: Naudinot et al. 2017b, Tomasso et al. 2014). On the Mediterranean coast, rare Laborian incursions are now attested in the Var (Naudinot and Tomasso 2012), whereas the large majority of the industries are attributed to the Recent then terminal Epigravettian (Gagnière 1948). These complexes are still sometimes gathered into specific local cultural entities (Escalon de Fonton and Onoratini 1977, Escalon de Fonton et al. 1978) and demonstrate the complexity of human interactions during this period. In the Northern Alps and the Jura, alongside some rare unquestionable evidence of the Laborian (Monin 2000), we observe the emergence of original industries which have been linked to the Epigravettian (Mevel et al. 2014).

The millennia marking the second half of the French Lateglacial are thus separated into several main phases, for which the limits and internal rhythm remain unclear. One of the challenges of the coming years will include reflections on the mechanisms underlying this evolution and on regional discrepancies. Climatic parameters are often cited but archaeological and environmental data are still too tenuous to provide perfect correlations. There is no doubt that climatic instability and its implications for resources and landscapes had important consequences on societies, their technical systems and more generally their socio-economic organization, but research now needs to be developed further in order to avoid mechanistic models. Recent paleogenetic studies (Fu et al. 2016) also show that other parameters should also be included to explain these shifts during the Lateglacial. Our knowledge of these Final Palaeolithic societies has thus made a lot of progress over the past thirty years with the development of environmental studies, palethnographic and technological perspectives and also through the contribution of rescue archaeology. Ultimately, this Lastglacial is no longer merely the antechamber of the Mesolithic -an "Epipalaeolithic", as it was called- studied in particular to contextualize the emergence of complex societies, wrongly solely attributed to the Neolithic. These last Pleistocene periods, with their abundant cultural changes and complex evolutionary techno-complexes and traditions, are particularly rich in their own research issues and constitute a subject in their own right. 
Depuis le milieu des années 1980, une importante dynamique de recherche bénéficie aux derniers temps du Paléolithique supérieur en France. Cette époque, marquée par une forte instabilité climatique, voit se succéder sur un temps finalement assez court des phases climatiques de réchauffement et de péjoration importantes et elle est le théâtre de plusieurs cycles de recomposition des systèmes techniques, économiques, symboliques et probablement socioculturels. Pour rendre compte des connaissances réunies depuis une trentaine d'années ${ }^{1}$, cet article est divisé en quatre parties traitant d'unités géographiques macrorégionales dont l'exploration permet aussi de suivre les différentes étapes de construction des scénarios actuels. Ces parties présentent ainsi successivement :

1. Le cadre chronostratigraphique général de la période à partir des gisements du Nord de la France, région pionnière de ce point de vue (J. -P. Fagnart) ;

2. Un bilan des recherches, elles aussi fondatrices, menées dans le Bassin parisien dès les années 1990 (B. Valentin);

3. De plus récents développements sur la chronologie, les choix techniques, l'organisation économique des sociétés et leurs pratiques symboliques sur la façade atlantique (M. Langlais et N. Naudinot);

4. Des développements du même ordre dans l'Est de la France (L. Mevel).

De cette esquisse sur la France au Tardiglaciaire ressort l'image d'une succession de phases de simplification technique et d'autres marquées par une grande exigence, de moments de « globalisation culturelle » (Valentin 2008a) suivis de relatif morcellement, le tout sur fond de changements dans les stratégies paléo-économiques, tantôt à tendance plutôt résidentielle, tantôt plutôt logistique. Au final, ce Tardiglaciaire ne constitue plus l'antichambre du Mésolithique - un "Épipaléolithique » disait-on - surtout étudié pour contextualiser l'avènement des sociétés complexes, attribuées à tort au seul Néolithique (Testart 2005). On se gardera ici de tout finalisme de ce genre pour s'intéresser aux dynamiques particulières à cette fin du Paléolithique supérieur et à leur rythme ainsi qu'à la délicate question des mécanismes du changement.

\section{LE PALÉOLITHIQUE FINAL DU NORD DE LA FRANCE : L'APPORT DES RECHERCHES SUR LE BASSIN DE LA SOMME}

Les recherches pluridisciplinaires menées, dès le début des années 1980, dans le bassin de la Somme ont permis d'intégrer les différentes occupations du Paléolithique final ${ }^{2}$ dans un

1. Ce bilan est né d'une commande pour l'ouvrage de synthèse édité à l'occasion du XVIII ${ }^{e}$ congrès de l'UISPP (juin 2018, Paris). Notre projet initial, n'ayant pu aboutir pour diverses raisons, se trouve ici finalisé.

2. Nous entendons ici par Paléolithique final la période correspondant à la fin du Paléolithique supérieur ou plus exactement du Paléolithique récent. Dans le cadre de cet article, le Paléolithique final regroupe les cultures postérieures au Magdalénien et antérieures au Mésolithique. cadre lithostratigraphique, chronostratigraphique et paléoécologique relativement précis. À partir de 1985, la découverte de nombreux gisements tardiglaciaires (fig. 1) enfouis sous les plaines alluviales actuelles a pleinement révélé l'importance et la richesse du potentiel archéologique préservé sous la sédimentation holocène des fonds de vallées (Fagnart 1988, 1993, 1997). L'ouverture de ballastières dans ces zones humides a largement contribué au développement des recherches et à l'établissement d'un cadre fiable pour la paléohistoire des chasseurs-cueilleurs de la France septentrionale à la fin des temps glaciaires. Une série de travaux interdisciplinaires a mis en évidence les grandes phases de l'évolution de l'environnement depuis 15000 ans et leurs corrélations avec les variations globales du climat (Antoine 1990, 1997a, 1997b, 1997c). Au cours des décennies 1990 et 2000 , les recherches ont connu un essor et une dynamique sans précédent associant les différents acteurs de l'archéologie et du paléo-environnement. Le cadre chronologique et culturel du Paléolithique final a été détaillé et les différentes occupations humaines reconnues ont été replacées dans un contexte paléo-écologique et environnemental de plus en plus précis (Antoine et al. 2000, 2003, 2011, 2012, 2014).

\section{LES DONNÉES DE LA STRATIGRAPHIE ET DE L'ENVIRONNEMENT : LE MODĖLE DE LA SÉQUENCE DE FOND DE VALLÉE DU BASSIN DE LA SOMME}

La sédimentation tardiglaciaire du Nord de la France et plus particulièrement du bassin de la Somme est principalement représentée dans les vallées tandis que les processus d'altération dominent sur les plateaux et les versants. Les recherches interdisciplinaires menées depuis un peu plus de vingt ans sur les fonds de vallées ont mis en évidence les grandes phases de l'évolution environnementale durant le Tardiglaciaire weichselien et le début de l'Holocène (Antoine 1997a, 1997b, 1997c, Antoine et al. 2000, 2003, 2011, 2012, 2014). Les travaux menés en particulier à Conty, dans la vallée de la Selle à une vingtaine de kilomètres au sud-ouest d'Amiens, ont montré l'évolution progressive dès le début du Tardiglaciaire de la morphologie des systèmes fluviatiles, depuis le système périglaciaire en tresses vers un système à méandres (fig. 2).

L'oscillation de Bølling (GIle : Rasmussen et al. 2014) correspond à la première amélioration climatique du Tardiglaciaire. Durant cette période, caractérisée par une incision et une évolution du système fluviatile vers un système de transition à chenaux stables, on assiste pour la première fois depuis le Pléniglaciaire supérieur au développement d'une végétation arbustive à Bouleau et à Saule dans un milieu toujours ouvert. La recolonisation progressive du milieu par la végétation est confirmée par la malacologie et par les études de coléoptères, ces derniers indiquant des températures moyennes estivales proches du climat actuel $\left(15\right.$ à $\left.16^{\circ} \mathrm{C}\right)$. Le cerf fait sa première apparition régionale depuis le Pléniglaciaire à Conty vers 12300 BP (14450 cal. BP) ainsi que dans le « Marais de Dourges » (fig. 1) où il est associé à l'aurochs et au chevreuil (Deschodt et al. 2005). 
Fig. 1 - Carte des sites évoqués dans le texte (fond de carte M. Sauvage d'après Géoatlas, carte L. Mevel).

Map of sites mentioned in the text (base map M. Sauvage after Geoatlas, map L. Mevel).

1. Conty;

2. Marais de Dourges;

3. Belloy-sur-Somme;

4. Rinxent :

5. Saint-Just-des-Marais ;

6. Hangest-sur-Somme;

7. Saleux;

8. Warluis ;

9. Étiolles;

10. Pincevent;

11. Verberie :

12. Cepoy;

13. Marsangy;

14. Le Closeau ;

15. Grotte de Gouy;

16. Donnemarie-Dontilly ;

17. Les Mureaux ;

18. Acquigny;

19. Alizay;

20. Calleville;

21. Monruz;

22. Champréveyres;

23. Balma Margineda

24. Rhodes II ;

25. Murat;

26. Pont d'Ambon ;

27. Bois Ragot;

28. Morin ;

29. Gare de Couze ;

30. Pinelles :

31. La Borie del Rey;
32. Peyrazet;

33. Le Cuze de Sainte-Anastasie ;

34. Saint-Michel d'Arudy;

35. Troubat;

36. Baume Goulon;

37. Gouerris ;

38. Champ-Chalatras ;

39. Port-de-Penne :

40. Rocher de I'Impératrice ;

41. Kerbizien :

42. Chaloignes;

43. Camp d'Auvours ;

44. La Fosse ;

45. Abri de la Fru;

46. Gerbaix « dessus»;

47. La Chênelaz;

48. Abri des Douattes;

49. Grotte Blénien :

50. Abri Gay;

51. Grotte Jean-Pierre 1;

52. Grotte du Taï 1 ;

53. Grotte du Taï 2 ;

54. Varennes-les-Mâcons ;

55. Mannlefelsen I;

56. Abri de Rochedane;

57. Grotte du Seuil-des-Chèvres ;

58. Abri de la Vieille Église;

59. Abri des Balmettes;

60. Méaudre;

61. La Passagère.

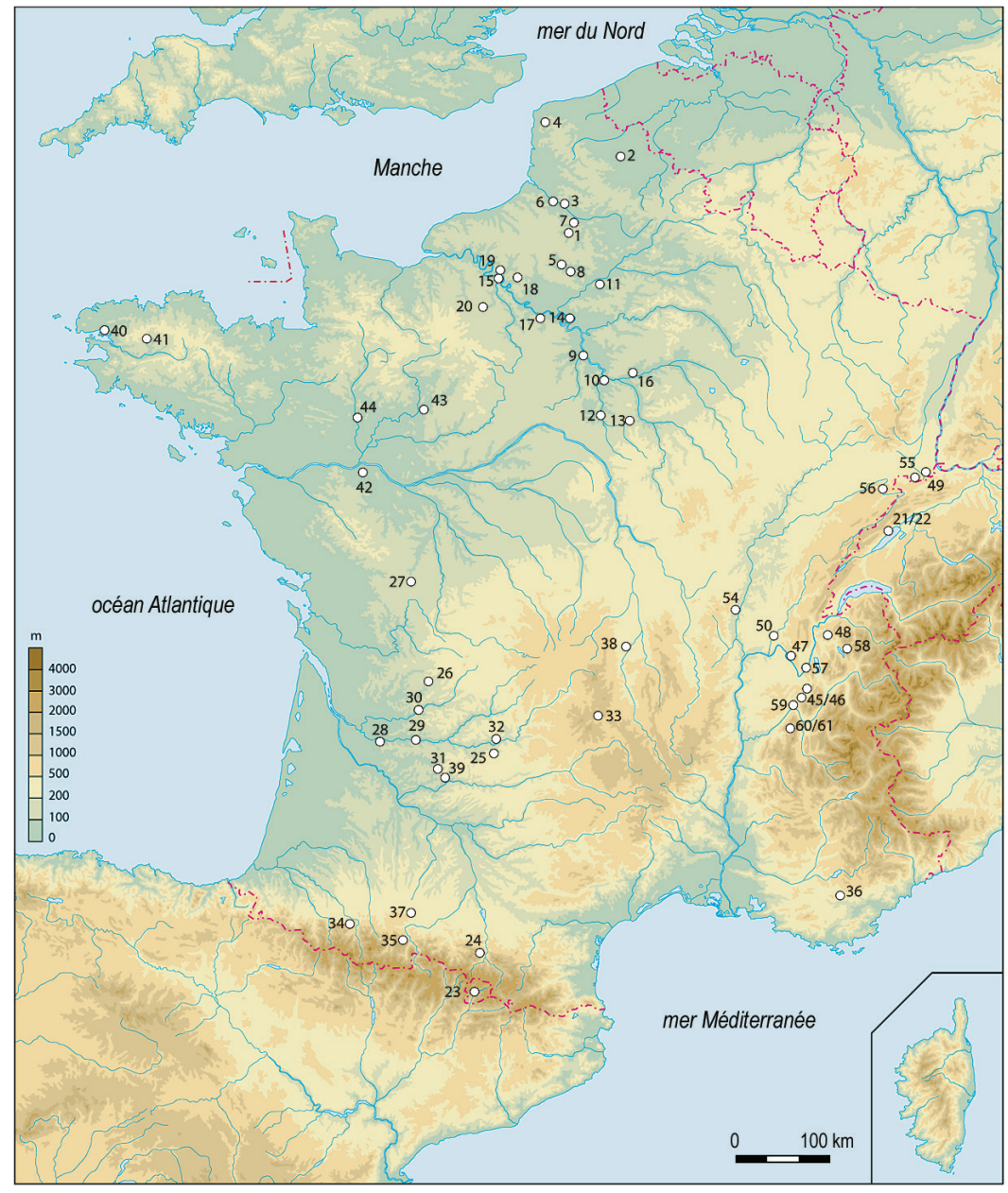

Le Dryas moyen (Dryas II, Older Dryas ou GIld) représente une courte péjoration climatique, marquée d'un point de vue morphologique par des apports crayeux de versant et, d'un point de vue environnemental, par le recul des taxons arboréens au profit des herbacées. Les spectres malacologiques témoignent de la présence de plusieurs espèces boréo-alpines et se caractérisent par une baisse générale des effectifs.

Au cours de l'oscillation d'Allerød (GI1a à GIlc), les cours d'eau se stabilisent et le système fluviatile évolue résolument vers un régime à larges méandres. La végétation se développe à nouveau avec l'extension du bouleau puis du pin, mais le milieu reste toujours relativement ouvert. Le couvert forestier demeure relativement clairsemé et la couverture végétale au sol n'est pas uniformément dense. L'augmentation et la diversité du nombre d'individus dans les associations malacologiques soulignent l'amélioration climatique suite à la phase de péjoration précédente. Les cortèges de mammifères composés par l'aurochs, le cerf, le chevreuil et le cheval traduisent un environnement climatique tempéré relativement clément alors que les assemblages entomologiques restent stables depuis l'oscillation de Bølling.

Le Dryas récent (GS1) représente la dernière péjoration climatique du Tardiglaciaire qui s'individualise par une importante érosion des versants crayeux et par un colmatage généralisé des fonds de vallées par des dépôts carbonatés. Cette importante réactivation des versants témoigne de l'intensité des phénomènes de gel et de dégel durant le Dryas récent. Le remblaiement de la vallée par des dépôts calcaires issus des versants s'accompagne de l'augmentation du rythme et de l'intensité des crues qui vont remobiliser ces dépôts détritiques sur l'ensemble de la vallée. Les données polliniques indiquent une nette régression du pin au profit d'une nouvelle expansion des graminées. Les malacofaunes montrent une forte baisse de la diversité des biotopes, suivie cependant par un épisode de recolonisation par les mollusques, corrélée à une nouvelle expansion de la végétation et à une réduction de la fréquence des crues dans la seconde moitié du Dryas récent.

Le réchauffement brutal du Préboréal se traduit par une nouvelle incision majeure du réseau hydrographique dans un régime de chenal unique à méandres qui atteint ses dimensions maximales. Suite à cette importante phase d'incision, le développement de la végétation et des sols traduit la mise en place de conditions nettement interglaciaires. Les premières tourbes préboréales, en relation avec l'amélioration climatique de l'Holocène, se mettent en place vers 9900 BP (11400 cal. BP) dans la moyenne vallée de la Somme (Antoine et al. 2000, 2003, 2011, 2012, 2014). 


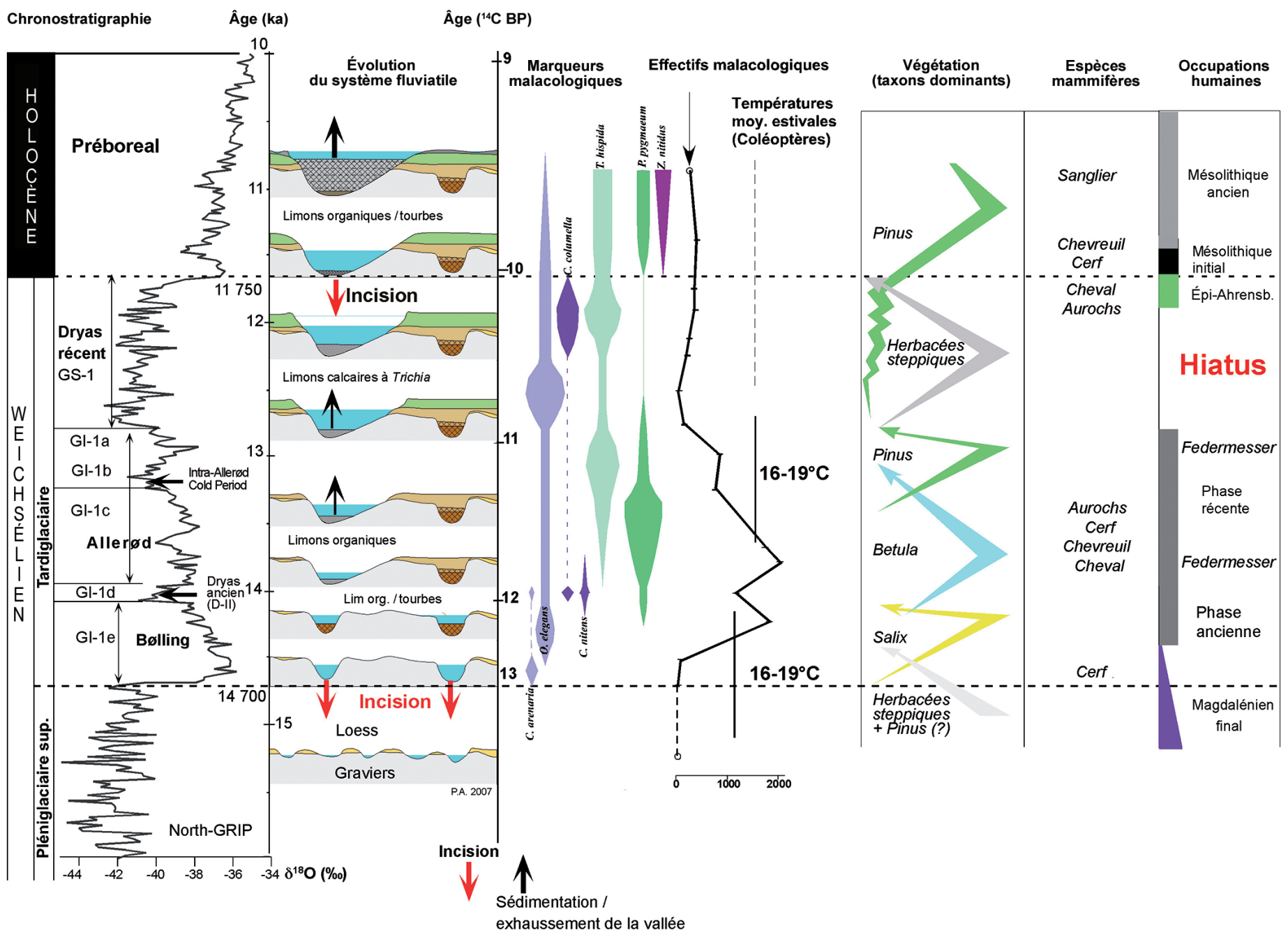

Fig. 2 - Évolution du système fluviatile et synthèse des données paléo-environnementales du bassin de la Somme durant le Tardiglaciaire weichselien en liaison avec les principales phases du peuplement humain (d'après NORTH GRIP Members [2004] et Antoine et al. 2012 [modifié] ; DAO J.-P. Fagnart).

Evolution of river systems and summary of paleo-environmental data from the Somme basin during the Weichselian Lateglacial in liaison with the main phases of human settlement (after NORTH GRIP Members [2004] and Antoine et al. 2012 [modified]; CAD J.-P. Fagnart).

\section{LES GRANDES ÉTAPES DU PEUPLEMENT DU NORD DE LA FRANCE DURANT LE TARDIGLACIAIRE}

\section{La Fin du MagdalÉNIEN}

Le repeuplement du Nord de la France après le maximum de froid du Pléniglaciaire supérieur weichselien s'effectue dans un environnement steppique continental froid à la fin du Dryas ancien (fin du GS2) ou au tout début de l'oscillation de Bølling (GI1e). On le doit à des groupes de chasseurs magdaléniens à un stade avancé de l'évolution de leur culture. Les phases anciennes et moyennes du techno-complexe magdalénien sont par contre totalement inconnues dans la région. De fait, la région lœssique du Nord de la France, compte tenu de sa position géographique, est particulièrement soumise aux conditions rigoureuses périglaciaires lors des grandes péjorations froides du Pléistocène. L'occupation humaine de la région apparaît donc étroitement liée aux conditions climatiques et aux modifications du milieu naturel. En conséquence, un hiatus de plus de 10000 ans sépare les occupations du Gravettien récent du gisement d'Amiens-Renancourt, dans la vallée de la Selle, datées des environs de 23000 BP (27500 cal. BP), des occupations des chasseurs de rennes et de chevaux du Magdalénien récent. Leur repeuplement du Nord de la France et d'une grande partie de l'Europe du Nord-Ouest s'effectue dans un environnement continental encore très ouvert. Les données sur la chronostratigraphie et l'environnement précis des gisements magdaléniens de la région restent cependant très lacunaires. Les témoins osseux sont absents (Belloy-surSomme, Saint-Just-des-Marais ; fig. 1) ou rares (Rinxent ; fig. 1) ce qui limite considérablement l'état actuel de nos connaissances. Si l'on excepte les quelques rares grottes et abris du Boulonnais, l'habitat magdalénien du Nord de la France est surtout connu par des sites de plein air établis dans 
le fond des principales vallées. La faible densité des gisements dans l'espace étudié permet de considérer le Nord de la France comme un territoire épisodiquement occupé ou parcouru par les chasseurs, peut-être en marge de plus grands centres de peuplement (Bassin parisien, Ardennes belges, Rhénanie).

Le Magdalénien final du Nord de la France est surtout documenté par le gisement de Belloy-sur-Somme (fig. 1), situé sur la très basse terrasse de la Somme à une quinzaine de kilomètres au nord-ouest d'Amiens. Les principales caractéristiques du débitage sur ce gisement sont tout à fait classiques du schéma conceptuel opératoire des industries du Magdalénien récent et final. La mise en forme élaborée des blocs assure un déroulement optimal du débitage. La création d'un plan de frappe préférentiel très oblique et la mise en place de convexités longitudinale et transversale sont des principes assez constants qui régissent le processus d'exploitation. Le plein débitage est orienté vers la production de lames longues, arquées et bien calibrées, extraites au percuteur organique tendre. La plupart des supports laminaires présentent une préparation de talon en éperon. La fin d'exploitation de certains nucléus à lames montre cependant l'usage du percuteur de pierre tendre afin d'obtenir des supports courts et rectilignes destinés à la fabrication des armatures.

Les armatures du gisement magdalénien de Belloy-surSomme s'individualisent par la présence de pointes à dos, à cran ou troncature et d'un faible nombre de lamelles à dos, permettant de rattacher l'industrie au faciès " CepoyMarsangy » (Valentin 1995, 2008a ; voir infra) qui semble, sur la base de critères technologiques, caractériser les ensembles les plus tardifs du Magdalénien en France septentrionale. La disparition du renne dans le bassin de la Somme, à la fin de l'oscillation de Bølling (GIle), vers 12300 BP (14450 cal. BP), semble avoir mis un terme à l'économie de prédation des sociétés magdaléniennes du Nord de la France dont les traditions s'engagent ensuite vers le processus d'azilianisation.

\section{L'AZILIANISATION : LA tRADITION des GROUPES À Federmesser}

Dès la fin de l'oscillation de Bølling (GIle), mais surtout durant l'oscillation d'Allerød (GIla à GI1c), l'occupation humaine dans le Nord de la France apparaît beaucoup plus importante, en liaison avec le développement des groupes à Federmesser. Cette tradition s'inscrit dans le processus d'azilianisation et correspond à une vaste transformation au sein des cultures du Tardiglaciaire. Ce phénomène, qui s'observe à l'échelle européenne, se caractérise par des changements techniques profonds, notamment par le grand développement des pointes à dos courbe et des grattoirs courts dans les assemblages lithiques. En ce qui concerne la production, l'emploi systématique du percuteur de pierre dans les différentes étapes de la chaîne opératoire s'accompagne d'une certaine simplification des méthodes de débitage. Ces modifications des industries pourraient représenter une adaptation à un milieu de plus en plus boisé qui s'est étendu au cours du Tardiglaciaire et leur relative ubiquité témoigne d'une forte unification des cultures au cours du Paléolithique final.
L'utilisation du terme Federmesser pour désigner les industries du Nord de la France repose sur des considérations historiques liées au développement de la recherche. Dans un premier temps, l'emploi du terme a permis de souligner la proximité et la continuité géographique de la région étudiée avec les assemblages de l'extrémité de la grande plaine européenne, autrement dit le Nord-Ouest européen. Ce terme permet également d'introduire une distinction entre l'Azilien pyrénéen, aquitain et atlantique, dont l'extension est reconnue jusque dans le centre du Bassin parisien, et les ensembles au nord-ouest de l'Europe qui s'individualisent par la fabrication de pointes barbelées très spécifiques et par l'absence totale de galets gravés ou peints. Azilien et tradition Federmesser s'inscrivent néanmoins dans le même techno-complexe à pointes à dos courbe du Paléolithique final et dont l'extension couvre une grande partie du territoire actuel de l'Europe.

La tradition à Federmesser apparaît dans le bassin de la Somme à la fin de l'oscillation de Bølling, aux environs de 12300 BP (14450 cal. BP) dans un environnement encore ouvert caractérisé par la recolonisation d'une végétation arbustive dominée par le bouleau et le saule. À partir de l'oscillation d'Allerød (GIlc à GIla), les forêts claires de bouleaux puis de pins occupent de plus en plus l'espace. Dans le même intervalle de temps, la faune froide magdalénienne a cédé la place à une biocénose tempérée forestière. Les gisements étudiés dans le bassin de la Somme apportent d'excellents fondements lithostratigraphiques, chronostratigraphiques et paléo-écologiques pour l'étude des groupes à Federmesser (Fagnart 1993, 1997, Coudret et Fagnart 1997, Fagnart et Coudret 2000a, 2000b). La plupart des occupations archéologiques sont associées au sol de Belloy-sur-Somme, attribué à l'oscillation d'Allerød. Seule l'industrie du niveau inférieur du gisement d'Hangestsur-Somme III.1 (fig. 1) se situe immédiatement au-dessous de cette pédogénèse, ce qui permet de lui attribuer un âge un peu plus ancien dans la séquence, très vraisemblablement à la fin de l'oscillation de Bølling (GIle).

Les informations sur l'environnement animal sont beaucoup plus abondantes que pour le Magdalénien. La biocénose des ongulés est dominée par le cerf, le chevreuil, l'aurochs et le cheval (Bridault 1997, Auguste 2012). Le sanglier n'est pas connu pour l'instant dans les spectres du bassin de la Somme.

D'un point de vue technique, la rupture avec le Magdalénien semble avoir été progressive comme nous le verrons en détail dans les paragraphes qui suivent. L'étude détaillée des industries lithiques a permis de distinguer une phase ancienne d'âge pré-Allerød et une phase récente d'âge Allerød, ce qui révèle le caractère graduel des changements au sein de la tradition des groupes à Federmesser (Fagnart 1993, 1997, Coudret et Fagnart 1997, Fagnart et Coudret 2000a, 2000b). La phase pré-Allerød présente un caractère transitionnel manifeste. Elle s'éloigne du Magdalénien final, mais sans en avoir perdu tous les caractères. La phase récente de la tradition à Federmesser marque par contre une véritable rupture et apparaît relativement homogène dans le bassin de la Somme, tout au long de l'oscillation d'Allerød, contrairement au bassin de la Seine où un quasi-abandon de l'objectif laminaire a pu être mis en évidence dans une phase particulièrement tardive 
(Bodu et Valentin 1997, Bodu 1998a, 1998b). Dans le bassin de la Somme, à la fin de l'oscillation d'Allerød, on note tout au plus une baisse générale de qualité du débitage et un choix moins sélectif dans l'acquisition des matériaux siliceux.

\section{La phase ancienne de la tradition à Federmesser}

Dans la vallée de la Somme, la phase initiale de la tradition des groupes à Federmesser est représentée par le niveau inférieur du gisement d'Hangest-sur-Somme III-1 (Fagnart 1997, Fagnart et Coudret 2000a, 2000b) et par la série à patine blanc bleuté en silex « turonien » du secteur 3 du gisement de Saleux (Coudret et Fagnart 2015 ; fig. 1). L'occupation archéologique d'Hangest III-1 se situe stratigraphiquement sous le sol d'âge Allerød et repose sur des limons ruisselés probablement attribuables à une phase ancienne du Tardiglaciaire. Deux datations radiocarbone obtenues sur os indiquent cependant un âge plus récent, vers 11600 BP (13480 cal. BP). Il faut donc considérer que les données radiochronologiques sont légèrement rajeunies et qu'une datation pré-Allerød, un peu antérieure à $12000 \mathrm{BP}$ (13980 cal. BP), serait davantage en accord avec les données de la stratigraphie.

L'industrie lithique présente un certain nombre de caractères qui la rapprochent du Magdalénien final : stratégie d'acquisition de la matière première, processus techniques mis en œuvre, gestion du débitage. La matière première employée est alors d'excellente qualité (silex du Turonien ou du Coniacien basal). Le débitage se caractérise par un objectif laminaire où la recherche de produits rectilignes, réguliers et bien calibrés est prioritaire. La morphologie de ces produits laminaires et l'observation des surfaces d'éclatement permettent d'établir l'emploi exclusif du percuteur de pierre tendre comme l'ont montré les récentes observations (Valentin et al. 2006, Valentin 2008a). Les nucléus recueillis, généralement à deux plans de frappe opposés, témoignent fréquemment de l'utilisation préférentielle d'un seul en cours de débitage.

L'outillage retouché, caractérisé par l'abondance de burins sur troncature retouchée, présente quelques magnifiques exemplaires de burins de Lacan, très appointés et à troncature concave. La retouche appliquée aux outils communs - lamellaire pour les grattoirs ; plate, écailleuse et envahissante sur les bords de certains burins - témoigne de l'emploi d'un matériau tendre organique (fig. 3A). Les lamelles à dos sont abondantes (37\% de l'outillage) et un peu plus d'un tiers présentent une extrémité tronquée. Les armatures macrolithiques du niveau inférieur d'Hangest-sur-Somme constituent $11 \%$ de l'outillage. Les monopointes à dos courbe ou à dos droit dominent mais la série s'individualise par la présence d'une grande bipointe et d'au moins un élément qui pourrait correspondre à une ébauche de fabrication de ce type d'armature. À cet inventaire s'ajoutent quelques couteaux à dos retouché de belle facture.

Les différentes caractéristiques techniques et typologiques permettent de situer l'industrie du niveau inférieur d'Hangest-sur-Somme III-1 dans une phase de transition entre le Magdalénien final (type Belloy-sur-Somme) et les industries de la tradition à Federmesser de la phase récente de l'Allerød.
L'industrie d'Hangest-sur-Somme témoigne ainsi de la transformation graduelle au cours du processus d'azilianisation dont le plein développement sera atteint durant l'oscillation d'Allerød. La position stratigraphique de l'industrie permet de proposer un âge pré-Allerød sans qu'il soit cependant possible de déterminer plus précisément sa position exacte au sein de l'oscillation de Bølling (GIle).

La comparaison de l'industrie du niveau inférieur du gisement d'Hangest-sur-Somme III.1 avec l'Azilien ancien du Closeau (Bodu et Valentin 1997, Bodu 1998a, 1998b, 2000b ; voir infra et fig. 1) permet d'établir des rapprochements techniques concernant la production des supports laminaires, mais la dominance des monopointes à dos courbe, la rareté des bipointes et l'abondance des lamelles à dos tranchent sur ce que l'on connaît au Closeau. L'absence de lames à retouche rasante dans le niveau inférieur d'Hangest-sur-Somme III.1 est suppléée par la présence de couteaux à dos retouché. Le caractère transitionnel de l'industrie du niveau d'Hangest-sur-Somme III.1 est bien perceptible, mais il est difficile, dans l'état actuel de nos connaissances, de situer précisément cet évènement dans le temps par rapport à l'Azilien ancien du Closeau.

\section{La phase récente de la tradition à Federmesser}

Le début de la phase récente de la tradition à Federmesser est représenté par le niveau inférieur du gisement de la gravière du Marais de Conty dans la vallée de la Selle (Fagnart 1997, Antoine et al. 2012). Le niveau archéologique se situe à la base $\mathrm{du}$ sol Allerød dont les caractères pédostratigraphiques sont particulièrement bien exprimés dans ce secteur de la vallée. Les analyses palynologiques d'A.-V. Munaut ont permis de situer l'occupation archéologique dans la phase à Betula du début de l'oscillation d'Allerød. Plusieurs datations radiocarbone sur os, comprises entre 11800 et 11500 BP (13700 et $12780 \mathrm{cal}$. BP), ont confirmé cette attribution.

La plupart des autres gisements étudiés dans le bassin de la Somme se rapportent plutôt à la seconde moitié de l'oscillation d'Allerød. Pour les différents locus du gisement de Saleux ou pour le niveau supérieur de la gravière d'Hangest-sur-Somme III-1, les témoins archéologiques reposent directement à la surface du sol Allerød (Fagnart 1993, 1997, Fagnart et Coudret 2000a, 2000b, Coudret et Fagnart 2004, 2006, 2015). Les analyses palynologiques révèlent chaque fois un paysage de forêts claires de bouleaux. Cet environnement est cependant légèrement antérieur aux installations humaines puisque les analyses concernent le sédiment organique immédiatement sous-jacent aux occupations. Les datations radiocarbone effectuées sur ossements indiquent en effet des mesures d'âge comprises entre 11200 et 11000 BP (13090 et 12900 cal. BP), c'est-à-dire dans la seconde moitié de l'Allerød ou à la fin de cette oscillation (GI1a/GIlb).

Durant la phase récente de la tradition à Federmesser, la production laminaire est orientée vers l'obtention de supports courts, larges, un peu épais et de profil rectiligne, la régularité n'étant pas un objectif prioritaire. La mise en forme des blocs est généralement réduite ou même absente. Les produits laminaires sont obtenus au percuteur de pierre, le plus souvent 

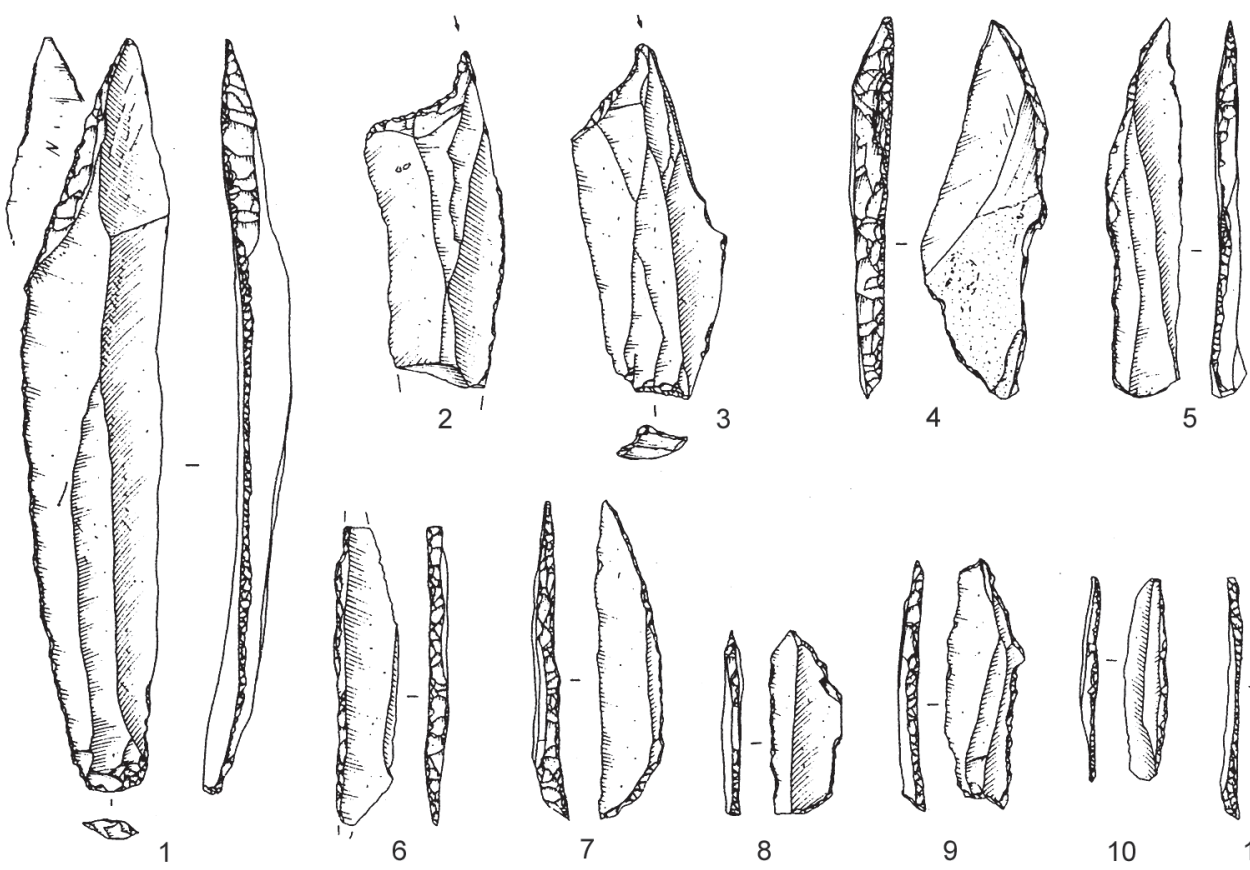

A
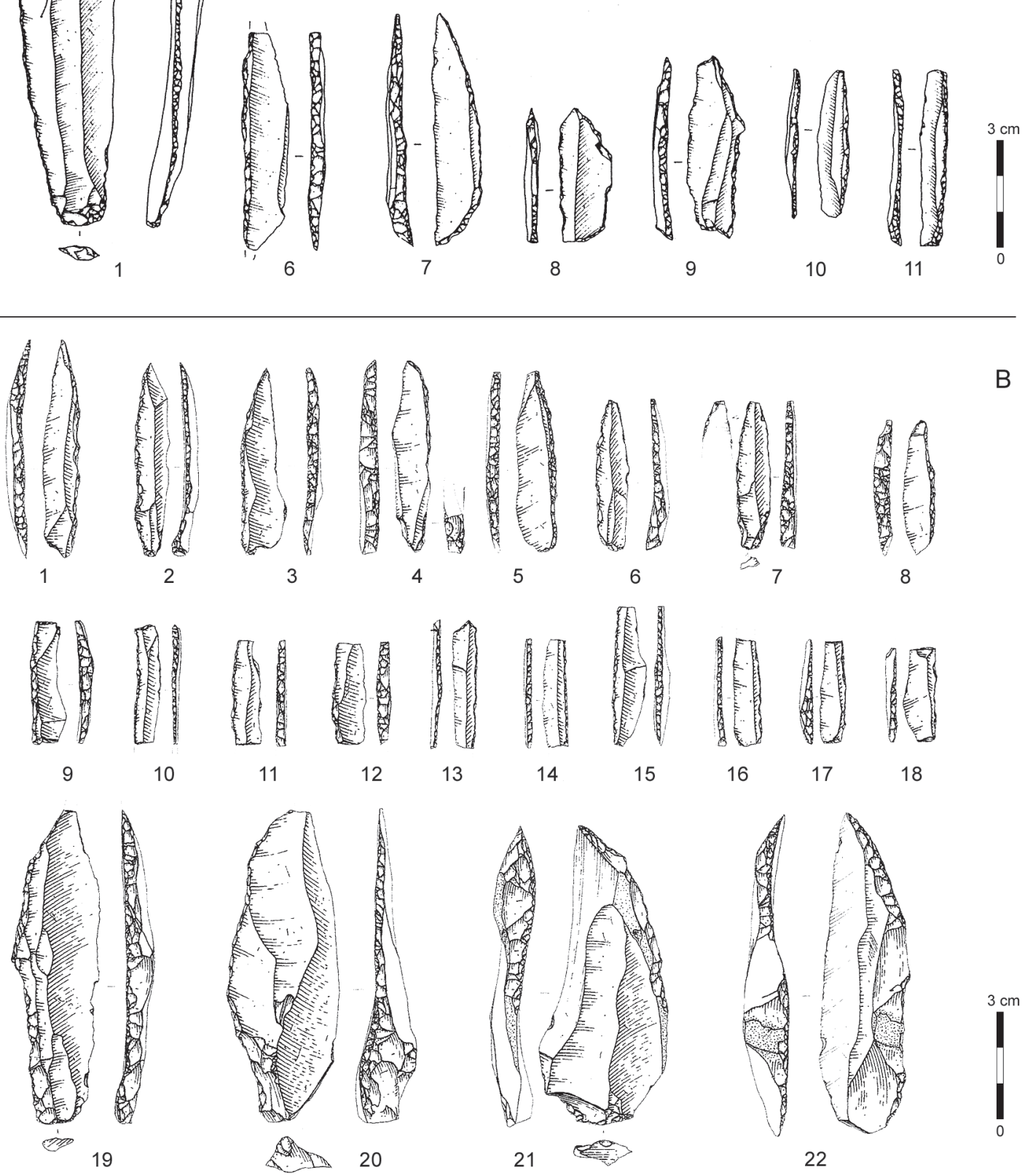

Fig. 3 - Industrie lithique de la tradition des groupes à Federmesser du bassin de la Somme (dessins P. Alix). A. Phase ancienne pré-Allerød, niveau inférieur du gisement d'Hangest-sur-Somme III.1; B. Phase récente de l'Allerød, locus 244 du gisement de Saleux.

Lithic industry from Federmesser tradition groups in the Somme basin (drawings P. Alix). A. Early pre-Allerød phase, lower level of the site of Hangest-sur-Somme III.1; B. Recent phase of the Allerød, locus 244 of the Saleux site. 
à partir de nucléus à deux plans de frappe opposés, chacun fonctionnant de manière plutôt autonome. La percussion est appliquée en retrait du plan de frappe selon un geste au dessin plus rectiligne que tangentiel (Pelegrin 2000, Valentin 2000). L'économie de débitage n'est tournée ni vers une forte productivité ni vers une bonne calibration des supports. L'intensité de la retouche permet en revanche de modifier suffisamment le support pour lui conférer les critères jugés nécessaires à son utilisation, dans le cas des pointes à dos notamment. Les industries se caractérisent par l'abondance des monopointes à dos courbe ou droit (fig. 3B). Les séries présentent assez systématiquement un nombre modéré de lamelles à bord abattu. Les couteaux à dos retouché, relativement abondants, constituent un élément remarquable de l'outillage. Parmi les burins, les exemplaires sur troncature sont généralement beaucoup plus nombreux que les dièdres. Les grattoirs se caractérisent très souvent par le caractère court de leur support. Les bords latéraux des outils sont rarement retouchés et quelques lames sont tronquées. Les outils de type bec ou perçoir sont rares, et c'est aussi le cas des outils mixtes ou multiples.

Des ressources alimentaires diversifiées, réparties de manière régulière tout au long de l'année mais relativement dispersées dans un environnement plus fermé, constituent les nouveaux fondements de l'économie du Paléolithique final, conduisant les chasseurs à se déplacer souvent dans leur territoire. Le mode d'exploitation du territoire par les groupes à Federmesser s'inscrit donc dans une mobilité résidentielle élevée où l'ensemble du groupe humain, apparemment peu important vu la taille des sites, se déplace assez fréquemment pour éviter l'épuisement des ressources alimentaires. Ce modèle économique s'oppose à celui des chasseurs magdaléniens de la steppe reposant sur la chasse d'un gibier migrateur au comportement grégaire. Par ailleurs, l'utilisation de l'arc, possiblement généralisé durant l'Azilien dans un milieu qui reste somme toute encore assez ouvert, représenterait une parfaite adaptation aux nouvelles circonstances écologiques et environnementales. Son emploi renforcerait l'efficacité de la chasse d'un gibier au comportement plus individuel comme le cerf, le chevreuil ou l'aurochs.

L'organisation spatiale des gisements à Federmesser présente des caractères constants dans la région étudiée. Le diamètre de dispersion des témoins lithiques et osseux est réduit et donne l'impression de sites occupés à une seule reprise et lors d'un séjour limité. La structuration de l'espace montre généralement une organisation radiale des vestiges centrée sur un seul foyer. Les structures de combustion sont généralement des foyers à plat ou à faible cuvette et se matérialisent souvent par une simple concentration de petits silex chauffés ou craquelés au feu (Coudret et Fagnart 2006).

\section{Le hiatus du Dryas réCENT}

La densité du peuplement semble avoir fortement décliné dans le bassin de la Somme lors du Dryas récent (Fagnart 1993, 1997, Fagnart et Coudret 2000a, 2000b). Bien que les conditions morphologiques nécessaires à la conservation des gisements soient très favorables au niveau des plaines alluviales, on observe une absence totale des occupations humaines en dépit de trente années de sondages et d'observation. Les conditions climatiques et environnementales dans le bassin de la Somme durant cette période sont vraisemblablement responsables de cette lacune. L'étude des formations sédimentaires de la fin du Tardiglaciaire a mis en évidence une importante érosion des versants crayeux, liée à l'accentuation de l'intensité des phénomènes gel-dégel, et corrélativement à un grand colmatage des fonds de vallées par des dépôts calcaires (Antoine et al. 2000, 2003, 2011, 2012, 2014). Le retour brutal des conditions périglaciaires proches de celles de la fin du Pléniglaciaire supérieur (GS2) ne semble donc pas avoir créé un environnement favorable à une implantation humaine.

\section{Les DeRNIÈres ocCupations palÉOltTHIQUes : BeLloisien ou ÉPI-AhrensBourgien}

Vers $10000 \mathrm{BP}$ (11500 cal. BP), à la charnière entre le Dryas récent et le Préboréal, la région est de nouveau occupée de manière significative par des groupes humains qui se caractérisent par la production de grandes lames de section plate (Naudinot 2013), au profil bien rectiligne, associées à un débitage lamellaire. La forte unité technique et économique qui se dégage de ces ensembles témoigne d'un haut degré de savoir-faire des tailleurs de silex (Bodu et al. 1997, Valentin 1995, 2008a, Fagnart 1997, Bodu 2000a, Valentin et al. 2014, Biard et Valentin à paraître ; voir infra). L'objectif principal du débitage consiste à produire de grandes lames au profil rectiligne (longueur habituelle des produits : 15 à $20 \mathrm{~cm}$, mais pouvant atteindre 25 ou $30 \mathrm{~cm}$ ) et aussi des petites lames et lamelles à partir de petits volumes. Les processus mis en œuvre incluent une mise en forme élaborée des volumes à traiter et une exploitation menée à partir de deux plans de frappe ouverts dès le début de la séquence de débitage. Les deux plans sont utilisés généralement selon un rythme alternatif afin de produire des supports rectilignes et d'éviter les accidents de taille sur des surfaces peu carénées. Les bords des plans de frappe sont préparés avec soin par abrasion, doucissage ou piquetage. Initialisée à partir de la face la plus étroite du bloc, la progression du débitage est souvent dissymétrique et semitournante. Elle évolue souvent sur la face la plus large du bloc afin d'obtenir des produits larges et plats (Naudinot 2013) avec en plus une certaine recherche de performance en matière de longueur. Les exploitations symétriques sont cependant bien représentées également, en particulier à Belloy-sur-Somme (Valentin et al. 2014). Les produits de la séquence initiale du débitage ne présentent pas une grande régularité, mais le plein débitage est nettement plus normalisé. Dans les gisements du bassin de la Somme, les petits volumes destinés à la production de petites lames et de lamelles sont traités selon le même mode que les grands volumes. La technique de percussion employée est la pierre tendre maniée selon un geste tangentiel avec recherche d'impacts en bordure du plan de frappe (Pelegrin 2000, Valentin 2000, Valentin et al. 2014).

Dans ces assemblages, les outils retouchés sont généralement rares et contrastent avec l'abondance des produits débités. Les rares armatures recueillies sont exclusivement 
des pointes à troncature oblique. Les lames et éclats aux bords mâchurés constituent en revanche une grande composante de l'industrie de ces gisements. Ce sont des outils a posteriori dans la mesure où ils ne résultent pas d'un façonnage intentionnel, étant le produit d'une utilisation souvent opportuniste de supports bruts. Il s'agit très généralement de sous-produits, issus de la séquence initiale du débitage (lames à crête, lames épaisses peu régulières ou produits d'entretien de la surface laminaire). Les mâchures affectent généralement un ou deux bords le plus souvent en secteur mésial ( $85 \%$ des cas). Elles se présentent sous la forme d'écrasements ou d'esquillements scalariformes avec fissurations du silex plus ou moins intenses. Les études tracéologiques de $\mathrm{H}$. Plisson et plus récemment de J. Jacquier révèlent souvent un contact violent avec une matière dure minérale, parfois abrasive (Fagnart et Plisson 1997, Jacquier 2014, 2015). À Belloy-sur-Somme et dans de nombreux gisements, l'étroite association spatiale de ces outils avec des postes de taille indique de manière évidente une action liée aux activités de débitage. À l'hypothèse initiale de la réfection des percuteurs en grès, il faut surtout ajouter l'abrasion ou le piquetage des bords de plans de frappe et très certainement des crêtes des nucléus en cours d'exploitation. Ces différents procédés techniques permettent aux tailleurs de nettoyer les aspérités qui nuisent au débitage et aussi d'adoucir les zones tranchantes afin de se protéger les mains et d'assurer un certain confort lors de la manipulation de volumes lourds et de grandes dimensions. D'autres fonctions concernant l'utilisation des pièces mâchurées ont été proposées, en particulier par N. Barton (1986a, 1986b, 1989, 1991). Il s'agit du travail d'un matériau assez tendre comme l'os ou le bois de cervidé. Cette activité a été confirmée récemment par les analyses tracéologiques réalisées sur le gisement de Calleville en Normandie (Biard et Hinguant 2011, 2013, Jacquier 2014). L'utilisation des pièces mâchurées mérite donc une explication plurielle, leur fonction pouvant varier d'un site à l'autre.

Dans le bassin de la Somme, cette ultime tradition technique du Paléolithique se singularise par la présence de nombreux gisements spécialisés dans l'acquisition de la matière première et la production de supports lithiques. Ces aires dévolues à la taille du silex sont parfois associées à des zones d'activités liées au travail de boucherie (abattage et découpe primaire de chevaux ou d'aurochs). À ce jour, aucun site à vocation domestique témoignant d'une occupation prolongée n'a été découvert dans la région étudiée (Chevallier et al. 2014). Les sites résidentiels, connus dans les régions et pays voisins, restent encore à découvrir. La présence quasi-exclusive de pointes à troncature oblique dans le corpus des armatures rattache ces ensembles aux traditions techniques septentrionales et plus particulièrement à la phase la plus récente du techno-complexe ahrensbourgien, c'est-à-dire aux assemblages attribués à l'Épi-Ahrensbourgien (Stapert 2000, Johansen et Stapert 2000, Terberger 2006). Le terme «Belloisien », utilisé depuis un peu plus d'une vingtaine d'années dans la littérature archéologique (Bodu et al. 1997, Fagnart 1997, 2009, Valentin 1995, 2008a, 2009, Bodu 2000a), parfois sous des acceptions différentes, pourrait cependant continuer à désigner l'extension géographique tardive de la tradition ahrensbourgienne (Épi-
Ahrensbourgien ou Ahrensbourgien final) dans les régions septentrionales de France situées au nord de la vallée de la Loire.

La transition vers le Mésolithique régional, vers $9800 \mathrm{BP}$ (11200 cal. BP), est longtemps apparue comme une rupture technologique et socio-économique assez brutale entre les productions laminaires très exigeantes du Paléolithique final et les débitages simplifiés à vocation plus lamellaire du début du Mésolithique. Cette apparence de rupture est renforcée, du point de vue fonctionnel, par l'importance qu'accordent les populations du Mésolithique au travail des végétaux, ces activités n'apparaissant que de manière très sporadique durant le Paléolithique final (Guéret 2013, Jacquier 2015). La découverte des gisements de Warluis dans l'Oise (fig. 1) et du niveau supérieur de Conty dans la Somme (fig. 1) a cependant révélé la présence d'armatures mésolithiques, obtenues par la technique du microburin, clairement associées à des débitages dont les conceptions volumétriques et l'exigence qualitative rappellent les toutes dernières industries du Paléolithique final. Ces ensembles du Mésolithique initial évoquent des faciès transitionnels que les recherches futures permettront de mieux caractériser (Ducrocq et al. 2008, Coudret et Fagnart 2012, Ducrocq à paraître).

\section{AU SUD DU BASSIN PARISIEN ET EN NORMANDIE : UN DÉBUT DE MISE EN PERSPECTIVE DES ÉCONOMIES DE LA FIN DU PALÉOLITHIQUE SUPÉRIEUR}

\section{L'ESSOR DES ÉTUDES SUR LA FIN DU PALÉOLITHIQUE SUPÉRIEUR AU SUD DU BASSIN PARISIEN ET EN NORMANDIE}

Au début des années 1990, les premiers acquis sur la chronologie de la fin du Paléolithique supérieur dans la Somme, son environnement et ses particularités techniques furent étendus à une bonne part de la moitié septentrionale de la France. Une synthèse exploratoire (Valentin 1995) fut alors proposée sur la Normandie, la région Centre et la région parisienne, celle-ci étant surtout connue jusque-là pour ses quelques gisements magdaléniens devenus des « laboratoires» de la démarche palethnographique (voir, par exemple, Julien et al. 1988, Julien 1989). Cette synthèse de 1995 portant sur des sites médiocrement conservés, elle ne disposait encore d'aucun moyen pour préciser la chronologie et l'évolution des paysages dans l'aire concernée aussi bien que dans le bassin de la Somme (voir supra). Mais la confrontation des techniques de travail du silex fut approfondie à travers un corpus d'une quarantaine de sites, ce qui permit de bien dégager l'originalité des choix nommés pour l'occasion " aziliens $»^{3}$ et " belloisiens », par contraste avec ceux du Magdalénien. Ces derniers étant déjà

3. Plutôt que de faire référence à la tradition à Federmesser, nous avons fait ce choix - déjà pratiqué aux mêmes latitudes en Suisse - de cohérence lexicale, F. Bordes et D. de Sonneville-Bordes ayant donné le nom «d'azilianisation » à un processus dont les étapes et la logique pouvaient enfin être retracées minutieusement dans le Bassin parisien. 
beaucoup décrits à Étiolles, Pincevent, Verberie et Marsangy (Pigeot 1987, Audouze et al. 1988, Olive 1988, Ploux et al. 1992, Schmider 1992, Bodu 1993 ; fig. 1), ils furent alors examinés sur un plus vaste ensemble de gisements (Valentin 1995, p. 106-448), en particulier sur les occupations de la confluence Seine-Yonne tout juste révélées par l'archéologie préventive. C'est à cette occasion qu'un genre d'assemblage magdalénien très original fut analysé en profondeur, le faciès " Cepoy-Marsangy », caractérisé d'abord sur les deux sites éponymes (Valentin 1995, p. 311-364 et 441-445) et reconnus ensuite ailleurs, par exemple à Belloy-sur-Somme (voir supra). Cette caractérisation initiale eut lieu alors que débutaient en parallèle les fouilles préventives au Closeau (Hauts-de-Seine) dans un contexte favorable cette fois aux études chronostratigraphiques (Bodu 1995, 1998a). Exploré sur plus de deux hectares, ce gisement livra, en plus de l'Azilien récent déjà bien connu dans la Somme (voir supra), des occupations attribuées à la phase ancienne de l'Azilien (Bodu 2000b). Elle était très peu décrite jusque-là (Pion 1990, Célerier 1993) et on s'appuya sur les données du Closeau pour caractériser l'assemblage similaire trouvé à l'entrée de la grotte de Gouy en Seine-Maritime (Valentin 1995, p. 541-558; fig. 1) et pour poursuivre l'enquête un peu au-delà du Bassin parisien (Valentin 2005). Cette phase ancienne ainsi que le faciès « Cepoy-Marsangy » furent considérés comme des chaînons jusque-là manquants en France septentrionale entre les autres types d'assemblages magdaléniens et l'Azilien dans sa phase récente, tel qu'il était décrit dans la Somme et tel qu'on le retrouvait assez fréquemment ailleurs, par exemple en Normandie (Valentin 1995, p. 487-566, Valentin et al. 2004) ou dans les niveaux tardifs du Closeau (Bodu et Valentin 1997, Bodu 1998a).

En observant toute cette suite de transformations, on fut alors incité à développer sur l'azilianisation une perspective «paléohistorique » (Valentin 2008a). Dans cette visée, l'évolution des techniques est étudiée en lien avec les transformations économiques, l'approche de celles-ci bénéficiant de l'apport décisif des études archéozoologiques régionales (Bignon 2008) et aussi de la palethnographie des habitats telle qu'elle se pratique depuis A. Leroi-Gourhan. Pour le moment, les probables changements sociologiques corrélatifs sont hors d'atteinte, les bouleversements idéologiques décrits ailleurs au cours de l'azilianisation n'étant qu'effleurés au travers des très rares témoignages symboliques découverts dans le Bassin parisien.

$\mathrm{Au}$-delà de la phase récente de l'Azilien, c'est-à-dire entre les débuts du Dryas récent et sa fin qui voit l'émergence du Belloisien, il subsiste, encore aujourd'hui, un hiatus chronologique peu explicable dans le sud du Bassin parisien et la Normandie comme dans la Somme (voir supra). Il est par conséquent impossible d'adopter une perspective paléohistorique continue jusqu'au tout début de l'Holocène. En revanche, depuis la fouille du gisement de Donnemarie-Dontilly (Bodu et Valentin 1992 ; fig. 1), la réflexion s'appuie sur plusieurs nouveaux sites en Normandie (Biard et Hinguant 2011, Bémilli et al. 2014) et elle progresse à la fois sur l'originalité des techniques de travail du silex à cette époque (Valentin et al. 2014, Biard et Valentin à paraitre) et aussi sur le statut des gisements (Valentin 2008a, p. 173-223). On peut désormais modéliser un peu mieux l'orga- nisation économique en France septentrionale au moment du basculement entre Dryas récent et Préboréal, mais sans savoir comment cette organisation a émergé.

\section{DU MAGDALÉNIEN RÉCENT À L'AZILIEN : DISPARITION D'UNE ÉCONOMIE PROGRAMMÉE}

\section{Précisions sur la Chronologie}

C'est sur un autre changement climatique brutal, le début du Tardiglaciaire, que nos recherches connaissent les plus nettes avancées. Dans le sud du Bassin parisien, les conséquences de ce réchauffement rapide sont maintenant bien repérées dans de nouvelles séquences naturelles de référence (Leroyer $e t$ al. 2014) et l'on peut y suivre ensuite le détail des recompositions végétales. En revanche, nous manquons encore de bons signaux correspondants dans les séquences archéologiques. On sait tout de même que l'Azilien ancien du Closeau est contemporain d'une pédogénèse attribuable à la chronozone du Bølling (GIle : Chaussé 2005) tandis qu'il existe aujourd'hui un nouvel espoir, également fondé sur la pédologie, d'attribuer une part du Magdalénien d'Étiolles à la même chronozone. Ceci viendrait alors confirmer ce que suggèrent déjà les datations ${ }^{14} \mathrm{C}$, avec toutes les précautions s'imposant toutefois en période de plateau (Valentin 2008a, p. 92-99, Debout et al. 2014). En somme, on pourrait enfin étayer deux hypothèses importantes. D'abord celle que le Magdalénien récent en France septentrionale est, pour l'essentiel, plus tardif que celui de la Belgique, de l'Allemagne méridionale et de la Suisse, et qu'il s'est développé surtout en parallèle des expansions de ce courant vers l'Angleterre (voir Magdalénien de type creswellien : Barton et al. 2003) et jusqu'à l'Allemagne septentrionale (voir de type hambourgien classique : Weber 2012). L'autre hypothèse soutenable, c'est que le Magdalénien récent connaît alors une suite de transformations vraiment rapides puisque c'est durant ce même court GIle que l'Azilien apparaît, les observations sur la phase ancienne du Closeau s'ajoutant aux très bons calages concomitants obtenus en Suisse à Monruz et Champréveyres ${ }^{4}$ (Leesch et al. 2004 ; fig. 1). C'est dans ce passage rapide à l'Azilien qu'il est très tentant d'inscrire, bien qu'il ne soit pas daté de façon fiable, le faciès "Cepoy-Marsangy » par ailleurs très similaire au Hambourgien classique (Weber 2012).

\section{Symboles et TeCHNIQUeS : DES TRANSFORMATIONS NON SYNCHRONES}

C'est aussi de Cepoy dans le Loiret (fig. 1), et ce n'est pas le moindre des paradoxes apparents, que proviennent deux des seules quatre œuvres connues pour tout le Magdalénien récent de

\footnotetext{
4. À ce titre, les deux sites en bord du lac de Neuchâtel peuvent être considérés pour l'Azilien - comme pour le Magdalénien d'ailleurs comme de véritables «stratotypes » puisque les calages ne reposent pas sur le seul ${ }^{14} \mathrm{C}$, mais aussi, comme au Closeau, sur une stratigraphie claire et, en plus, sur de multiples indicateurs environnementaux convergents.
} 


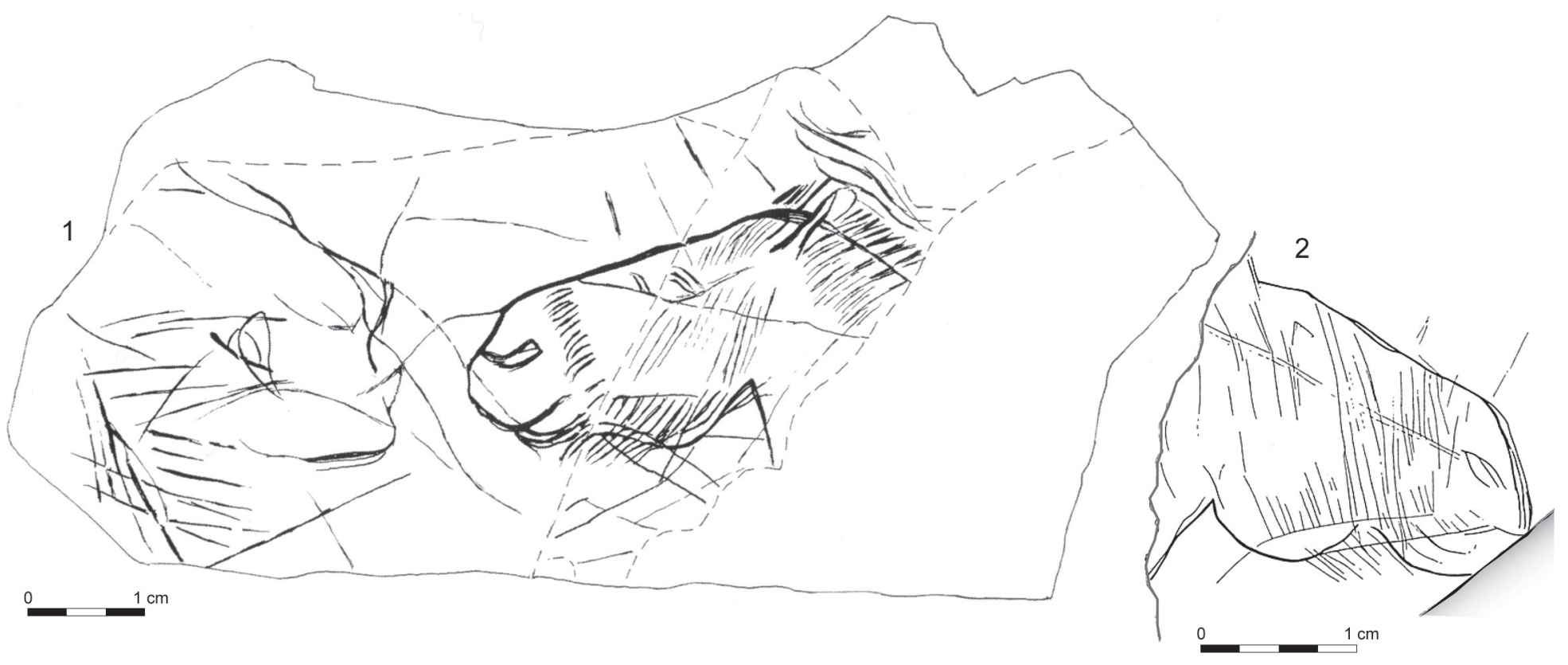

Fig. 4 - CEuvres gravées du Tardiglaciaire provenant du sud du Bassin parisien (DAO B. Valentin). 1. Plaquette de schiste gravée de Cepoy (Loiret; d'après Tosello 2008) ; 2. Éclat de silex au cortex gravé du niveau III20 de Pincevent (Seine-et-Marne; d'après D. Baffier in Bodu et al. 1996).

Engraved pieces from the Tardiglaciaire from the south of the Paris Basin (CAD B. Valentin). 1. Engraved schist plate from Cepoy (Loiret; after Tosello 2008); 2. Flint flake with engraved cortex from level III20 of Pincevent (Seine-et-Marne; after D. Baffier in Bodu et al. 1996).

France septentrionale (fig. $4, \mathrm{n}^{\circ}$ ), très pauvre donc (parce qu'il est souvent tardif ?) en témoignages artistiques. Pour autant, le plus ancien, trouvé dans un niveau intermédiaire d'Étiolles, est très emblématique du style et de l'iconographie magdalénienne (Fritz et Tosello 2011). Ensuite, après Cepoy, ces témoignages restent très discrets pour l'Azilien. Mais ils comptent tout de même un cortex d'éclat de silex gravé d'une tête de cheval au style lui aussi typique du Magdalénien (fig. $4, \mathrm{n}^{\circ}$ 2) alors que cet éclat provient assurément d'un niveau de Pincevent (le III.20 associé à une pédogénèse rapportée au GI1c) dont l'industrie lithique tranche, par ses caractères aziliens, sur le Magdalénien (Bodu et al. 1996). C'est donc un indice fort et rare de perduration symbolique, auxquels s'ajoutent d'autres gravures animalières plus allusives, également sur cortex, provenant d'une occupation de l'Azilien ancien diagnostiquée il y a peu aux Mureaux (Yvelines : Debout et Gauduchon 2016 ; fig. 1). Ces témoins sont, comme à Pincevent, chronologiquement plus fiables que les gravures impossibles à dater et au style si singulier de la grotte de Gouy en Seine-Maritime (Martin 2010). Cela étant, la même pérennité symbolique ne s'observe pas dans la parure en coquillages : relativement fréquente dans le Magdalénien (Taborin 1994, Peschaux et al. 2017) - hormis dans le faciès " Cepoy-Marsangy » ? -, elle est absente dès l'Azilien ancien.

L'Azilien ancien se signale aussi par une rupture nette dans l'industrie en matière osseuse. Bien attestée dans le Magdalénien récent local, mais peu diversifiée puisqu'elle se limite essentiellement à des pointes de sagaie, des bâtons percés et des aiguilles et qu'elle ne compte pas de pointes barbelées, cette industrie ne subsiste ensuite que sous forme de quelques poinçons expéditifs et seulement dans l'Azilien ancien du Closeau. C'est aussi à partir de l'Azilien ancien que les compléments d'armes en silex changent : plus aucune lamelle à bord abattu faisant office de barbelures latérales (du moins dans un premier temps, car elles réapparaissent, en petite quantité, pendant la phase récente) et beaucoup de pointes à bord abattu (fig. $5, \mathrm{n}^{\circ} 4-8$ ), c'est-à-dire de têtes de projectiles (bipointes et monopointes d'abord, les secondes devenant exclusives au cours de la phase récente). Et on se demande si ce n'est pas avec le faciès « Cepoy-Marsangy » que cette évolution s'amorce puisqu'il est très riche en pointes à bord abattu polymorphes (souvent à cran comme certains équivalents du Hambourgien), les lamelles à bord abattu y étant rares, voire absentes (voir notamment Valentin 2008a, p. 122-130).

Si l'Azilien ancien marque donc une rupture assez nette dans l'armement et ses différentes composantes osseuses et lithiques, il n'en va pas de même pour l'outillage en silex (fig. 5, $n^{\circ}$ 1-3 et 9-15), si l'on excepte des couteaux sur lame à retouche rasante assez innovants (Bodu et Mevel 2008), et aussi sans lendemain puisque, après la phase ancienne, il ne subsiste que des couteaux dont le tranchant n'est pas avivé, l'autre bord étant fréquemment abattu par de la retouche. Pour le reste, l'ergonomie des outils ne paraît pas changer avec l'Azilien ancien et ce sont toujours d'assez belles lames qui constituent les supports privilégiés comme au Magdalénien (Bodu 2000a, Valentin 2005). Il est bien connu que cette norme ne disparaît qu'avec la phase récente de l'Azilien, l'indice le plus flagrant concernant, bien entendu, les grattoirs faits sur toutes sortes de supports courts. 


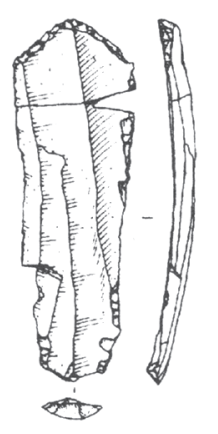

1

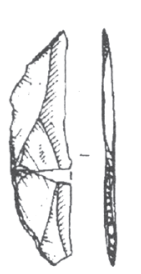

4
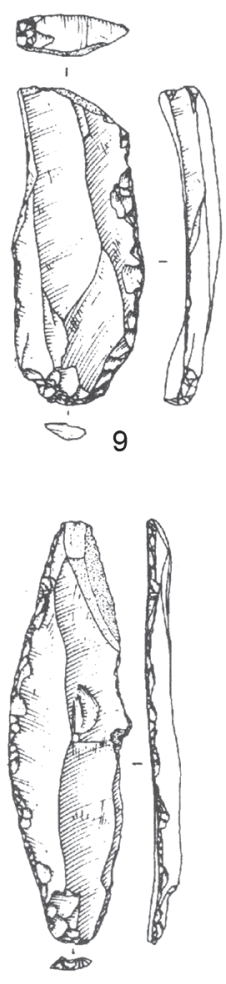

12

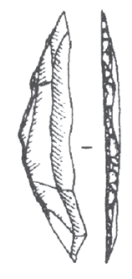

5

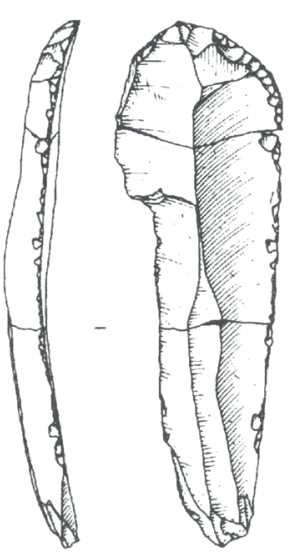

2

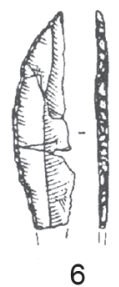

6
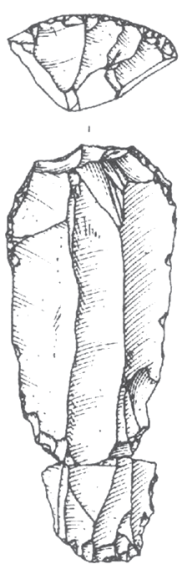

3

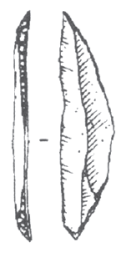

7

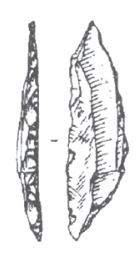

8

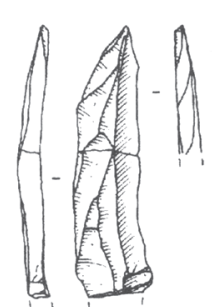

10

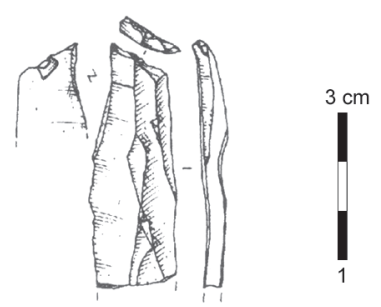

11

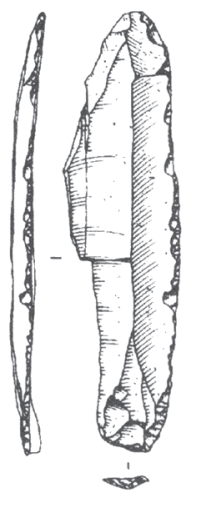

13

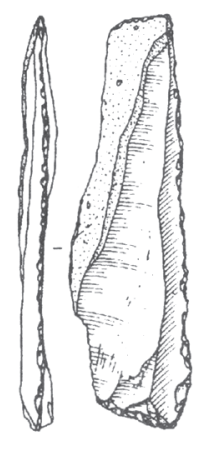

14

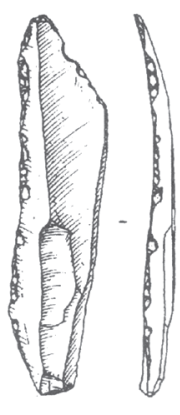

15
Fig. 5 - Industrie lithique recueillie sur le niveau inférieur du Closeau (Hauts-de-Seine ; dessins P. Alix in Bodu 2000b). 1-3. Grattoirs, 4-8. Bipointes, 9-11. Burins, 12-15. Lames à retouches rasantes.

Lithic industry from the lower level of le Closeau (Hauts-de-Seine; drawings P. Alix in Bodu 2000). 1-3. End scrapers; 4-8. Bipoints; 9-11. Burins; 12-15. Blades with flat retouch.
Il est aussi de notoriété que l'effacement progressif des normes magdaléniennes concerne également les méthodes de taille et c'est en France septentrionale que l'on peut décomposer le plus finement leur évolution. Le faciès " Cepoy-Marsangy " - non daté rappelons-le - pourrait constituer l'amorce locale de cette évolution vu le caractère mixte de sa méthode. Dans ce type d'assemblage, on observe en effet une production au percuteur organique de grandes lames (supports des grattoirs, burins, etc.) qui respecte les principes grosso modo communs à tous les autres débitages magdaléniens en France septentrionale (voir la préparation et l'entretien des convexités et des angles). Mais en fin d'exploitation sur les mêmes blocs ou bien sur des volumes spécifiques, on constate aussi un usage systématisé $\mathrm{du}$ percuteur de pierre tendre pour produire des petites lames, supports des pointes à bord abattu (et non pour débiter des lamelles comme cela se faisait sur plusieurs autres sites magdaléniens). Ensuite, si l'on retient l'hypothèse d'une évolution plutôt linéaire des méthodes ${ }^{5}$, on peut ajouter, dans l'enchaînement d'étapes conduisant à l'Azilien ancien, l'industrie du niveau inférieur d'Hangest III.1 (Somme) avec ses belles lames débitées, en totalité cette fois, avec une pierre tendre percutant en bord de plan de frappe (voir supra). L'Azilien ancien affiche le même usage exclusif de la pierre tendre en version tangentielle pour des objectifs toujours assez conformes au Magdalénien mais, à la différence d'Hangest III.1, totalement dépourvus de lamelles.

En somme, c'est surtout à partir de la phase récente - et à un moment assez avancé de l'Allerød (voir GIlc) vu la régularité des productions persistant au début à Conty dans la Somme (Antoine et al. 2012 ; voir supra) - que se produit une nette rupture technique. L'objectif laminaire perdant à ce stade sa primauté, les méthodes deviennent beaucoup plus versatiles, faisant coexister quelques débitages occasionnels de belles lames et beaucoup de productions expédientes d'éclats plus ou moins allongés (exclusifs dans certains locus du niveau le plus récent du Closeau : Bodu et Valentin 1997), détachés avec une pierre tendre appliquée dorénavant plutôt en retrait du bord de plan de frappe. C'est aussi à cette époque tardive que la qualité des silex collectés devient très variable d'un site à l'autre - reflétant alors la qualité moyenne des sources proches - et également diverse d'un bloc débité à l'autre sur le même gisement, sans corrélation nette avec l'habileté des tailleurs, ce qui traduit une baisse généralisée d'exigence.

5. L'hypothèse n'est pas dépourvue de risques vu les nuances que certaines stratigraphies magdaléniennes nous apprennent sur l'évolution de détail et très locale des méthodes (E. CaronLaviolette, recherches en cours à Étiolles). 


\section{L'ÉVOLUTION DES TECHNIQUES, SYMPTOMME DES TRANSFORMATIONS ÉCONOMIQUeS DEPUIS le MAGDALÉNIEN}

Nous pensons, après d'autres (voir notamment Floss 2000), que cette diminution franche d'exigence et cette souplesse à la fin de l'Allerød (voir GIlc), réduisant la dépendance aux sources de silex de qualité, s'accordent bien avec les indices de mobilité très élevée déduits de la fugacité des vestiges d'habitat, par contraste avec ce qui est connu pour le Magdalénien (voir supra). On ne sait malheureusement pas encore évaluer précisément le changement de rythme des déplacements entre ces deux époques. Mais il est maintenant clair que la dissemblance ne va tout de même pas jusqu'à des formes distinctes de mobilité. Celle-ci était déjà probablement surtout résidentielle au Magdalénien (plutôt que logistique comme on le pensait naguère), vu la monotonie fonctionnelle d'occupations réunissant des enfants - reconnus à travers de la taille malhabile - et donc des familles entières (Audouze 2006, Langlais 2017). Entre les deux, on ne dispose que des habitats de l'Azilien ancien du Closeau (fig. 6), qui présentent, avec leurs infrastructures en lourdes dalles de calcaire, quelques analogies avec des unités magdaléniennes que l'on présume avoir été assez longuement occupées (voir U5 à Étiolles).

Dans le même temps, les vastes foyers centraux du Closeau sans bordures ou appareillages tranchent déjà avec le Magdalénien sans doute beaucoup plus économe en combustible pour faire face à la pénurie en végétaux (Leesch et al. 2004, p. 124). La nécessaire gestion de cette carence (et de celle en bois d'œuvre), avec, comme autre conséquence, la difficulté pour approcher le gibier à découvert sauf à disposer de protections topographiques particulières, permettent déjà de prédire que les économies magdaléniennes exigeaient une programmation attentive des parcours pour toutes ces raisons. L'hypothèse est confirmée par ce que l'on sait des tactiques cynégétiques en région parisienne quand la faune est conservée : chasse collective portant sur des groupes familiaux de chevaux supposant la mise en œuvre de techniques de rabattage ou d'interception (Bignon 2008), techniques également indispensables pour l'abattage en masse des rennes lors des migrations automnales (voir notamment Julien et Karlin 2014). Le risque accompagnant ces abattages stratégiques et la nécessité corrélative de disposer d'un outillage très performant pour traiter en peu de temps des quantités considérables de matières animales pourraient constituer de bons motifs à l'investissement des chasseurs du Magdalénien dans la fabrication de longues lames normalisées et aisément affûtables, quelques-unes étant transportées d'un site à l'autre par anticipation des besoins.

Ignorant pour l'instant ce qui se passe en matière de chasse avec le "faciès Cepoy-Marsangy ", on sait en revanche que les rennes ne figurent déjà plus dans la faune capturée de l'Azilien ancien du Closeau. Elle est essentiellement constituée de cerfs et surtout de chevaux à propos desquels ce sont des tactiques individuelles de poursuite ou d'approche qui, cette fois, sont mises en œuvre avec peu d'animaux abattus à chaque fois (Bignon 2008, p. 127-141). En attendant de le confirmer ailleurs, c'est donc dans ce contexte qu'apparaîtraient les

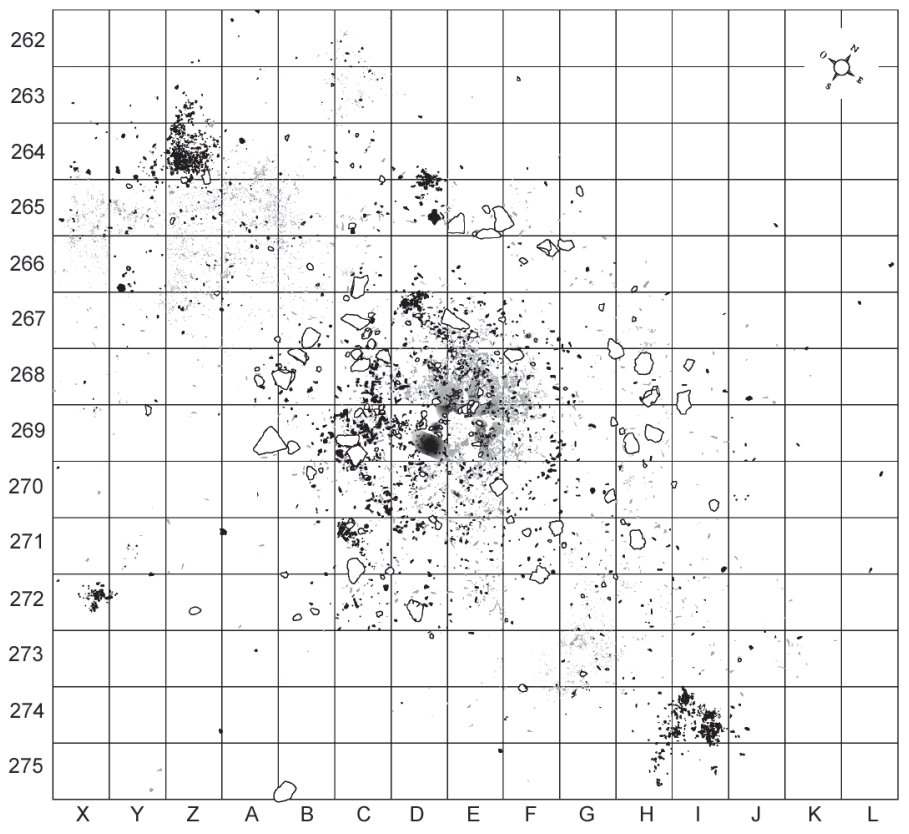

Fig. 6 - Le locus 46 du niveau inférieur du Closeau (Hauts-de-Seine; DAO G. Debout).

Locus 46 of the lower level of Closeau (Hauts-de-Seine; CAD G. Debout).

premiers signes d'imprévisibilité relative dans l'économie de chasse. Et cette faible programmation pourrait constituer ensuite un facteur important dans l'adoption, au cours de la phase récente, d'un outillage en silex à usage bref et toujours immédiat, quand la méthode de taille est simplifiée permettant alors de moins dépendre du silex.

Cette faible anticipation des besoins pourrait se détecter aussi dans l'armement, les observations sur les tactiques de l'Azilien ancien confirmant des prédictions préalables de J. Pelegrin (2000). Selon lui, la prolifération des pointes en silex fragiles - dès le « faciès Cepoy-Marsangy » - et la disparition (synchrone ?) des pointes en bois de renne résistantes et affûtables pourraient tenir à la rapidité de fabrication des premières. Elle constituerait un avantage quand la possibilité de retrouver et réemployer les projectiles ayant raté leur cible se restreint brutalement alors que les tirs n'ont plus lieu dans des lieux d'interception ou de rabattages choisis au préalable par les chasseurs. Dans le même modèle explicatif, l'auteur, qui intègre les changements de méthode, considère que le percuteur de pierre tendre présente de l'intérêt s'il faut produire rapidement des pointes en silex pour remplacer beaucoup de projectiles. Il $\mathrm{y}$ a eu depuis des nuances et des enrichissements à ce modèle (Valentin 2005, 2008a, p. 160-171, 2008b) qui soulignent aussi les avantages de la pierre tendre (en version en retrait) pour tirer parti de silex variés dans le contexte d'augmentation de la mobilité évoqué plus haut.

Ce scénario explicatif, déjà riche d'une logique multifactorielle, est resté en l'état, en l'attente de vérifications dans d'autres régions sur les contrastes entre chasses magdaléniennes et aziliennes et aussi de l'intégration d'autres paramètres très 
importants, comme la possible généralisation de l'arc (avec toutes ses conséquences sur les tactiques). Si de telles tentatives de compréhension systémique sont momentanément suspendues - au profit d'un retour analytique sur les assemblages recueillis au Closeau (Mevel et Bodu 2018) -, c'est aussi parce que ces essais sont insuffisants pour interpréter l'articulation entre toutes les mutations observées et les bouleversements idéologiques se déroulant en parallèle. Un cadre théorique reste à forger pour comprendre ce que cette articulation nous apprend sur la sociologie de l'époque (Valentin et Pétillon 2018).

\section{LE BELLOISIEN : DE BELLES LAMES POUR UNE ORGANISATION LOGISTIQUE}

De plus, nos efforts les plus récents portent beaucoup sur l'archéologie du basculement entre Dryas récent (voir GS1) et Préboréal. C'est un moment pour l'instant déconnecté de ce qui précède par un hiatus archéologique correspondant à la presque totalité du GS1 (voir supra). En conséquence, on ne peut pas savoir comment les particularités techniques et économiques de ce moment ont pris forme.

\section{Du gOÛT POUR LES BELLES LAMES}

Le nom même de « Belloisien » dit l'embarras persistant pour nommer des assemblages pas toujours datés mais clairement reconnaissables par le style des productions laminaires et lamellaires qui tranche globalement sur l'Azilien récent. Au sud du Bassin parisien et en Normandie, certains assemblages sont pratiquement dépourvus de compléments d'armes en silex tandis que d'autres mêlent des exemplaires inspirés tout à la fois des courants ahrensbourgiens (pointes à troncature oblique concave) et laboriens (pointes de Malaurie, bitroncatures et pointes des Blanchères). Quant aux parentés en matière de méthode, une fois constaté en divers lieux de l'Europe à cette époque le regain d'exigence concernant la régularité des productions, il faut tout de même se méfier de ce goût répandu pour les belles lames qui conduisit naguère à un rapprochement étroit avec l'Ahrensbourgien, ce que tempèrent les observations approfondies les plus récentes (Mevel et al. à paraître). Des comparaisons aussi serrées doivent être conduites avec le Laborien et peut-être même avec le Swidérien polonais, maintenant qu'un réexamen technologique approfondi du Belloisien est entamé (Valentin et al. 2014, Biard et Valentin à paraître). Stimulé par les observations de N. Naudinot (2010, 2013) sur la valeur particulièrement distinctive que revêt dans ce contexte l'aplatissement des produits, ce réexamen a porté sur Donnemarie-Dontilly (Seine-et-Marne) puis sur Acquigny, Alizay et Calleville (Eure ; fig. 1). Sur tous ces gisements, on observe la production au percuteur de pierre tendre de lames que nous considérons comme « favorites » (Biard et Valentin à paraître) d'un double point de vue économique - elles ont circulé de site en site - et technique - leur production a fait l'objet d'un soin tout particulier (fig. 7). Elles sont à la fois longues, régulières et bien minces tandis que leurs extrémités sont effilées, toutes qualités qui s'accordent bien avec leur usage fréquent comme couteaux pour de la découpe bouchère primaire et vigoureuse (Jacquier 2015). Pour leur conférer ces qualités, il fallait donc pas mal de méticulosité depuis la sélection des volumes jusqu'à la gestion de leur aplatissement pendant le débitage, en passant par la préparation très minutieuse des zones d'impact pour chaque lame (voir supra).

Curieusement, tous ces choix assez contraignants, auxquels s'ajoute l'acquisition nécessaire de bons outils de taille (notamment des percuteurs assez lourds au maniement délicat), ne s'accompagnent pas pour autant d'un très haut degré de prévision systématique, autrement dit d'une anticipation précise du résultat de chaque débitage, en qualité et en quantité. En somme, on peut penser que les tailleurs commencent fréquemment - et peut-être même systématiquement - leurs débitages avec en tête l'objectif de produire des belles lames, mais que la productivité n'est pas pour autant parfaitement prévisible. De fait, les tailleurs doivent s'adapter à tous les aléas engendrés par une méthode s'approchant parfois des limites techniques d'une conception laminaire en termes d'aplatissement. L'adaptation à ces aléas est aussi une question de choix économiques puisqu'à la recherche des lames favorites s'ajoute l'utilisation d'autres produits bien moins réguliers. Beaucoup de méticulosité coexiste donc avec de la souplesse, y compris dans la qualité des produits utilisés : pour saisir la signification de cette double tendance, il est maintenant nécessaire de développer les études palethnographiques sur les sites les mieux conservés.

\section{COMMENT INTERPRÉTER LA FONCTION DES OCCUPATIONS BELLOISIENNES?}

Or plusieurs de ces gisements paraissent assez spécialisés, ce qui explique aussi les hésitations pour désigner ce qui ressemble à des faciès d'activité et non à la pleine expression d'une tradition culturelle. De fait, les modes d'occupation connus s'écartent à première vue de ce que l'on considère traditionnellement comme un habitat : pas ou peu d'objets brûlés, des restes de taille abondants, généralement peu d'outils retouchés, des armatures quelquefois très rares, de temps en temps beaucoup d'éléments mâchurés, la plupart étant utilisés dans le cadre des activités de taille (voir supra). Il y a aussi de temps à autre des emports de lames favorites interprétés naguère comme le signe que ces occupations avaient pour fonction principale celle d'ateliers fournissant en lames des habitats. Mais ceux-ci sont rares dans les régions concernées et dans chaque occupation, plus ou moins spécialisée donc, on trouve toujours des lames importées mais en petit nombre. Comme, de plus, chacune des particularités que nous venons d'évoquer connaît des degrés divers, nous proposons l'hypothèse de statuts économiques assez variés pour ces gisements belloisiens (Valentin 2008a, p. 207-210, Valentin 2009): sites de boucherie primaire comme Acquigny (Biard 2010) ; lieux, comme Donnemarie, de fabrication d'instruments de découpe en partie à destination des sites de boucherie (Valentin 1995, p. 592-680) ; sites d'agrégation relative comme Alizay ou Calleville (Biard et Hinguant 2011, Bémilli et al. 2014). Combinée à la brièveté 


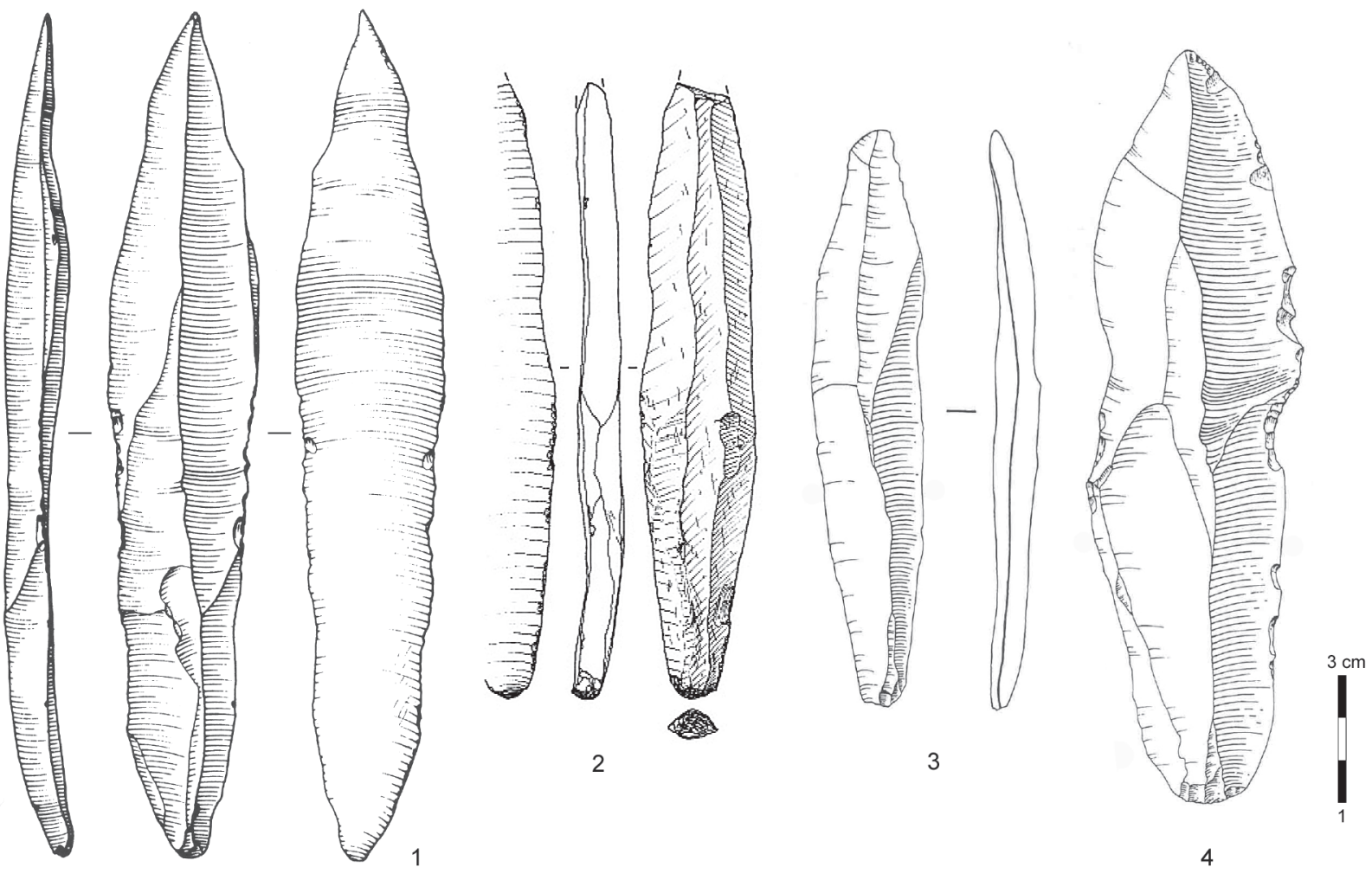

Fig. 7 - Lames «favorites » du Belloisien (DAO B. Valentin). 1. Flixecourt (Somme; dessin S. Lancelot in Fagnart 1997); 2. Calleville (Eure ; dessin P. Forré in Biard et Hinguant 2011) ; 3-4. Donnemarie-Dontilly (Seine-et-Marne ; dessins D. Molez in Valentin 1995).

"Favourite" Belloisian blades (CAD B. Valentin). 1. Flixecourt (Somme; drawing S. Lancelot in Fagnart 1997); 2. Calleville (Eure; drawing P. Forré in Biard and Hinguant 2011); 3-4. Donnemarie-Dontilly (Seine-et-Marne; drawings D. Molez in Valentin 1995).

probable des séjours, cette gradation évoque une assez grande mobilité, et plutôt des petits groupes fréquemment dispersés puisque les lieux d'agrégation demeurent si rares. On a vu plus haut que les économies du Magdalénien de notre région semblent s'éloigner de l'idéal type logistique. L'avenir dira si les économies de la transition Pléistocène-Holocène ne sont pas celles qui s'en rapprochent le plus, ce qui ne saurait finalement surprendre dans un contexte de grande instabilité climatique, y compris à l'échelle inter-annuelle, et même inter-saisonnière apparemment (voir notamment Renssen 2001).

\section{0-11 000 CAL. BP : TROIS MILLÉNAIRES D'INSTABILITÉ CULTURELLE ET D'ÉVOLUTION PALÉO-ÉCONOMIQUE SUR LA FAÇADE ATLANTIQUE FRANÇAISE (ENTRE PYRÉNÉES ET MANCHE)}

\section{AUTOUR DE 14000 CAL. BP : " DERNIER » MAGDALÉNIEN, "PREMIER » AZILIEN}

Contrastant avec les débuts du Magdalénien situés autour de 21000 cal. BP, les comportements techniques et économiques des groupes humains du Magdalénien moyen et récent se stabilisent globalement entre 19000 et 14000 cal. BP au sein d'environnements contrastés (voir Lacombe 1998, Cazals 2000, Bündgen 2002, Dachary 2002, Langlais 2007, Sécher 2017). Néanmoins, des variations au cours de ces cinq millénaires, notamment dans la segmentation des chaînes opératoires de production lithique et donc d'acquisition des matières premières, mais aussi dans la morphotypologie des armatures lithiques (Langlais 2010) ou osseuses (Pétillon 2006, Lefèbvre 2016), permettent désormais d'entrevoir quatre temps d'évolution culturelle au cours du Magdalénien moyen et récent (Langlais et al. 2012, 2016, Pétillon 2016, Laroulandie et al. 2017).

Autour de 14000 cal. BP, à la transition climatique (Rasmussen et al. 2014) entre le GI1e (ca. Bølling) et le GI1d (ca. Allerød), on assiste, au moins dans le sud de notre aire d'étude $^{6}$, à la fin du processus de remplacement des espèces froides par des cortèges tempérés. Le renne, espèce emblématique des temps glaciaires, disparaît des tableaux de chasse et visiblement des paysages de la façade atlantique (Langlais et al. 2014c, Costamagno et al. 2016). La question reste néanmoins ouverte au nord de la Loire et à proximité du paléo-fleuve Manche et des actuelles îles britanniques dans lesquelles

6. Ces données sont malheureusement absentes dans une grande partie du Grand-Ouest du fait de l'importante acidité des sols qui interdit la préservation des vestiges organiques. 
la présence du renne durant cette période est débattue. On rappellera également qu'à quelques centaines de kilomètres plus à l'est, les ossements de lion du niveau inférieur du Closeau dans les Hauts-de-Seine garderaient la trace isotopique d'une consommation de renne (Drucker et Bocherens 2002) même si cette espèce reste pour le moment absente des tableaux de chasse des Hommes.

C'est à cette période que l'on voit deux trajectoires évolutives se chevaucher chronologiquement si l'on en croit les datations radiométriques, voire géographiquement. Il s'agit d'une part de sites parfaitement attribuables au Magdalénien récent par leur équipement lithique ou osseux mais datés (en AMS, sur objet connu) autour de 14000 cal. BP, comme Saint-Michel d'Arudy dans les Pyrénées daté sur harpon (Barshay-Szmidt et al. 2016 ; fig. 1) et d'autre part, des sites de la phase ancienne de l'Azilien telle qu'elle est définie dans les séquences régionales de Pont d'Ambon (fig. 1), de Murat (fig. 1) et de Bois Ragot (fig. 1) notamment (Lorblanchet 1985, Célérier 1993, Chollet et Dujardin 2005). Cette apparente synchronie reflète-t-elle une réalité archéologique ? Les dates obtenues sur restes de renne permettent d'alimenter cette réflexion puisqu'en l'état aucun site azilien n'a livré de restes de cet ongulé indubitablement associés (sans risque d'intrusion stratigraphique depuis le Magdalénien). Cette discussion rappelle plus largement le questionnement sur l'existence d'une perduration du Magdalénien dans les Pyrénées (Barbaza 1996). Les nouvelles dates retenues placent le début de l'Azilien (Rhodes II foyer 5 et Balma Margineda c. 10 ; fig. 1) au début du GIld (Fat Cheung 2015). En revanche, au nord de la Dordogne (Fat Cheung et al. 2014) et jusqu'en Finistère (Naudinot et al. 2017a, 2018a), l'Azilien ancien se développe entre 14500 et $14000 \mathrm{cal}$. BP. La fin du Magdalénien et les débuts de l'Azilien ne représenteraient-ils pas plutôt les étapes d'une seule et même évolution, le second succédant au premier ? La synchronie suggérée par le cadre radiométrique serait alors possiblement la conséquence d'un important plateau sur cet espace chronologique dans la courbe de calibration du radiocarbone. La façade atlantique, avec ses nombreux sites stratifiés, constitue une aire de recherche particulièrement riche en perspectives sur cette question. À ce stade de la réévaluation des archéoséquences régionales - telles que Murat dans le Lot (Lorblanchet 1985, 1996 ; M. Langlais et S. Costamagno, monographie en cours), le Pont d'Ambon en Dordogne (Célérier 1998) ou le Bois Ragot dans la Vienne (Chollet et Dujardin 2005) -, l'absence d'interstratification entre Magdalénien et Azilien ancien sur ces sites est l'argument principal pour envisager une succession chronologique plutôt que l'hypothèse d'une contemporanéité dans un même espace géographique. Notons en revanche que les gisements du Morin (fig 1) et de Gare de Couze (fig. 1), mis à contribution pour établir un modèle d'azilianisation par accrétion interne au Magdalénien (Bordes et Sonneville-Bordes 1979), sont désormais considérés comme des stratigraphies mélangées ne permettant pas de discriminer de véritables ensembles homogènes (Langlais et al. 2014b, Mallye et al. 2018).

Comme dans les autres régions de France (voir supra et infra), on observe trois transformations majeures le long de la façade atlantique du point de vue des équipements lithiques et osseux (Lorblanchet 1996, Célérier et al. 1997, Chollet et Dujardin 2005, Valentin 2005, Langlais 2007, 2010, Naudinot 2008, 2010, Barbaza 2011, Fat Cheung et al. 2014, Marchand et al. 2004, Fat Cheung 2015, Naudinot et al. 2017a) :

- La généralisation de la percussion minérale (le plus souvent tendre) ;

- La réduction drastique de l'équipement osseux qui se résume à la présence de quelques pointes barbelées (voir harpons) ;

- La généralisation des pointes à dos au détriment des lamelles à dos, avec notamment le développement d'un nouveau morphotype d'armature lithique : la bipointe qui accompagne des monopointes sur supports laminaires réguliers et minces (fig. 8).

Ces deux derniers points s'accompagnent d'un abandon des sagaies composites magdaléniennes au profit de projectiles uniquement armés de pointes axiales. Ce phénomène met les équipements de chasse, et les stratégies dans lesquelles ils interviennent, au cœur de la dynamique de changement de l'Azilien. L'effacement des lamelles à dos est logiquement accompagné d'une disparition de l'objectif lamellaire, si développé au Magdalénien. En revanche, on peut souligner la persistance d'une production laminaire soignée - aux principes techniques toutefois différents du Magdalénien - notamment pour l'obtention de tranchants fréquemment avivés (i.e. lames à retouches écailleuses).

Le probable changement des stratégies de chasse au cours de l'Azilien ancien est-il corrélé à la recomposition des gibiers intervenant au cours de cette période ? À partir de là, le renne est en effet systématiquement absent des tableaux de chasse et on remarque désormais la dominance du cheval à l'abri Murat, et du cerf et du lapin au Pont d'Ambon et au Bois Ragot (Delpech 1983, Cochard 2004, Griggo 2005, Jones 2006, Fat Cheung et al. 2014, Chevallier 2015). Notons que cette évolution concernant la disponibilité des ressources va

Fig. 8 - Exemples d'armatures lithiques de l'Azilien et du Laborien dans la moitié ouest de la France (DAO M. Langlais et N. Naudinot).

A. Peyrazet (d'après Langlais et al. 2015, dessins S. Ducasse); B. La Fosse (d'après Naudinot 2013, dessins F. Blanchet); C. Le Morin (d'après Langlais et al. 2014b, dessins S. Pasty) ; D. Rochereil (d'après Langlais et al. à paraître, dessins C. Fat Cheung); E. Troubat (d'après Fat Cheung 2015) ; F. Les Chaloignes (d'après Marchand et al. 2009) ; G. Murat (d'après Lorblanchet 1996) ; $\boldsymbol{H}$. Le Morin (d'après Mallye et al. 2018, dessins S. Pasty) ; I. Le Rocher de l'Impératrice (d'après Naudinot et al. 2017a, dessins F. Blanchet).

Examples of Azilian and Laborian lithic armatures in the western half of France (CAD M. Langlais and N. Naudinot).

A. Peyrazet (after Langlais et al. 2015, drawings S. Ducasse); B. La Fosse (after Naudinot 2013, drawings F. Blanchet); C. Le Morin (after Langlais et al. 2014b, drawings S. Pasty); D. Rochereil (after Langlais et al. forthcoming, drawings C. Fat Cheung); E. Troubat (after Fat Cheung 2015); F. Les Chaloignes (after Marchand et al. 2009); G. Murat (after Lorblanchet 1996); H. Le Morin (after Mallye et al. 2018, drawings S. Pasty); I. Le Rocher de I'Impératrice (after Naudinot et al. 2017a, drawings $F$. Blanchet). 

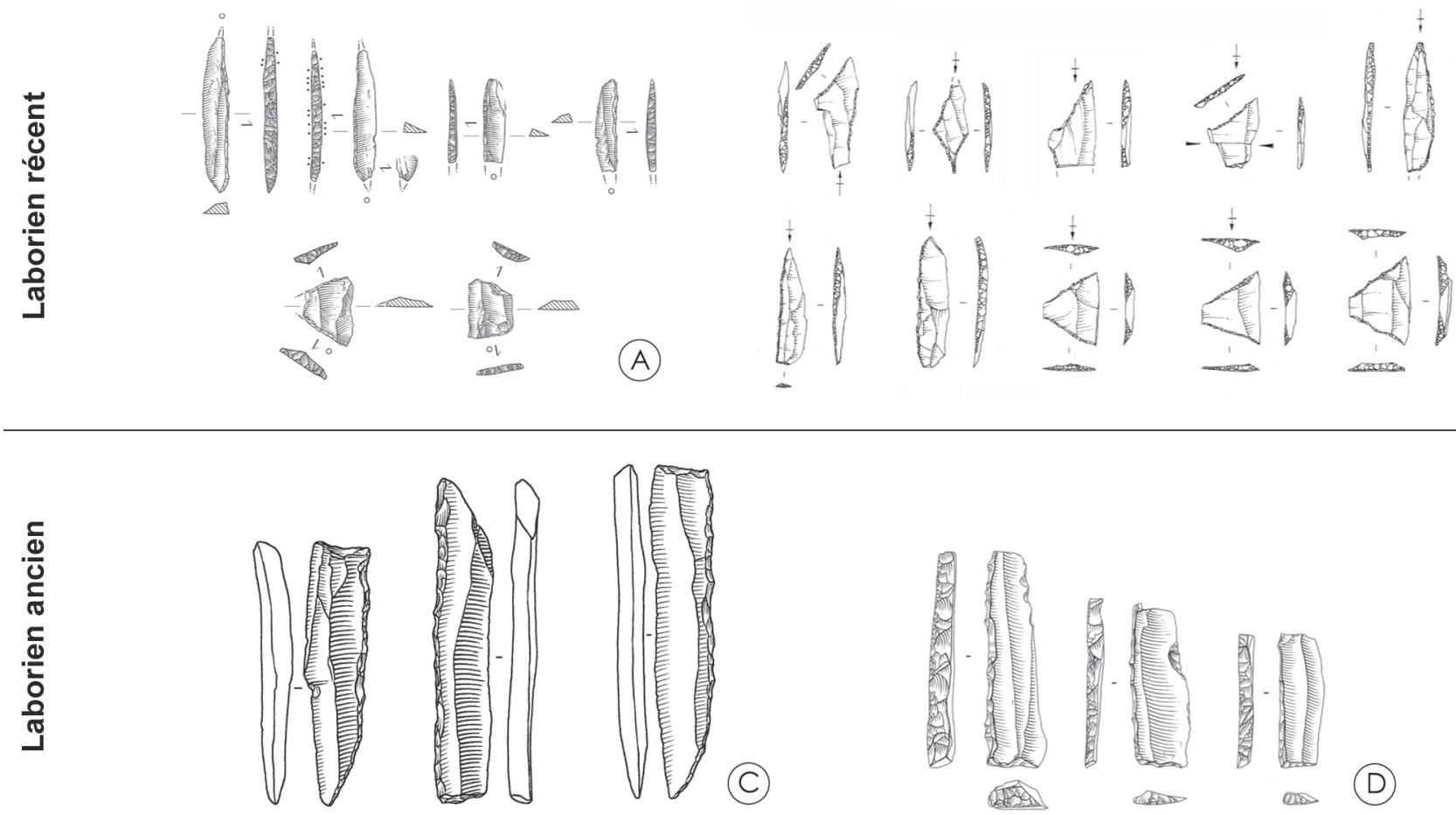

(C)
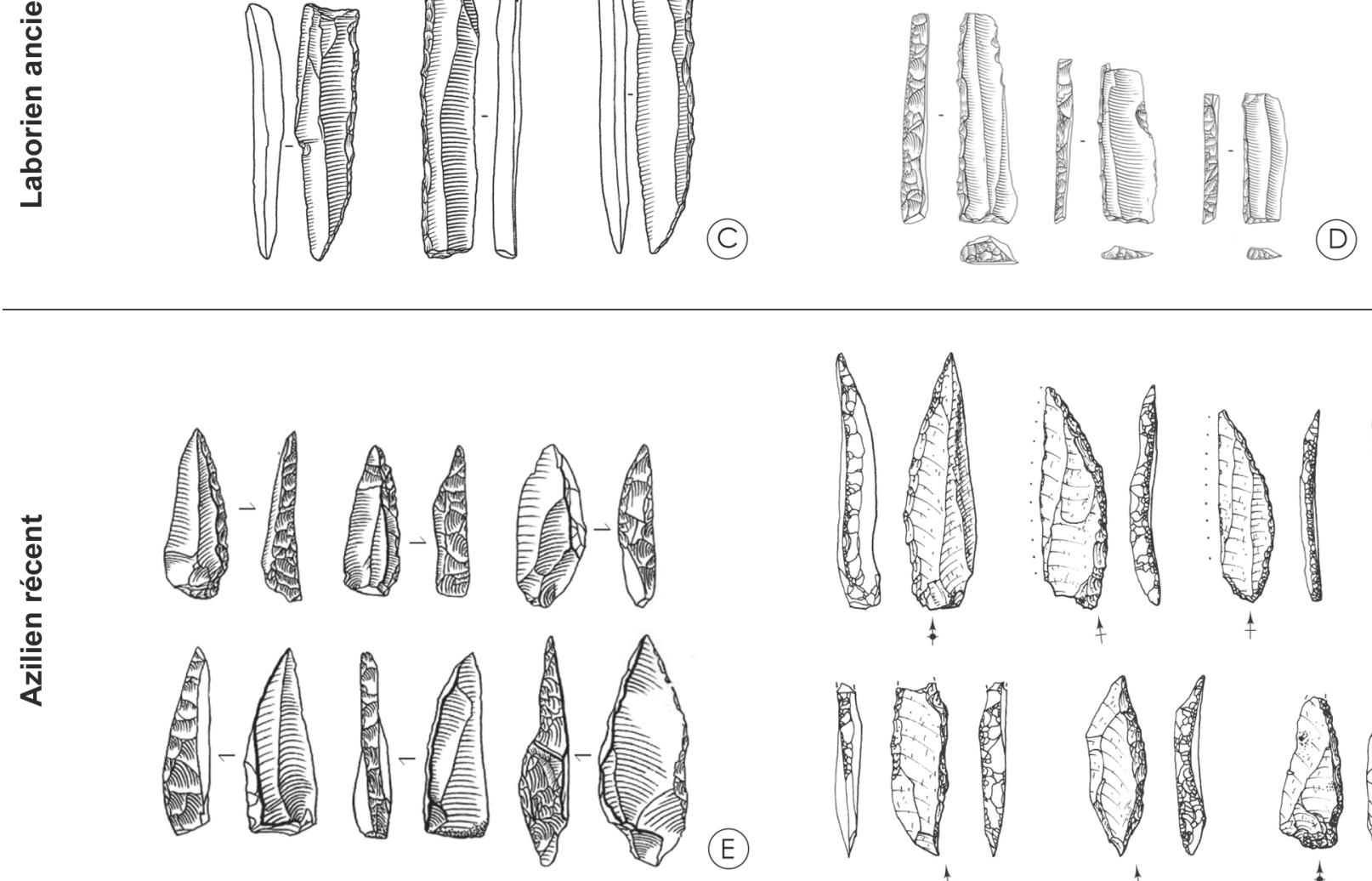

(E)
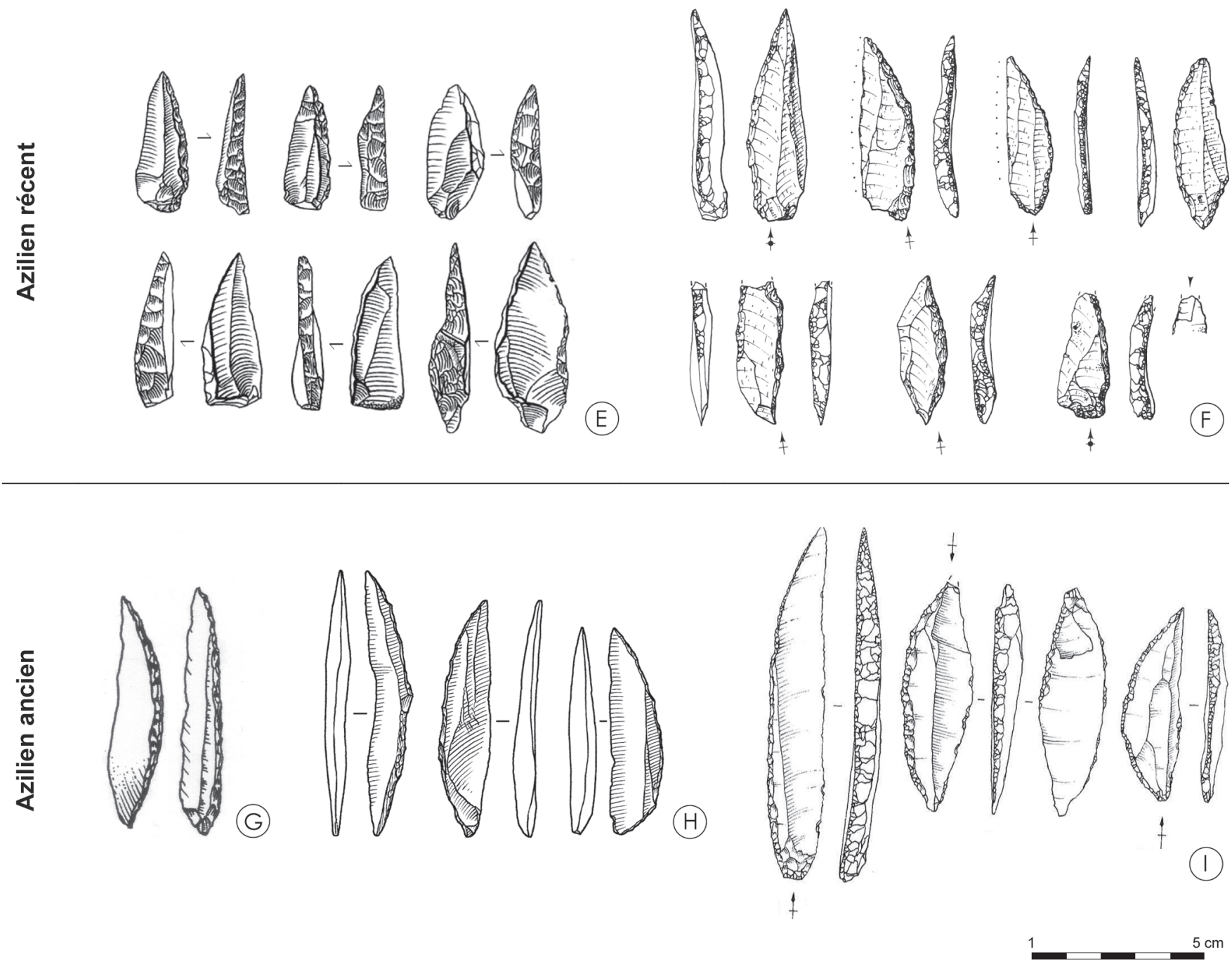

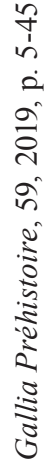


dans le sens d'une diachronie entre derniers Magdaléniens et premiers Aziliens. Cette question constitue donc une problématique prioritaire dans une région particulièrement riche en restes fauniques.

Cette aire d'étude permet également de développer les réflexions concernant les comportements symboliques des premières communautés aziliennes (fig. 9). Les deux gisements au plus grand corpus d'art mobilier attribués à l'Azilien ancien sont en effet localisés dans cette région : l'abri Murat dans le Lot (Lorblanchet 1985, 1996) et le Rocher de l'Impératrice dans le Finistère (Naudinot et al. 2017a, 2018a, 2018b ; fig. 1). Les données recueillies suggèrent, à partir de riches corpus pour le moment sans équivalent, le maintien durant cette période de représentations zoomorphes figuratives, très naturalistes au Rocher de l'Impératrice, en parallèle d'autres animaux plus schématiques et de rares thèmes géométriques (fig. 9). Il en ressort un fort ancrage de la symbolique dans le Magdalénien récent (Lorblanchet 1985, Naudinot et al. 2017a, 2018a, 2018b). Mis en parallèle avec les changements techniques touchant les systèmes lithiques et osseux, ce lien iconographique conduit à s'interroger sur les rythmes de l'azilianisation. Plus précisément, les travaux en cours au Rocher de l'Impératrice montrent ainsi une claire arythmie entre transformations du sous-système lithique et changements des représentations graphiques et de leurs techniques de production (Naudinot et al. 2017a).

Si le corpus important de sites, la présence de gisement stratifiés et la richesse des témoignages artistiques font de la façade atlantique une région particulièrement propice pour discuter de l'émergence des sociétés aziliennes, l'actuelle absence de sites de plein air fouillés pour cette période charnière limite les interprétations paléo-économiques argumentées dans cette aire géographique. Les premiers résultats croisés obtenus sur le site du Rocher de l'Impératrice suggèrent, au moins pour ce site, plusieurs occupations courtes par de petites communautés de l'Azilien ancien, dont les activités sont essentiellement tournées vers la préparation de la chasse et le traitement du gibier. Dans la même région, d'autres occupations assez éphémères d'abris-sous-roche sont également attestées à Kerbizien (Marchand et al. 2014 ; fig. 1). Par ailleurs, on note une perduration de certains réseaux de circulation au sein des « litho-espaces » (Delvigne 2016) étendus au regard des matières premières siliceuses soulignant un maintien d'exigences qualitatives élevées.

\section{L'AZILIEN RÉCENT ENTRE ARMORIQUE ET PYRÉNÉES : ACCÉLÉRATION DU PROCESSUS D'AZILIANISATION}

Si l'Azilien ancien semble finalement peu implanté dans les massifs armoricains et pyrénéens, la phase récente indique au contraire une expansion géographique recouvrant l'ensemble de la façade atlantique française avec une densité de gisements beaucoup plus importante. On notera que dans le Grand-Ouest, l'Azilien récent semble témoigner d'une installation plus pérenne, alors que plusieurs indices (notamment la brièveté des occupations et le resserrement des activités) suggèrent plutôt des incursions spécialisées de " pionniers 》 durant l'Azilien ancien après un long hiatus débutant à la fin du Dernier Maximum Glaciaire (Marchand et Naudinot 2015).

L'Azilien récent se développe au cours du GIld-c-b-a (Allerød) et du GS1 (ca. Dryas récent). Chronologiquement, on peut observer un nouveau décalage de part et d'autre de la Dordogne avec, au nord, un Azilien récent correspondant au GI1 (ca. 13 500-13000 cal. BP) et, au sud, une perduration au cours du GS1 (ca. 12500 cal. BP : Fat Cheung 2015, Tomasso et al. 2018).

Les études portant sur les équipements lithiques montrent, comme dans les régions voisines, une évolution vers une plus faible normalisation des supports d'outils et de pointes à partir de méthodes de production simplifiées (Jude 1960, Célérier 1993, Valentin 2005, Naudinot 2010, Fat Cheung 2015). Les monopointes, déjà présentes dans la phase ancienne, se généralisent et leurs supports deviennent beaucoup moins normés et plus épais, la relative standardisation des projectiles se faisant alors principalement par la retouche (fig. 8). Dans les Pyrénées (Fat Cheung 2015) et possiblement dans le Grand-Ouest (Genieux 2015), le développement de débitages sur enclume rend encore plus flagrante cet assouplissement technique. La capacité à s'affranchir de lourdes normes techniques est également perceptible dès les premiers temps de la chaîne opératoire avec l'usage dans les Pyrénées ou sur le Massif armoricain de roches tenaces tels que des quartz, des grès ou des phtanites (Naudinot 2010, 2012, Fat Cheung 2015). Ceci suggère alors une différence avec les périodes précédentes concernant les réseaux de circulation et les territoires d'approvisionnement (Célérier 1993, Lacombe 1998, Marchand et al. 2009, Naudinot 2010, 2012, Fat Cheung 2015).

Dans le domaine de l'industrie osseuse, la façade atlantique fournit l'essentiel de la documentation. On note alors, en continuation avec l'Azilien ancien, une pauvreté typologique de l'équipement. Seule la pointe barbelée (ou harpon) perdure ainsi que quelques poinçons obtenus selon des méthodes de production qui doivent être précisées. La morphologie des

Fig. 9 - Éléments d'arts mobilier de l'Azilien au Laborien dans la moitié ouest de la France (DAO M. Langlais et N. Naudinot).

A. Champ-Chalatras (d'après Pasty et al. 2002, relevé P. Alix) ; B. Le Pont d'Ambon (d'après Paillet et al. 2018, relevé P. Paillet et E. Paillet) ; C. Les Chaloignes (d'après Marchand et al. 2009, relevé G. Marchand) ; D. Rochereil (d'après Paillet et Man-Estier 2014, relevé P. Paillet et E. Paillet) ; E. Le Rocher de I'Impératrice (d'après Naudinot et al. 2018b, relevé P. Paillet et E. Paillet); F. Murat (d'après Bourdier et al. 2017, relevés P. Paillet et $E$. Paillet).

Elements of portable art from the Azilian to the Laborian in the western half of France (CAD M. Langlais and N. Naudinot).

A. Champ-Chalatras (after Pasty et al. 2002, drawing P. Alix); B. Le Pont d'Ambon (after Paillet et al. 2018, drawing P. Paillet and E. Paillet); C. Les Chaloignes (after Marchand et al. 2009, drawing G. Marchand); D. Rochereil (after Paillet and ManEstier 2014, drawing P. Paillet and E. Paillet); E. Le Rocher de I'Impératrice (after Naudinot et al. 2018b, drawing P. Paillet and E. Paillet); F. Murat (after Bourdier et al. 2017, drawing P. Paillet and E. Paillet). 


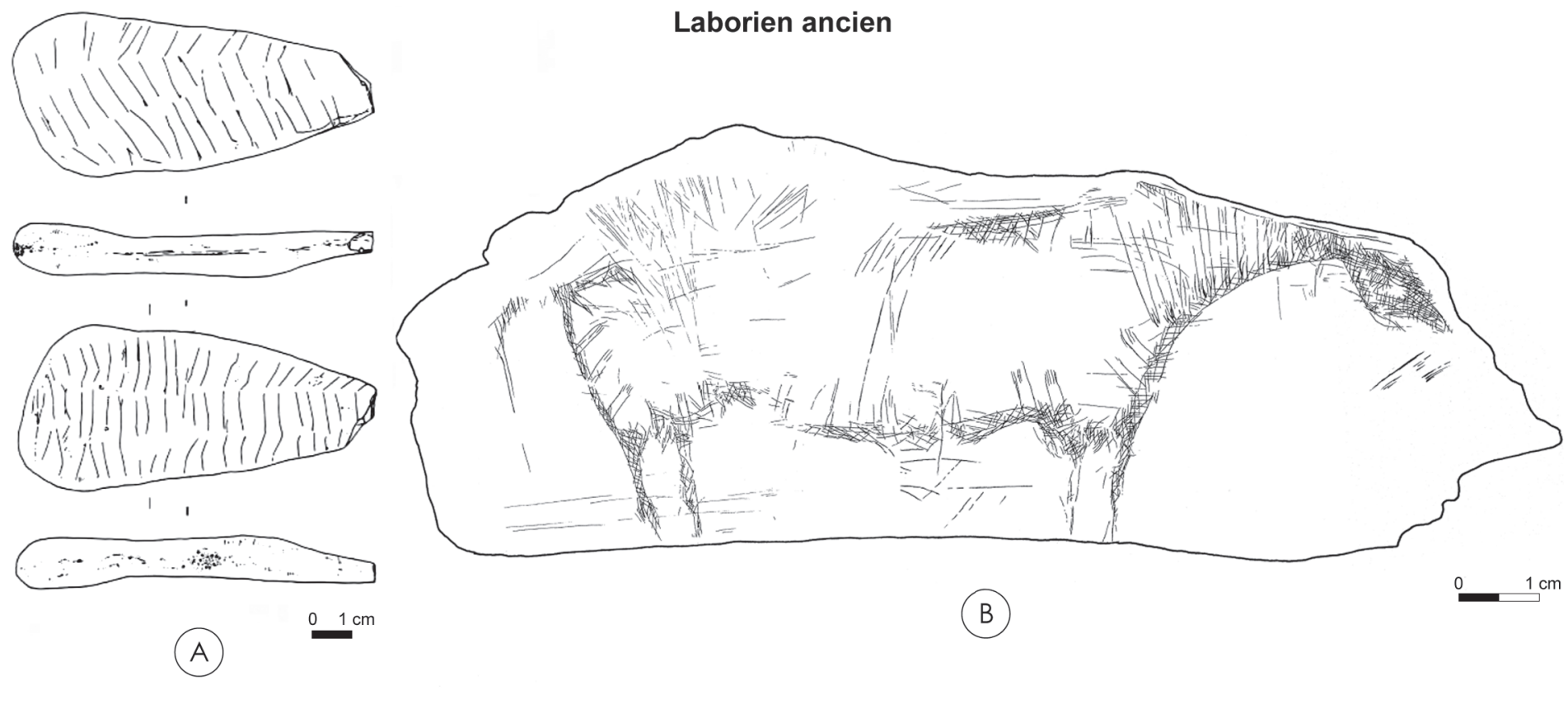

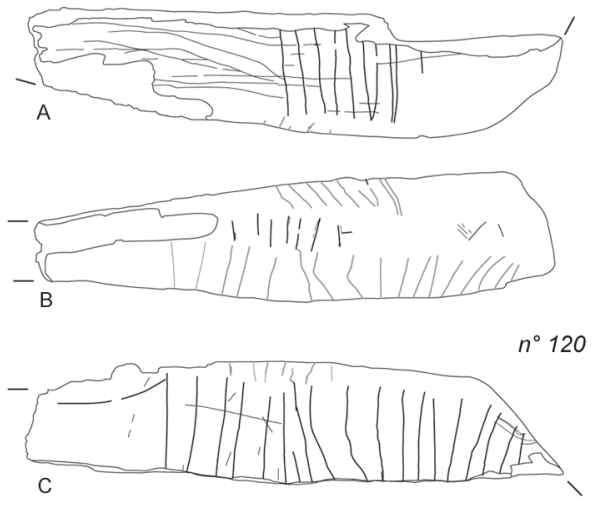

(C)

\section{Azilien récent}

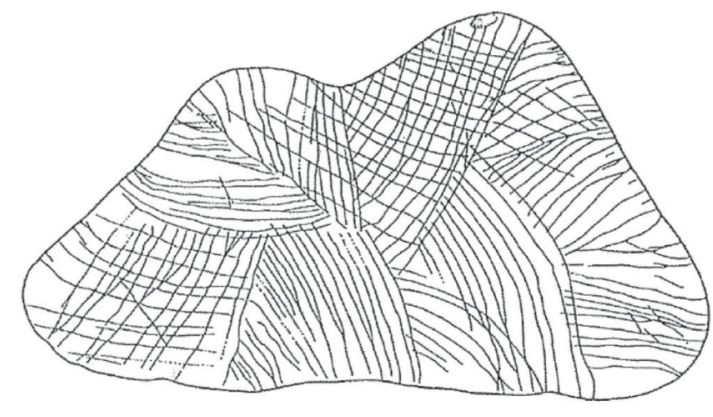

(D)

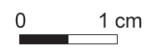

Azilien ancien

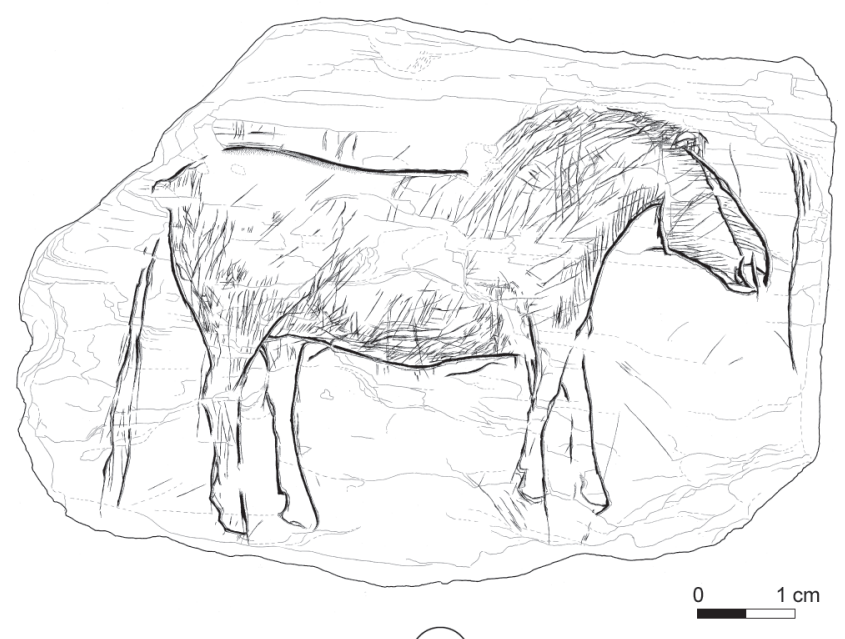

(E)
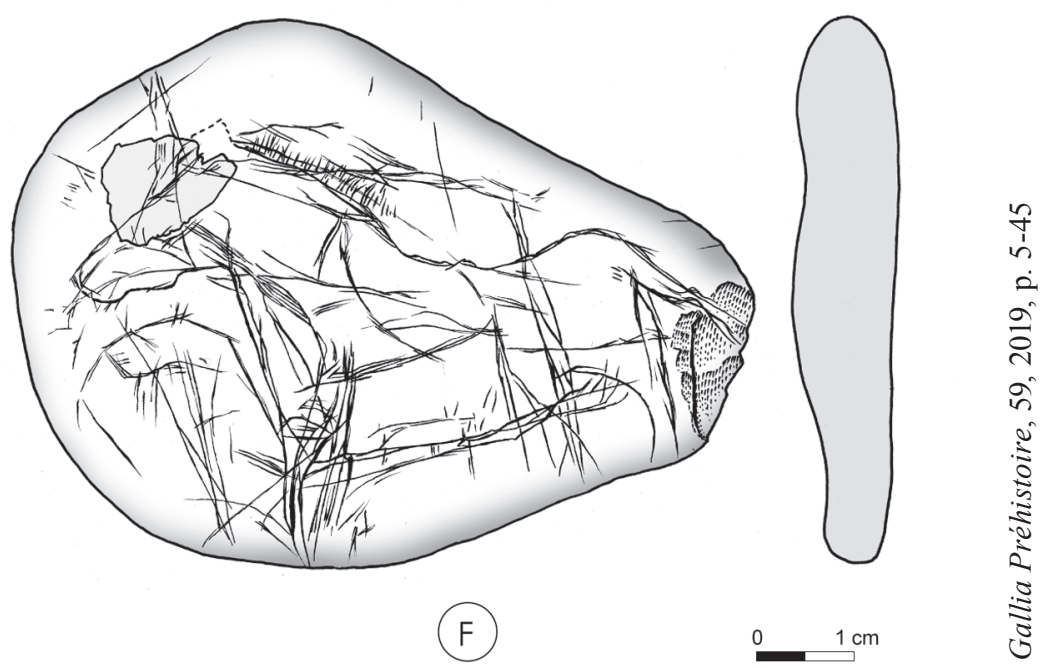

(F)

$0 \quad 1 \mathrm{~cm}$ 
harpons aziliens évolue dans le sens d'un éloignement avec les modèles magdaléniens, la forme « en sapin » de l'Azilien récent avec une perforation en boutonnière correspondant au modèle classique, très abondant dans certains sites comme Troubat dans les Pyrénées (Barbaza 2009 ; fig. 1).

Les riches assemblages fauniques disponibles montrent une faune chassée toujours dominée par les espèces tempérées (cerf, chevreuil, sanglier). Le lapin tient dans le nord du Bassin aquitain une place essentielle comparée aux Pyrénées (Fat Cheung et al. 2014, Chevallier 2015). Une exploitation plus exhaustive des carcasses à l'Azilien et une évolution des schémas de boucherie pourraient témoigner d'une transformation des besoins durant cette période, dans le sens d'une moindre conservation de la viande (Chevallier 2015). Ces stratégies font parfaitement écho aux données issues des industries lithiques qui suggèrent des productions à faible anticipation et à durée de vie courte en lien avec une forte mobilité à tendance résidentielle (Naudinot 2010, Jacquier et Naudinot 2015).

Dans le domaine des représentations graphiques, la façade atlantique apporte encore une fois l'essentiel des données disponibles en France. L'art de l'Azilien récent révèle des différences considérables avec les canons magdaléniens, mais aussi avec l'Azilien ancien, à travers la géométrisation des motifs gravés ou peints (Couraud 1985, Lorblanchet 1985, D'Errico 1994) et l'abandon (dès la phase ancienne ?) des supports pariétaux (fig. 9). Il reste toutefois à préciser le moment de cette bascule stylistique, qui pourrait finalement intervenir assez tardivement (Naudinot et al. 2017a) si l'on en croit la représentation encore très figurative de l'assemblage de Pincevent III.2 attribué aux premiers temps de l'Azilien récent (Baffier 1996 ; voir supra) et le rythme de développement de ces nouveaux concepts graphiques.

Contrairement à l'Azilien ancien, la phase récente de ce techno-complexe est connue sur quelques sites de plein air de la façade atlantique. C'est le cas notamment sur le gisement ligérien des Chaloignes dans le Maine-et-Loire (fig. 1) qui éclaire l'organisation de l'espace durant cette période (Marchand et al. 2008, 2009, 2011) et dont l'étude a amorcé la dynamique de recherche sur les sociétés tardiglaciaires dans le Grand-Ouest. L'étude des différents locus mis au jour lors de la fouille de ce vaste site dans le cadre de l'archéologie préventive contribue à mieux évaluer les stratégies d'occupation du territoire de ces communautés. Il semblerait en effet que ces différentes aires de concentrations soient le résultat de successions d'installations au cours de l'Azilien récent, plutôt que le signe d'un seul et même vaste site. Si les activités semblent la plupart du temps diversifiées sur les différents locus, les tâches liées à la préparation d'un équipement de chasse prédominent. Ces données, avec celles collectées sur les autres sites régionaux moins bien conservés, alimentent l'image de groupes à forte mobilité à dominante résidentielle (Naudinot 2010). En Aquitaine, le site des Pinelles (Dordogne ; fig. 1), également découvert dans le cadre de l'archéologie préventive, permet également de documenter plusieurs occupations en plein air de l'Azilien récent (Mevel 2017).

\section{LES INDUSTRIES DE LA TRANSITION PLÉISTOCÈNE- HOLOCÈNE SUR LA FAÇADE ATLANTIQUE : DES SCÉNARIOS ENRICHIS}

Initialement reconnues dans le Bassin aquitain, notamment sur le site éponyme de la Borie del Rey (Coulonges 1963 ; fig. 1) et sur celui de Pont d'Ambon (Célérier 1998), les industries de l'extrême fin du Pléistocène et du début de l'Holocène sont restées longtemps délaissées dans cette zone géographique. Stimulée par les travaux réalisés dans le Bassin parisien au sens large (voir supra), une nouvelle dynamique de recherche s'est ensuite mise en place dans le Grand-Ouest (Marchand et al. 2004, Naudinot 2008, 2010, 2013), puis dans le Bassin aquitain (Langlais et al. 2014a, 2014b, 2015, à paraître). Elle a donné lieu, ces dernières années, à deux rencontres scientifiques structurantes à l'échelle nationale : un premier échange lors d'une session du Congrès préhistorique de France, à Bordeaux et aux Eyzies, en 2010, organisée par N. Naudinot et S. Michel (Naudinot et Michel 2014), puis une seconde rencontre à l'occasion d'une séance de la Société préhistorique française, organisée à Bordeaux en 2012 (Langlais et al. 2014d). Entre autres actions, un programme collectif de recherches sur le Laborien (M. Langlais, PCR en cours) poursuit depuis 2016 une intense dynamique de recherche sur ces derniers temps du Paléolithique entre Pyrénées et Manche. Ces travaux ont rapidement contribué à mieux comprendre les systèmes techniques de ces dernières sociétés paléolithiques et ont surtout mis en lumière, derrière de grandes idées communes, une certaine diversité des comportements techniques. Grâce à des sites aux signatures techniques plus variées que dans le Bassin parisien et à des approches croisées - pétro-archéologiques, technologiques et fonctionnelles -, ces recherches sont également à l'origine de réflexions paléoéconomiques, voire socio-économiques, testables à plus grande échelle (Naudinot et Jacquier 2014, Jacquier et Naudinot 2015, Langlais et al. 2018).

Tandis que dans les Pyrénées un Azilien récent/final perdure pendant la seconde moitié du GS1, cette période voit se développer dans la plaine aquitaine les premières occupations du Laborien (Fat Cheung et al. 2014, Langlais et al. 2014b). Ces industries sont rattachables à un plus vaste courant caractérisé par des productions lamino-lamellaires spécifiques évoquées plus haut à propos de la France septentrionale (voir supra). Ces réalisations font appel à des matériaux parfois récoltés sur des distances importantes (notamment dans les secteurs dépourvus de matériaux de bonne qualité comme le Massif armoricain) et adaptés à des normes techniques exigeantes. Ces données témoignent de la fréquentation de litho-espaces de nouveau étendus (Naudinot 2010, 2012, Langlais et al. 2014a). Au sein de ce grand phénomène laminaire de la fin du Paléolithique final, on distingue plusieurs traditions techniques essentiellement définies à partir de la morphologie des pointes de projectiles. Au sein de notre zone d'étude, il s'agit dans un premier temps du Laborien ancien à pointes de Malaurie et bitroncatures à dos (ou rectangles ; Le Tensorer 1979, Langlais et al. 2014b, 2014c, à paraître), phase pour laquelle les témoignages restent pour le moment isolés au nord-ouest de la 
Loire (pièces issues d'assemblages de surface : Naudinot 2008, 2010, 2013 ; fig. 8). Cet ensemble est documenté de façon anecdotique dans le Bassin parisien (Bodu 2000a, Teyssandier 2000, Valentin 2008a) et vers l'Est de la France. On le connaît également sporadiquement dans le Sud-Est de la France, comme à la Baume Goulon dans le Var (Gagnière 1948 ; fig. 1) dans un contexte dominé par des éléments rapportables à un Épigravettien récent, avec qui les groupes laboriens semblent avoir partagé les mêmes territoires lithologiques (Naudinot et Tomasso 2012, collection en cours de reprise). Une telle observation présente l'intérêt de complexifier notre vision de la géographie culturelle tardiglaciaire, écartant, tout du moins pour cette période, l'idée d'une frontière culturelle stricte le long de la vallée du Rhône.

Les débitages du Laborien s'inscrivent en rupture technique avec l'Azilien récent avec le retour d'un investissement dans la production lamino-lamellaire : les lames les plus larges sont essentiellement réservées à un usage sans retouche et peuvent ensuite être recyclées en différents types d'outils de transformation (Jacquier 2015, Jacquier et Naudinot 2015) tandis que les petites lames sont dédiées à la fabrication d'une vaste gamme de pointes de projectiles (voir infra). Les travaux menés dans le Grand-Ouest ont joué un rôle majeur dans notre appréciation des objectifs spécifiques de production. Alors que, suite aux travaux réalisés dans le Bassin parisien, c'est plutôt la régularité des lames et leur longueur qui étaient mises en avant pour caractériser ces productions (Valentin 1995, Bodu et Valentin 1997, Fagnart 1997). L'analyse des assemblages du Grand-Ouest, et notamment celles issues des sites du Camp d'Auvours (Sarthe ; fig. 1) et de la Fosse (Mayenne ; fig. 1) ont montré que ces débitages visaient surtout la recherche de lames plates (Naudinot 2013) aux tranchants aigus. L'obtention de ces supports à partir de surfaces larges est audacieuse et nécessite l'enchaînement de gestes techniques spécifiques (Naudinot 2010, 2013, Naudinot et Jacquier 2014). Les débitages sont essentiellement limités à la surface la plus large des volumes, ce qui donne une véritable exploitation faciale à partir de deux plans de frappe avec le recours courant à des débordements sur les flancs par lames antéro-latérales destinées à réamorcer le débitage sur des surfaces plus cintrées. La recherche de tranchants particulièrement aigus semble ainsi structurer la chaîne opératoire de production. Ces tranchants semblent d'ailleurs également particulièrement valorisés lors de l'utilisation de l'outillage (Jacquier 2015, Jacquier et Naudinot 2015). Depuis, l'importance de ce choix technique mis en évidence dans le Grand-Ouest a pu être également détecté dans le Bassin parisien après réévaluation des collections à la lueur de ces résultats (voir supra). Le partage de ces conceptions dans des régions aux armements différents peut inciter à parler de "flat blade techno-complex" (FBT) pour décrire ce vaste phénomène dont il conviendra dans les années à venir de mieux préciser l'extension vers l'Est (Naudinot 2013, Naudinot et Jacquier 2014).

Même si elle est beaucoup mieux documentée que dans d'autres régions, l'industrie osseuse du Laborien ancien demeure peu importante et monotone comme à Peyrazet (Pétillon in Langlais et al. 2015 ; fig. 1) ou la Borie del Rey
(Marquebielle in Langlais et al. 2014b). Elle est composée de poinçons et plus rarement de pointes barbelées comme à Gouerris (B. Marquebielle, étude en cours ; fig. 1).

Dans le Bassin aquitain la richesse des assemblages fauniques permet, contrairement à d'autres régions peu documentées sur le sujet, d'enquêter sur les faunes chassées par ces groupes humains. Dans la seconde moitié du GS1, les tableaux de chasse sont dominés, selon le biotope, par le cheval, l'aurochs ou le cerf, parfois accompagnés de petit gibier comme le castor (Langlais et al. 2014a, 2014b, 2015, à paraître).

Une fois de plus, ce sont surtout les données disponibles sur la façade atlantique qui permettent aujourd'hui d'enquêter sur les représentations graphiques réalisées par ces dernières communautés paléolithiques. Plusieurs sites du Bassin aquitain attribués au Laborien ancien livrent un art mobilier particulier. Illustrant un retour des représentations figuratives, ces œuvres s'écartent néanmoins du naturalisme qui caractérisait le Magdalénien et au moins en partie l'Azilien ancien. Les animaux gravés sont ici systématiquement schématisés et traités à partir de normes graphiques originales : membres non détaillés, animaux microcéphales aux contours souvent représentés par des hachures qui, avec des zigzags, remplissent également les corps. Il s'agit ainsi d'innovations stylistiques flagrantes tout à fait inédites et très homogènes sur une aire géographique encore restreinte (Guy 1993, Paillet et Man-Estier 2014, 2018 ; fig. 9). À côté de cet art figuratif nouveau, il existe également quelques figures géométriques sur galets qui rappellent les derniers temps de l'Azilien (voir notamment Pasty et al. 2002, Langlais et al. à paraître) signant à la fois un maintien de traditions artistiques ancestrales et de nouveaux canons iconographiques parallèlement à un changement dans les équipements de chasse.

Parmi les rares gisements de plein air fouillés attribués au Laborien ancien, on peut citer deux opérations menées par l'Inrap : Champ-Chalatras dans le Puy-de-Dôme (Pasty et al. 2002 ; fig. 1) et Port-de-Penne dans l'Agenais (Valdeyron et Detrain 2009, Langlais et al. 2014b, Detrain et al. 2018) qui révèlent notamment des activités de boucherie et de réfection des armes réalisées au sein d'espaces de vie structurés autour de foyers constitués de galets chauffés (M. Langlais, monographie en cours). Il est en tout cas délicat aujourd'hui de discriminer si ces unités d'habitats dont la vocation essentielle était de traiter le gibier correspondent à des bivouacs ou témoignent d'un fragment de vie au sein d'un campement plus large.

Lors des débuts de l'Holocène et notamment de l'événement 11400 cal. BP (Rasmussen et al. 2014), alors que les exigences lamino-lamellaires et les méthodes de production déployées dans les premiers temps du FBT sont maintenues dans les grandes lignes, le contenu lithique des carquois évolue. On assiste au remplacement des pointes de Malaurie et bitroncatures à dos par des pointes des Blanchères (petites pointes à troncatures très obliques et dos abattu) et des bitroncatures trapéziformes (fig. 8). Ces dernières armatures, considérées jusqu'en 2010 comme intrusions du Mésolithique récent dans ces assemblages du Paléolithique final, ont été récemment reconsidérées grâce aux travaux menés dans le Grand-Ouest (Naudinot 2008, 2010, 2013), notamment sur le site de la Fosse en Mayenne (Naudinot 
et Jacquier 2009, 2011, 2014), à partir de l'étude technologique fine des supports investis dans la fabrication de ces bitroncatures. Ces travaux ont également suggéré leur usage comme armatures essentiellement transversales, les plus anciennes en Europe (Naudinot et Jacquier 2011, Naudinot 2013). Cette importante nouveauté a ensuite également été mise en évidence plus au sud dans le Bassin aquitain (Langlais et al. 2014c, 2015). Le développement de cette nouvelle gamme de projectiles est aujourd'hui reconnu, à grande échelle et notamment dans le Bassin parisien (Bemilli et al. 2014). Par ailleurs, au nord de la Loire, quelques petites pointes pédonculées, associées à des pointes à troncature oblique concave, viennent compliquer la question des relations entre les différentes traditions constituantes du techno-complexe FBT. Elles suggèrent des liens entre des groupes essentiellement porteurs d'armatures du Laborien récent et d'autres utilisant des modèles connus dans le Nord de l'Europe (Ahrensbourgien et Épi-Ahrensbourgien, Naudinot 2013, Naudinot et Jacquier 2014). L'évaluation des différences culturelles régionales en France, et à plus large échelle, constitue une des questions en cours de développement sur la façade atlantique. Elle vise notamment à mieux évaluer les similitudes et différences avec certains assemblages lithiques du Bassin parisien rassemblés sous l'appellation de « Belloisien » (voir supra), ensembles que nous préférons attribuer à un faciès fonctionnel en partie lié à la disponibilité des géo-ressources plutôt qu'à un particularisme culturel.

Sur la façade atlantique, la multiplication des reprises de collections anciennes ainsi que la découverte et la fouille de nouveaux gisements ont permis d'affiner les modèles jusqu'alors proposés quant aux objectifs et méthodes de débitage de ces derniers groupes paléolithiques. Les données restent cependant assez fragmentaires en ce qui concerne l'industrie osseuse avec seulement quelques poinçons dans les sites actuellement reconnus. Le même constat peut être fait en ce qui concerne les témoignages artistiques qui restent pour le moment totalement inconnus dans la région pour le Laborien récent, interdisant une perspective diachronique complète sur les traditions iconographiques du Paléolithique final.

Après s'être focalisées sur le système techno-économique, les recherches dans cette grande moitié ouest de la France se sont ensuite efforcées d'aborder la question des organisations paléo-économiques. Certaines données issues de fouilles anciennes, mais surtout la mise en place de nouvelles opérations de terrain, ont permis d'intégrer de nouvelles données aux modèles jusqu'alors proposés dans le Bassin parisien (Valentin 2008 ; voir supra). Ces résultats vont dans le même sens d'une plus importante segmentation spatio-temporelle des activités que dans les périodes précédentes (notamment pendant l'Azilien récent). Ils ont également permis d'enrichir un peu ce modèle du Bassin parisien grâce à la fouille de gisements aux signatures techniques variées et installés dans des paysages contrastés. L'étude des grands sites de plein air est complémentaire de celle des sites en abri qui permettent, malgré des degrés de résolution palethnographiques souvent plus faibles, de renseigner toute une part du système paléo-économique non accessible en plein air (Marchand et Naudinot 2015). Des sites témoignant d'activités spécifiques sont ainsi aujourd'hui bien caractérisés
(Peyrazet : Langlais et al. 2015 ; le Cuze de Sainte-Anastasie : Langlais et al. 2018 ; Port-de-Penne, Langlais et al. 2014b et M. Langlais, monographie en cours ; fig. 1), ainsi que les vastes campements de base, aux activités plus diversifiées, occupés plus longuement et pouvant fonctionner en parallèle comme le Camp d'Auvours dans la Sarthe (Naudinot 2008, 2010, 2013) ou la Fosse en Mayenne (Naudinot et Jacquier 2011, 2014). Sur ce dernier site, plusieurs faisceaux d'indices conduisent même à interpréter cette vaste occupation de fond de vallée comme un site d'agrégation (Naudinot et Jacquier 2014).

\section{RECOLONISATION DU MASSIF ALPIN ET INTER- CULTURALITÉ : LES NOUVELLES DONNÉES ISSUES DE LA MOITIÉ EST DE LA FRANCE}

S'il n'a pas totalement été laissé en marge des dynamiques de recherche autour du Tardiglaciaire, un large quart sud-est de la France, comprenant toute la partie orientale de la vallée du Rhône, est resté longtemps mal connu, en particulier pour ce qui concernait l'évolution détaillée des industries lithiques. Pourtant la documentation archéologique est parfois relativement abondante dans certains secteurs géographiques. Ainsi les Alpes du Nord, en particulier les massifs préalpins (massifs des Bauges, des Bornes, de la Chartreuse et du Vercors), et aussi le Jura méridional ont livré depuis le premier tiers du XIX ${ }^{\mathrm{e}}$ siècle de nombreux témoignages d'occupation tardiglaciaire (Stahl-Gretsch 2004, Pion et Stahl-Gretsch 2007, Béreiziat 2011). Cette aire géographique constituera le cœur de notre bilan. Cependant, à la différence d'autres territoires, cette région a encore assez peu bénéficié de l'essor de l'archéologie préventive. Même rares, ces découvertes préventives permettent tout de même d'éclairer un peu mieux les processus évolutifs à fin du Tardiglaciaire à partir de gisements de plein air (Pasty 2017 ; Jallet et Bouvier 2012) ou d'apporter des données inédites sur les pratiques funéraires des derniers chasseurs épigravettiens (Mourre 2013). Si les Alpes du Nord et le Jura sont nettement à rattacher aux traditions techniques du Nord-Ouest européen pour les phases anciennes du Tardiglaciaire (Magdalénien, Azilien), la situation s'avère moins claire pour la fin de la période où semblent émerger plusieurs traditions techniques : Laborien d'une part (Monin 2000 ; Pasty 2017) et Épigravettien d'autre part (FornageBontemps 2013, 2016, Mevel et al. 2014a, 2014b).

Malgré l'existence de ce riche potentiel, la rareté des opérations de fouille depuis la fin des années 1970 concernant le Tardiglaciaire - et le Paléolithique récent en général révèle le peu d'intérêt porté par l'archéologie institutionnelle pour ces secteurs géographiques. En effet, il faut mettre ce constat en parallèle avec le faible nombre de postes de préhistoriens travaillant sur ces régions. Aussi convient-il de saluer l'apport important de l'archéologie bénévole dans cette région (G. Pion, M. Cartonnet...) sans laquelle plusieurs gisements majeurs n'auraient peut-être jamais été fouillés (abri de la Fru : Pion 1990 ; Gerbaix « dessus »: Pion 1981 ; la Chênelaz : Cartonnet et Naton 2000 ; fig. 1). Le mérite 
principal des générations suivantes d'archéologues aura été d'abord d'exploiter ces données collectées au tournant des années 1980-1990. Le renouvellement des méthodes d'approche appliquées notamment aux industries lithiques (critique des sources, approche techno-économique intégrant les données de la pétro-archéologie) aura permis de renouveler notre perception des sociétés magdaléniennes et aziliennes. Quant aux dernières opérations de terrain réalisées entre Alpes et Jura, elles ont surtout permis d'enrichir nos connaissances sur le Magdalénien récent (abri des Douattes, à Musièges en HauteSavoie : Pion et Mevel 2005 ; grotte Blénien à Wolschwiller dans le Haut-Rhin : Koehler et al. 2013, Griselin et al. 2017 ; fig. 1). À ce jour, l'Azilien et les traditions techniques plus tardives sont documentés par des gisements fouillés au mieux au début des années 1990.

La suite de notre propos tournera essentiellement autour des résultats issus de l'analyse des industries lithiques. En effet, les études concernant la chasse sont malheureusement rares et concernent surtout jusqu'ici le Mésolithique (Bridault 1993, Leduc et al. 2015). La publication prochaine des résultats sur l'important corpus provenant de l'abri de la $\mathrm{Fru}^{7}$ permettra de combler nos actuelles lacunes sur les comportements de subsistance des populations aziliennes. Enfin, l'industrie osseuse est peu représentée sur les sites de ces périodes (Pion 1990) en comparaison, notamment, de ce qui est connu pour le Magdalénien (Malgarini 2014).

\section{BREF RAPPEL DES DONNÉES PALÉO-ENVIRONNEMENTALES}

Le retrait des glaciers würmiens, vraisemblablement amorcé vers $22000 \mathrm{cal}$. BP dans les zones de basse altitude (Monjuvent et Nicoud 1988, Waelbroeck et al. 2001), a précédé une phase d'érosion se traduisant par une importante masse de sédiments transportés par des cours d'eau libérés des glaces (Schoeneich 1998, Girardclos et al. 2005). Le processus de recolonisation végétale de ces milieux a débuté vers 19000-18000 cal. BP par l'expansion d'une steppe d'herbacées et de plantes héliophiles (Richard et al. 2000, Richard et Bégeot 2000, Bégeot et al. 2006). Dans le même temps, de gigantesques lacs postglaciaires ceinturent le sud du Massif jurassien et la plupart des massifs préalpins (Evin et al. 1994).

C'est dans ce contexte paléogéographique qu'ont eu lieu la recolonisation progressive de ces territoires, nouvellement libérés des glaces pendant la phase moyenne du Dryas ancien, et celle du Magdalénien. Cette phase culturelle est pour le moment circonscrite à la vallée de l'Ain et à deux gisements. Le Magdalénien récent s'échelonnerait entre 17200 et $14700 \mathrm{cal}$. BP. Mais les mesures acquises récemment sont situées dans le plateau radiocarbone et demeurent difficiles à commenter sans une discussion détaillée sur les corpus archéologiques et leur intégrité stratigraphique. Sont-elles le

7. L'étude et la publication de la faune des niveaux aziliens de l'abri de la Fru est actuellement en cours sous la coordination d'A. Bridault (CNRS, UMR 7041). témoignage d'une occupation magdalénienne tardive pendant le Bølling, comme cela est peut-être le cas dans le Bassin parisien (Valentin 2008a) ou doivent-elles être plutôt rapportées à des occupations de la fin du Dryas ancien, limite chronologique du peuplement magdalénien sur le Plateau suisse (Leesch et al. 2004) ? Notons que ces dates problématiques n'ont pas été obtenues à partir des séquences les plus fiables d'un point de vue taphonomique et que ces gisements ont été généralement occupés ensuite par des groupes aziliens, ce qui laisse ouverte la possibilité de contaminations.

L'Azilien ancien de la partie nord-est des Alpes est plus précoce qu'on le pensait communément à la fin des années 1990. Il était alors réputé plus récent que l'Azilien ancien du Bassin parisien (Bodu 1998a, 2000b, Bodu et al. 2006) ou du Plateau suisse (Leesch et al. 2004), puisqu'il semblait apparaître pendant l'Allerød, ce qui avait conduit P. Bintz et J. Evin à argumenter en faveur d'une azilianisation tardive des groupes magdaléniens, liée au réchauffement climatique plus lent à se diffuser en milieu montagneux (Bintz et Évin 2002). Désormais, les mesures les plus anciennes situent cet Azilien ancien en dehors du plateau radiocarbone, autour de 14900-14200 cal. BP (Argant et al. 2009). Cependant, plusieurs datations vers $13900-13800 \mathrm{cal}$. BP laissent entrouverte la possibilité d'occupations de la phase ancienne jusqu'au tout début de l'Allerød.

La chronologie des phases les plus récentes du Tardiglaciaire est moins bien documentée. L'Azilien récent, presque exclusivement daté à partir de l'abri de la Fru, se développe essentiellement pendant la deuxième partie de l'Allerød. Une seule date le situe explicitement vers $13350 \mathrm{cal}$. BP, alors que les autres dates disponibles indiquent un peuplement plus récent entre cette phase médiane de l’Allerød et le début du Dryas récent.

\section{L'AZILIEN ANCIEN : UNE RÉVOLUTION À PAS DE VELOURS}

La phase ancienne de l'Azilien est documentée dans plusieurs gisements des Alpes du Nord : le niveau F2d de l'abri Gay à Poncin dans l'Ain (Desbrosses 1976, 1977, Béreiziat 2011, 2013 ; fig. 1), la couche 7 de la grotte Jean-Pierre 1 à Saint-Thibaud-de-Couz en Savoie (Bintz 1994 ; fig. 1), les couches C'1 de la grotte du Taï 1 et IIIa de la grotte du Taï 2 à Saint-Nazaire-en-Royans (Brochier et Livache 1997 ; fig. 1) ainsi qu'à l'abri de la Fru à Saint-Christophe-la-Grotte en Savoie. Sur ce site, ce sont deux niveaux distincts spatialement, la couche 3 de l'aire 1 et la couche 3 de l'aire 2, qui ont livré du matériel contemporain de cette tradition technique (Pion 1997, Mevel et Bressy 2009, Mevel 2013). Le matériel de l'abri Gay a, pour sa part, été réexaminé par G. Béreiziat (Béreiziat 2011, 2013). L'enquête sur les vestiges lithiques de l'abri de la Fru a mis en évidence les principales caractéristiques de l'Azilien ancien des Alpes du Nord. Dans les deux assemblages, la chaîne opératoire est animée par la recherche de deux catégories de supports laminaires. La première correspond à des lames de 7 à $10 \mathrm{~cm}$ de long, selon la taille des blocs sélectionnés. Ces supports ont été exclusivement dévolus à la fabrication de l'outillage commun. Dans l'aire 1, les lames 
les plus longues et les plus régulières ont été transformées en burins et en lames à retouche écailleuse (fig. 10). Cette situation est comparable à celle reconnue sur d'autres sites contemporains d'autres régions (Valentin 2005, Naudinot et al. 2017a ; voir supra). La situation est légèrement différente dans l'aire 2, puisque les meilleurs supports ont été très majoritairement transformés en grattoirs. Par contre, les lames retouchées et les burins ont presque exclusivement été fabriqués à partir de supports de second choix, épais pour les burins et significativement plus larges pour les lames retouchées. Les Aziliens anciens de l'abri de la Fru ont utilisé deux catégories de pointes à dos : des bipointes et des monopointes, confectionnés sur les lames les plus courtes, certainement dans une intention de rentabiliser les supports débités (fig. 10).

Alors que plusieurs gisements du Bassin parisien laissent entrevoir une évolution progressive des industries lithiques et des comportements entre le Magdalénien et l'Azilien, cette situation ne s'observe pas pour le moment dans les Alpes du Nord. De fait, au sein des stratigraphies régionales disponibles, l'émergence de l'Azilien ne paraît pas avoir été précédée par des stades intermédiaires. En revanche, dès l'apparition de l'Azilien ancien, les transformations affectent de façon bien lisible l'équipement lithique. Comme dans les autres secteurs géographiques, on voit l'utilisation du percuteur de pierre tendre et de pointes à dos courbe se substituer à la percussion tendre organique et aux têtes de projectiles en bois de cervidé. Mais, cette rupture est moins prononcée dès lors que l'on se place du point de vue économique. En effet, les parentés entre le Magdalénien récent et l'Azilien ancien sont nombreuses. Les indices conduisant à voir dans l'Azilien ancien un stade terminal du Magdalénien supérieur sont de plus en plus explicites. Ainsi, l'apport de ressources siliceuses d'excellente qualité (locales et allochtones) constitue un comportement économique partagé.

Si les données sont encore rares sur la façade méditerranéenne, de récents travaux, menées par C. Montoya (2004) et A. Tomasso (2014) permettent d'envisager un certain parallélisme des trajectoires évolutives entre sociétés épigravetiennes et aziliennes (Naudinot et al. 2017b). On perçoit en effet, peut-être dès la fin du Dryas ancien, un intérêt plus marqué en contexte épigravettien (ER2) pour des supports moins normés (éclats, éclats laminaires) en vue de confectionner l'outillage. Ce constat permet d'ailleurs de s'interroger sur une possible antériorité de ce phénomène en domaine méditerranéen alors qu'il va atteindre sa pleine mesure pendant l'Allerød ailleurs en Europe (Tomasso 2014, p. 472, Naudinot et al. 2017b).

\section{LES INDUSTRIES LITHIQUES DE L'ALLERØD : RUPTURES ET CONTINUITÉS DANS LES SYSTÈMES TECHNO-ÉCONOMIQUES}

Ce sont, ici aussi, les occupations de l'abri de la Fru qui permettent d'apprécier avec le plus de précision la variabilité des systèmes techniques des sociétés de l'Allerød. On dénombre en effet quatre niveaux contemporains de cette période à la Fru, répartis sur les trois aires fouillées. Seuls trois d'entre eux ont été étudiés (couches 2 et 1c de l'aire 1 et couche 5 de l'aire 3 ; Mevel 2017). Les ensembles archéologiques de la phase récente témoignent d'une franche évolution par rapport à la phase ancienne de l'Azilien. Les modalités de fabrication des supports se distinguent par une baisse d'exigence évidente à tous les stades des chaînes opératoires (débitage plus rapidement exécuté et importance accrue des étapes de retouche). Cette double tendance est surtout perceptible sur les différentes catégories d'armatures dont les supports initiaux sont sélectionnés dans une gamme relativement vaste (lames, éclats, éclats laminaires). Cependant, nous avons pu constater que, d'une série à l'autre, les degrés de simplification étaient variables et qu'un contraste net entre le corpus issu de l'aire 1 et celui de l'aire 3 était perceptible.

Les ensembles qui proviennent de l'aire 1, que l'on rapportera avec prudence à un stade terminal de l'Azilien, se distinguent en effet par des débitages très expéditifs réalisés à la pierre tendre en retrait du bord de plan de frappe sur des matières premières de qualité très médiocre. Pour sa part, la série provenant de la couche 5 de l'aire 3 s'écarte de cette tendance. Les productions y sont moins élaborées que celles réalisées pendant la phase ancienne de l'Azilien, mais elles sont plus soignées et plus régulières que les assemblages de l'aire 1 perçus comme les expressions les plus récentes de l'Azilien. Ainsi, dans l'aire 3, la production de lames, certes assez trapues mais régulières, prend clairement le pas sur les productions d'éclats. De plus, les lames produites et sélectionnées pour la confection des pointes à dos sont plus longues et plus régulières que dans l'aire 1 (fig. 10). On constate également l'existence de véritables lames à retouche écailleuse que l'on pensait seulement caractéristiques de la phase ancienne de l'Azilien. La couche 5 de l'aire 3 pourrait ainsi correspondre à un jalon intermédiaire de l'Azilien, ce que semble confirmer une datation la plaçant dans la première moitié de l'Allerød.

Ces données permettent d'esquisser les premières lignes d'une paléohistoire de ces groupes humains de l'Allerød. En l'état actuel, il ressort une évolution plutôt progressive des systèmes techniques, depuis le Magdalénien récent jusqu'à la fin de l'Azilien. Ce premier modèle évolutif, basé sur les informations techniques acquises à partir de l'étude d'un site en particulier, demande à être confronté à un corpus régional et suprarégional évidemment plus important. En attendant, il trouve un écho dans d'autres régions comme nous le verrons dans la conclusion (Célérier 1993, Lorblanchet 1996, Bodu 1998a, Fagnart et Coudret 2000a, 2000b, Chollet et Dujardin 2005, Coudret et Fagnart 2015, Mevel et Bodu 2018). On soulignera toutefois une cohérence régionale des comportements économiques tout au long de l'Allerød. Alors que l'essentiel des ressources lithiques utilisées par ces groupes sont évidemment locales, une part non négligeable de l'approvisionnement est constituée par des ressources allochtones. S'il existe une variation qualitative et quantitative d'une série à l'autre (Mevel 2017), ces matériaux allochtones proviennent presque exclusivement du sud du massif du Vercors (silex barrémobédoulien), voire de territoires plus éloignés (silex barrémobédoulien du Vaucluse ?). Cette orientation méridionale dans l'approvisionnement en silex des groupes de la phase récente de 

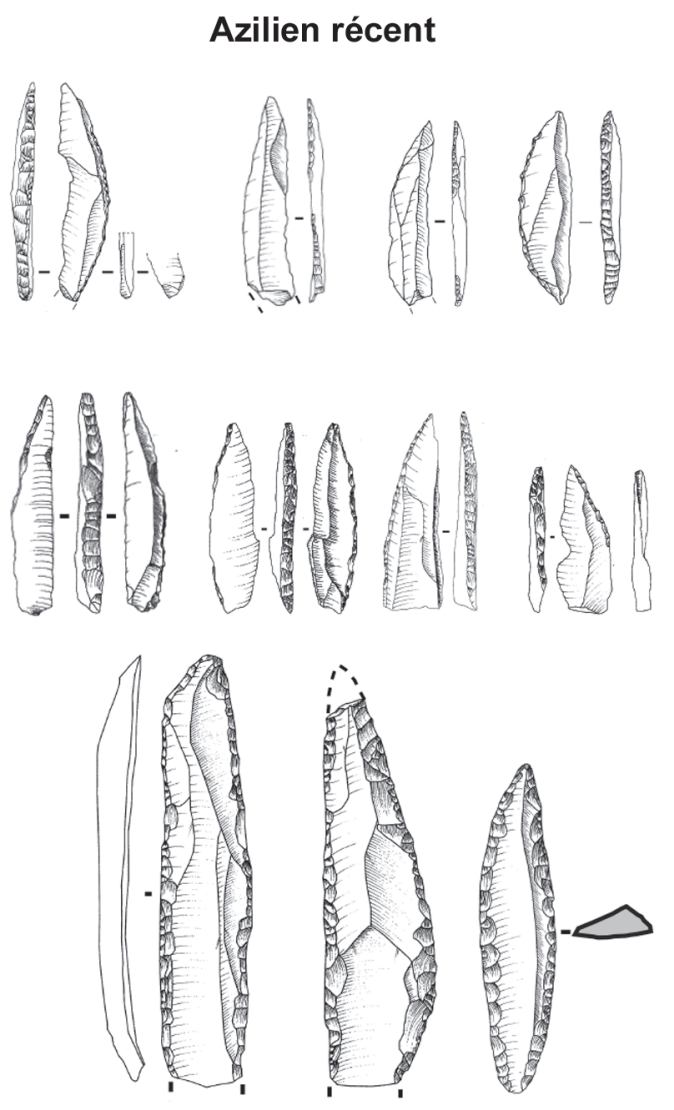

Abri de la Fru c. 3-1
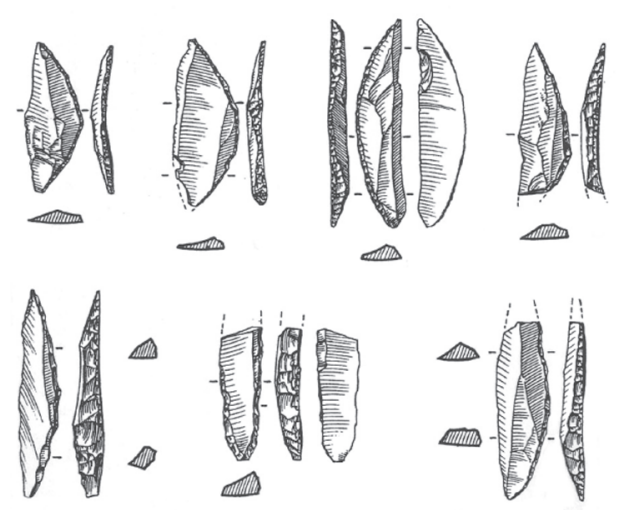

Abri Gay c. F2b
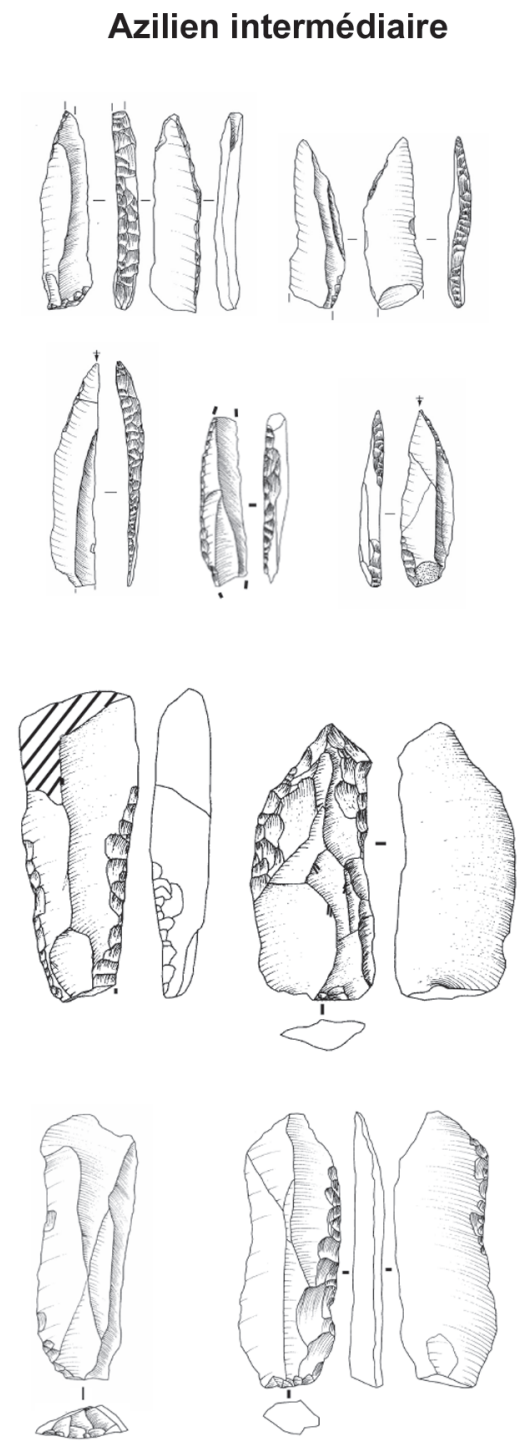

Abri de la Fru c. 5-3
Azilien récent
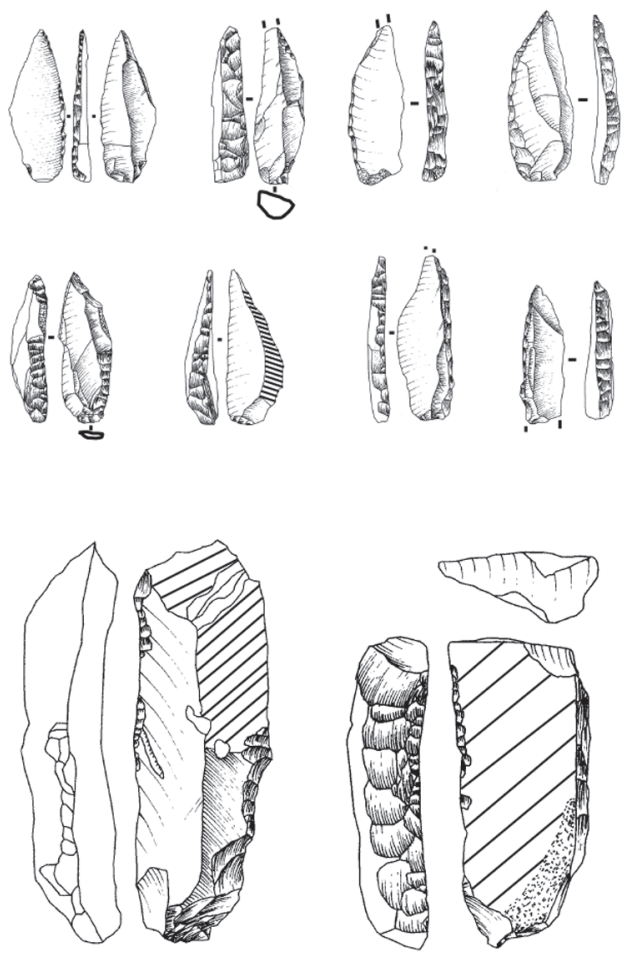

Abri de la Fru

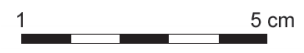

Fig. 10 - Équipement lithique des différentes phases de l'Azilien dans les Alpes du Nord (DAO L. Mevel).

Azilien ancien : bipointes, monopointes et lames à retouches écailleuses-scalariformes de la couche 3 de l'aire 1 de l'abri de la Fru (SaintChristophe-la-Grotte, Savoie); bipointes et monopointes de la couche F2b de l'abri Gay (Poncin, Ain).

Azilien intermédiaire : monopointes et lames retouchées de la couche 5 de l'aire 3 de l'abri de la Fru (Saint-Christophe-la-Grotte, Savoie).

Azilien récent : monopointes, lame retouchée et couteau à dos de la couche 2 de l'aire 1 de l'abri de la Fru (Saint-Christophe-la-Grotte, Savoie).

Lithic equipment for the different phases of the Azilian era in the Northern Alps (CAD L. Mevel).

Early Azilian: Bipoints, monopoints and blades with scalar-step retouch from layer 3 of area 1 of Abri de la Fru (Saint-Christophe-la-Grotte, Savoy). bipoints and monopoints from layer F2b of Abri Gay (Poncin, Ain).

Intermediate Azilian: Monopoints and retouched blades from layer 5 of area 3 of Abri de la Fru (Saint-Christophe-la-Grotte, Savoy).

Recent Azilian: Monopoints, retouched blade and backed knife from layer 2 of area of Abri de la Fru (Saint-Christophe-la-Grotte, Savoy). 
l'Azilien avait déjà été soulignée pour l'industrie du gisement azilien de Gerbaix « dessus » fouillé par G. Pion (Bressy 2009), et aussi dans le matériel lithique du site azilien de Varennes-lesMâcons en Saône-et-Loire (Floss 2000 ; fig. 1). Sur ce gisement, les groupes aziliens se sont procuré un silex originaire de l'Ardèche (silex bédoulien de Rochemaure : Floss 2000). La présence d'une Patella vulgata d'origine méditerranéenne sur le même site souligne ces relations privilégiées entre le Centre-Est de la France et ces territoires plus méridionaux.

Jusqu'ici, une nette bipartition entre les sociétés épigravetiennes du Sud-Est de l'Europe et les territoires occupés par les Magdaléniens était de rigueur. Avec le Dryas récent, de nouvelles influences culturelles semblent émerger.

\section{LE DRYAS RÉCENT : LA QUESTION DE L'IDENTITÉ CULTURELLE DES INDUSTRIES À PETITES POINTES À BORD ABATTU}

$\mathrm{Si}$, durant l'Allerød, les Alpes du Nord et le Jura ne sont concernés que par le phénomène azilien, cette relative homogénéité culturelle va être remise en question lors de la transition Pléistocène-Holocène. Cette période est effectivement marquée par l'apparition d'une nouvelle forme d'armature, les micropointes à dos (fig. 11). Ces industries affichent des concepts proches de ceux rencontrés dans le Sud-Est de la France et en Italie, en domaine épigravettien (fig. 11). Mais il existe aussi de rares témoignages d'affinités autres, plutôt laboriennes.

En l'état actuel de nos connaissances, dans le Jura et les Alpes du Nord, des petites pointes à bord abattu ont été identifiées dans sept séries : le niveau $\mathrm{R}$ de l'abri du Mannlefelsen I à Oberlarg dans le Haut-Rhin (FornageBontemps 2013 ; fig. 1), le niveau A4 de l'abri de Rochedane à Villars-sous-Dampjoux dans le Doubs (Thévenin 1982, Fornage-Bontemps 2013 ; fig. 1), les couches $1 \mathrm{~b}$ de l'aire I et $4 \mathrm{c}$ de l'aire III de la Fru à Saint-Christophe-la-Grotte en Savoie (Pion et Thévenin 2007), l'ensemble stratigraphique 6A et $5 \mathrm{C}$ de la grotte de Jean-Pierre I à Saint-Thibaud-de-Couz en Savoie), la couche 7i de la grotte du Seuil-des-Chèvres à La Balme en Savoie (fig. 1), la couche 7a de l'abri de la Vieille Église à La Balme-de-Thuy en Haute-Savoie (fig. 1), et enfin le niveau inférieur de $\mathrm{K} 5$ et l'unité stratigraphique 6 de F5 dans l'abri des Balmettes à Saint-Aupre en Isère (fig. 1). Ce corpus de sites reste modeste et il souffre de problèmes liés à certains contextes stratigraphiques peu fiables et à la disparité des surfaces fouillées (de plusieurs dizaines de $\mathrm{m}^{2}$ à des sondages de quelques-uns seulement).

À Rochedane et au Mannlefelsen I, la production s'organise autour d'une chaîne opératoire unique, aux objectifs de production multiples (Fornage-Bontemps 2013). L'obtention de lamelles de profil rectiligne destinées à être aménagées en armatures constitue le principal projet de débitage. Ce dernier est complété par une production de lames et d'éclats (futurs supports de grattoirs courts) totalement intégrée à la chaîne lamellaire. Le débitage lamellaire est effectué à la pierre tendre en version tangentielle sur des petits blocs ou, plus rarement, sur la tranche de gros éclats (Fornage-Bontemps 2013). Dans le cas des nucléus sur bloc, le plan de frappe est installé sur le pôle le plus volumineux et la table au niveau de la surface la plus étroite, dans l'axe de la plus grande longueur du volume. La plupart des blocs sélectionnés présentent des volumes naturellement favorables au débitage, demandant peu d'aménagements, voire aucun. Parfois, la dernière phase d'exploitation des volumes correspond à un débitage centripète d'éclats épais destinés à être aménagés en grattoirs unguiformes. La présence d'armatures identiques et aussi la similarité des techniques de débitage laisse entrevoir l'existence d'affinités étroites avec le domaine méridional. C'est vers l'Épigravettien - et plus particulièrement les industries de l'ensemble 3 défini par C. Montoya dans sa thèse (2004), pour lequel A. Tomasso (2014) a récemment proposé une distinction en deux phases que les analogies les plus convaincantes sont à rechercher pour ces ensembles à petites pointes à dos droit. C'est en particulier avec la seconde phase (ER 3b : Tomasso et al. 2014) que ces industries nord-alpines et jurassiennes présentent le plus d'affinités (Fornage-Bontemps 2013, Mevel et al. 2014a, 2014b, Tomasso 2014, p. 522).

Pour cette époque tardive, le panorama culturel s'est enrichi récemment avec la découverte d'un gisement attribué au Laborien dans les environs de Lyon (Jallet et Bouvier 2012, Pasty 2017, Langlais et al. à paraître). Cette découverte fait écho aux travaux de G. Monin sur les assemblages provenant des grottes Colomb et de la Passagère à Méaudre en Isère (fig. 1). Sur ces deux gisements, l'auteur avait mis en évidence l'existence d'une composante laborienne (Monin 2000), qu'une mesure radiométrique a permis d'attribuer à la fin du Dryas récent (vers 11640 cal. BP ; fig. 11). Les datations connues pour les ensembles à petites pointes à dos droit les situent plutôt dans des phases plus anciennes, au début du Dryas récent (Fornage-Bontemps 2013, Mevel et al. 2014a, 2014b). Est-ce l'indice d'une rupture, à partir de la fin de l'Azilien, avec les influences septentrionales? C'est en tous cas un témoignage supplémentaire du statut de carrefour de circulation, pour les hommes et les idées, qu'assumait l'axe Rhône/massifs alpins à la fin du Paléolithique (Mevel 2017).

\section{CONCLUSION}

Ce tour d'horizon du Paléolithique final français, articulé autour de quatre grandes régions témoignant de différentes dynamiques de recherche complémentaires, conduit à une image globalement homogène à l'échelle de la France. La généralisation des approches technologiques n'y est sans doute pas étrangère, mais elle souligne toutefois les relations fortes qui unissent les communautés humaines en France à la fin du Paléolithique. Entre la fin du Magdalénien et les premiers temps du Mésolithique, les groupes de chasseurs-collecteurs connaissent en effet trois grandes inflexions dont les rythmes restent flous et qui sont marquées par des transformations importantes de leurs systèmes techniques et, plus généralement, de leur organisation économique et peut-être sociale.

Le premier de ces moments est perceptible à la fin du GIle, période durant laquelle les normes qui structuraient le 


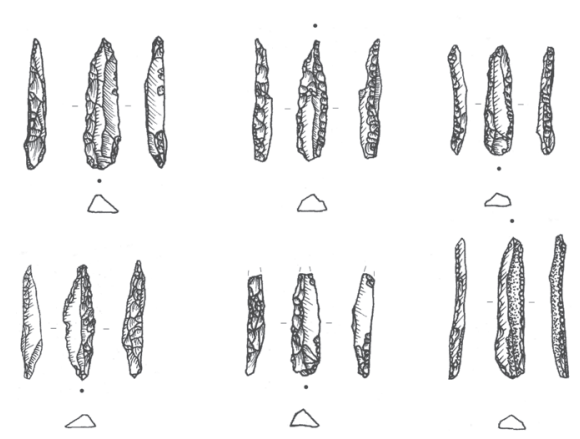

Rochedanne

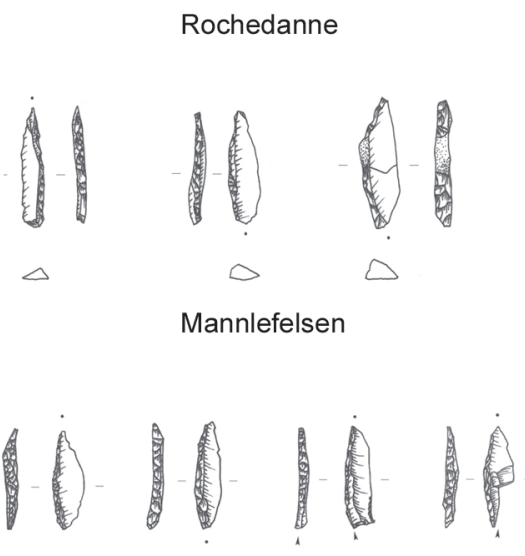

Abri de la Fru
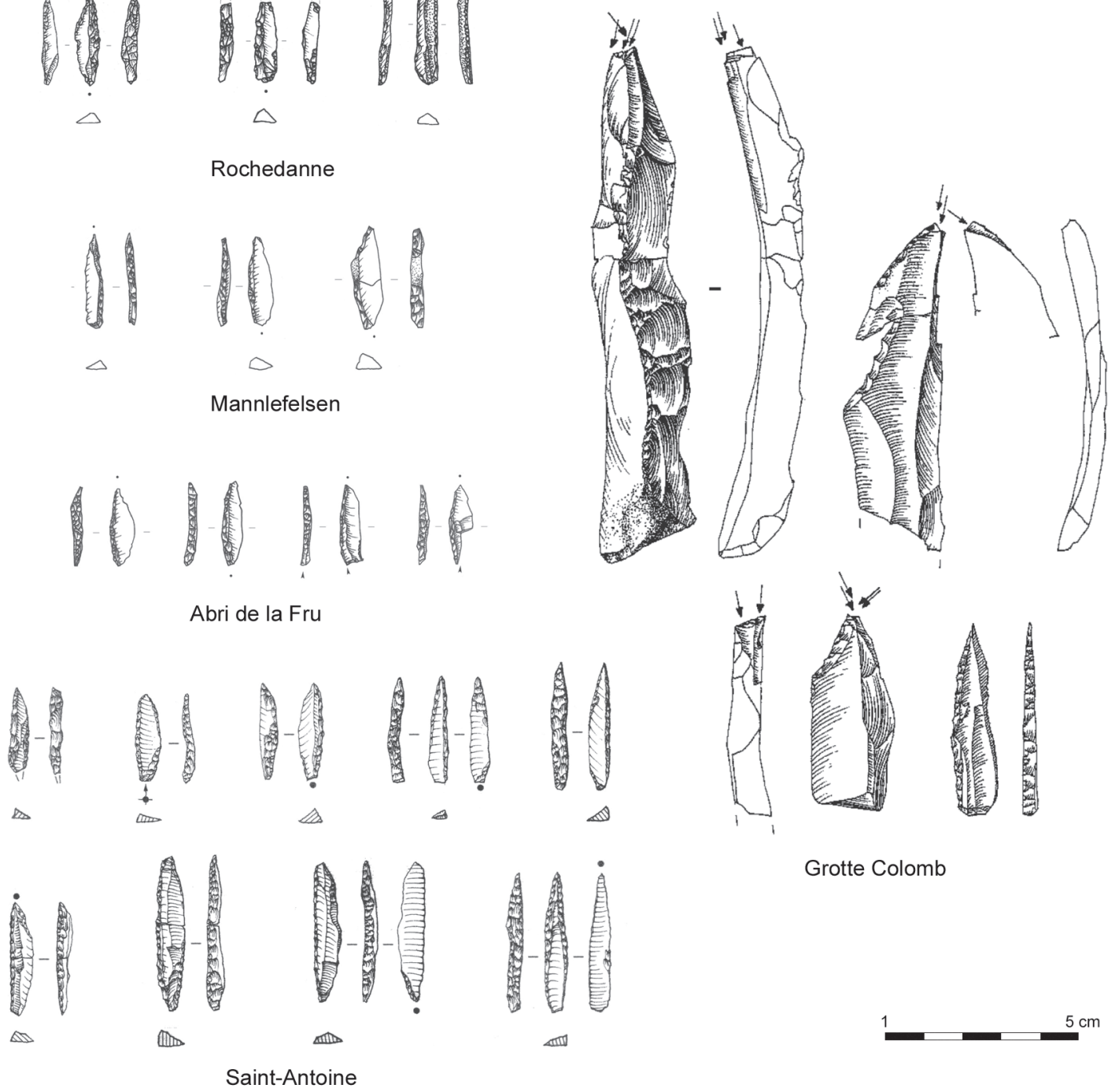

Grotte Colomb

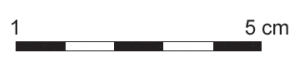

Fig. 11 - Variabilité de l'équipement des groupes du Dryas récent dans l'Est de la France (DAO L. Mevel). Petites pointes à dos droits des niveaux contemporains de l'abri de Rochedane (Villars-sous-Dampjoux, Doubs), de l'abri de Mannlefelsen (Oberlag, Haut-Rhin) et de l'abri de la Fru (Saint-Christophe-la-Grotte, Savoie) ; pointes à dos de l'Épigravettien récent de Saint-Antoine (Vitrolles, Hautes-Alpes) ; burins sur lames et pointe de Malaurie de la grotte Colomb (Méaudre, Isère).

Variability of equipment in recent Dryas groups in Eastern France (CAD L. Mevel). Small points with straight backs from contemporaneous Recent Dryas levels from Rochedane Villars-sous-Dampjoux, Doubs), Mannlefelsen (Oberlag, Upper Rhine), Abri de la Fru (Saint-Christophe-la-Grotte, Savoy) and backed points from the Recent Epigravettian of Saint-Antoine (Vitrolles, High Alps); Burins on blades and Malaurie point from Colomb Cave (Méaudre, Isère). 
Magdalénien s'effacent progressivement au profit de nouvelles solutions techniques au cours de l'Azilien ancien. Celui-ci semble maintenir quelques caractères chers aux Magdaléniens (débitage laminaire soigné, importance des burins, forte structuration de l'espace habité au Closeau), mais il s'en distingue par de nombreux choix : abandon des productions lamellaires, usage exclusif de pointes axiales au détriment des lamelles à dos ou encore recours systématique au percuteur de pierre. L'industrie osseuse semble également profondément remaniée avec une réduction drastique, ainsi qu'un net resserrement typologique. Les témoignages graphiques affichent quant à eux des conventions stylistiques clairement héritées du Magdalénien. Cette arythmie des changements culturels au cours de cette période questionne les causes de ces transformations. L'estimation du rythme global de cette transition pose encore problème puisque les datations de ces deux ensembles (Magdalénien récent et Azilien ancien) se chevauchent parfois. Est-ce la conséquence de l'important plateau dans la courbe de calibration du radiocarbone ou ce chevauchement témoigne-t-il plutôt de la cohabitation de groupes aux bagages techniques différents (Pelegrin 2000) ? Les données stratigraphiques plaident aujourd'hui plutôt en faveur de la première hypothèse, mais cette question, et plus généralement celle du tempo de ce passage entre Magdalénien et Azilien, constituent un axe de recherche à alimenter.

Les changements techniques initiés lors de la phase ancienne de l'Azilien s'expriment de façon de plus en plus affirmée dès le début du GIld-c-b-a, même s'il est difficile, là encore, de caler précisément le moment et le rythme de cette bascule. Les productions lithiques connues pour cette phase récente de l'Azilien sont souvent obtenues à partir de matériaux collectés au sein de litho-espaces nettement réduits et s'accommodent d'objectifs de production moins réguliers et moins normés que précédemment. Les lames (plutôt souvent des éclats allongés) sont obtenues selon des modalités opératoires simples (mise en forme réduite voire inexistante des volumes, percussion à la pierre en retrait des bords de plan de frappe avec inconstance des préparations au détachement et même usage de la percussion bipolaire sur enclume dans certaines régions). Alors que dans l'Azilien ancien, tout comme dans le Magdalénien, on perçoit des modalités d'entretien, de réutilisation et de recyclage importantes des outillages (avec notamment l'affûtage des tranchants laminaires par retouche rasante scalariforme dans l'Azilien ancien), les groupes de l'Azilien récent font le choix d'une production moins investie techniquement, à faible coût et à d'usage plus éphémère. Ces choix sont bien entendu le reflet de changements plus globaux touchant ces sociétés aussi bien dans leur organisation économique que dans leurs régimes de mobilité. L'équipement en matières osseuses, bien que montrant des différences typologiques avec la phase ancienne, ne connaît pas de bouleversements aussi importants à ce stade, la rupture avec le Magdalénien étant consommée plus tôt. Au contraire, l'art est marqué durant cette phase récente par un changement majeur avec la disparition des expressions figuratives au profit de tracés géométriques gravés ou peints sur des galets. $\mathrm{Ce}$ changement intervient certainement bien plus tard que ce que l'on a longtemps cru. Il reste toutefois à mieux définir le moment de cette mutation symbolique et sa portée. Il est en effet séduisant de voir dans le faible savoir-faire demandé pour ces réalisations le possible témoignage d'une ouverture des activités graphiques à une plus grande partie du groupe. Cette idée de plus faible degré de spécialisation trouve d'ailleurs des échos intéressants du côté des industries lithiques et osseuses. Peut-être faut-il ainsi voir dans ces comportements le signe de bouleversements sociétaux majeurs?

Alors que l'on sait aujourd'hui que l'Azilien récent perdure, au moins dans les Pyrénées (Fat Cheung 2015, Tomasso et al. 2018), durant la première moitié de la péjoration climatique du GS1, la seconde moitié de cette période et la première partie du Préboréal, sont marqués par le dernier grand moment du Paléolithique français. Contrairement à une idée courante, dans la majeure partie de la France, ce qu'on considère comme la fin du Paléolithique ne coïncide pas avec les débuts de l'Holocène. Il faudra en effet attendre la seconde moitié du Préboréal pour voir pleinement se développer le Mésolithique. Jusqu'à la fin de la première moitié du Préboréal, on trouve dans le Nord de la France des industries déjà riches en microlithes géométriques mais dont la production laminaire présente encore des similitudes avec celles des derniers Paléolithiques (Ducrocq et al. 2008, Ducrocq à paraître). De ce point de vue, seul l'extrême sud-est du territoire affiche une réelle précocité, la phase terminale de l'Épigravettien datée du GS1 regroupant la plupart des caractéristiques du premier Mésolithique (Tomasso et al. 2014). Partout ailleurs, les industries lithiques de ces dernières communautés paléolithiques du tout début de l'Holocène, plutôt que de laisser entrevoir les prémices de la mésolithisation en matière de débitage, montrent au contraire une réorganisation des systèmes techniques vers la recherche systématique de lames et de lamelles régulières et normées. En plus de la régularité des supports, c'est également l'obtention de tranchants aigus qui semble avoir été recherchée et ces deux intentions structurent les schémas opératoires. Dans le Bassin parisien, dans le faciès dit «belloisien », certains assemblages témoignent en plus d'une recherche de lames spécifiquement longues. Ces débitages, également connus au sud de l'Angleterre (Barton et al. 2003) dans des secteurs très riches en silex de bonne qualité, semble avoir été motivés par des activités assez spécifiques, de boucherie par exemple. On assiste également durant cette période à une importante transformation de l'organisation paléo-économique avec une segmentation spatio-temporelle des activités, parfois assez spécialisées, par contraste avec l'Azilien récent aux sites souvent décrits comme polyfonctionnels. Le regain d'intérêt pour les lames a pour effet de bouleverser à nouveau à la fois les stratégies d'acquisition des matériaux lithiques avec une extension importante des litho-espaces, et également pour conséquence de restructurer en profondeur les schémas opératoires de production avec la mise en place de débitage investis rythmés par des phases de mise en forme et d'entretien soignées. Ce phénomène semble partagé dans une large zone depuis les Pyrénées (et peut être même la côte atlantique ibérique) 
jusqu'au sud de la Scandinavie. L'industrie osseuse semble échapper à ce regain d'investissement technique puisque les données actuellement disponibles montrent, comme pour les phases aziliennes précédentes, un outillage peu abondant et monotone, même si des changements typologiques existent. Les témoignages graphiques de ces dernières sociétés paléolithiques sont encore assez méconnus car ils sont uniquement présents, en France, dans le Laborien ancien de la façade atlantique. Ce faible corpus est toutefois particulièrement intéressant puisque, contrairement à l'Azilien où un décalage existe entre changement technique et artistique, on assiste dans le Laborien, en parallèle des nouvelles exigences dans la production laminaire, à l'émergence d'un style figuratif tout à fait unique dans la Préhistoire (même si quelques galets gravés aux motifs géométriques emblématiques de l'Azilien récent semblent perdurer). Là encore, il convient désormais de mieux appréhender la chronologie fine de ces évolutions. Derrière cette forte unité à grande échelle on note également, si l'on en croit la typologie des pointes de projectiles, une certaine mosaïque culturelle (Laborien ancien/récent, Ahrensbourgien/Épiahrensbourgien). Dans le Sud-Est de la France, la situation semble encore plus complexe à l'interface entre les courants qui précèdent et le domaine épigravettien (dans lequel les industries semblent poursuivre un processus de simplification technique initié dès le Dryas ancien : Tomasso et al. 2014, Naudinot et al. 2017b). Sur la côte méditerranéenne, de rares incursions laboriennes sont aujourd'hui attestées dans le Var tandis que les industries sont très majoritairement attribuables à l'Épigravettien récent puis terminal. Ces ensembles, parfois encore regroupés au sein d'entités culturelles locales spécifiques (Escalon de Fonton et Onoratini 1977, Escalon de Fonton et al. 1978), témoignent de la complexité des interactions humaines durant cette période. Dans les Alpes du Nord et le Jura, à côté de quelques témoignages pouvant indiscutablement être rapportés au Laborien, apparaissent des industries originales pour lesquelles des liens avec l'Épigravettien ont été proposés.

Les quelques millénaires qui jalonnent la seconde moitié du Tardiglaciaire français sont donc scandés par plusieurs grandes phases dont les bornes tout comme le rythme interne restent à préciser. Un des enjeux des années à venir sera également de développer une réflexion sur les mécanismes à l'origine de cette évolution et aussi sur les décalages régionaux. Si les paramètres climatiques sont régulièrement mobilisés, force est de constater que les données, à la fois archéologiques et environnementales, sont encore trop ténues pour assurer de parfaites corrélations. Les scénarios proposés reposent en effet le plus souvent sur les données climatiques issues des courbes isotopiques glaciaires qui permettent de se faire une idée globale de l'évolution du climat dans l'hémisphère nord. Mais elles doivent nécessairement être complétées par des données environnementales régionales à haute résolution si l'on veut percevoir les réactions des environnements à ces stimuli climatiques globaux, et aussi les décalages potentiels entre ces impulsions et la transformation des milieux animal et végétal. Les données radiochronologiques restent encore trop peu nombreuses (en particulier pour l'Azilien récent) et la présence d'au moins deux plateaux dans les courbes de calibration a pour effet d'écraser la chronologie. Malgré tout, les recherches menées ces dernières années sur le Tardiglaciaire français révèlent d'intéressants décalages entre la chronologie environnementale et les transformations culturelles, montrant par exemple que les premiers signes de l'Azilien émergent dès le GIle ou que l'Azilien récent perdure dans certaines régions longtemps après les débuts de la péjoration du Dryas récent. De même, des approches croisées menées parallèlement en domaine Azilien et Épigravettien montrent un même phénomène de simplification techno-économique dans des environnements pourtant très différents (Naudinot et al. 2017b). Ces résultats invitent à la prudence quand il s'agit de généraliser les modèles régionaux. C'est le cas notamment à propos de la disparition du renne, et de ses conséquences dans les stratégies cynégétiques au cœur de certains scénarios explicatifs sur l'azilianisation (Naudinot et al. 2017b). Il ne fait aucun doute que l'importante instabilité climatique et ses répercussions sur les ressources et les paysages ont eu des conséquences sur les sociétés, leurs systèmes techniques, et plus généralement sur leur organisation socio-économique. Les recherches doivent désormais être affinées afin d'éviter les modèles mécanistes. Les études paléogénétiques de ces dernières années nous incitent également à intégrer tout autre paramètre permettant d'expliquer les bouleversements qui rythment le Tardiglaciaire. Ainsi, les alentours de 14000 cal. BP correspondraient à l'arrivée de nouvelles populations venues peut-être du Proche-Orient (Fu et al. 2016) ; il conviendra de confronter cette nouvelle hypothèse aux données archéologiques qui, pour le moment, montrent plutôt une transformation graduelle des techniques et des symboles.

Notre connaissance de ces sociétés du Paléolithique final a donc fait de grands progrès ces trente dernières années avec le développement des études environnementales, des perspectives palethnographiques et technologiques, et grâce aux nombreux apports de l'archéologie préventive. L'image d'un " Épipaléolithique » seulement transitoire est désormais loin derrière nous. Ces derniers temps du Pléistocène, du fait de ses nombreuses inflexions culturelles avec des techno-complexes et traditions aux schémas évolutifs complexes, sont en réalité particulièrement riches en problématiques de recherche propres. De ce fait, les derniers temps du Paléolithique constituent un exceptionnel laboratoire de recherche et, vu la qualité de certains sites, une véritable « oasis documentaire » pour reprendre les termes de F. Bon (2009). 


\section{BIBLIOGRAPHIE}

Antoine P. 1990 - Chronostratigraphie et environnement $d u$ Paléolithique du bassin de la Somme, Villeneuve d'Ascq, Université des sciences et techniques de Lille Flandres-Artois (Publications du Centre d'études et de recherches préhistoriques 2), $231 \mathrm{p}$.

Antoine P. 1997a - Modifications des systèmes fluviatiles à la transition Pléniglaciaire-Tardiglaciaire et à l'Holocène : l'exemple du bassin de la Somme (Nord de la France), Géographie physique et Quaternaire, 51 (1), p. 93-106.

Antoine P. 1997b - Évolution Tardiglaciaire et début Holocène des vallées de la France septentrionale : nouveaux résultats, Compte rendu de l'Académie des sciences, série IIA, Sciences de la terre et des planètes, 325 (1), p. 35-42.

Antoine P. 1997c - Évolution Tardiglaciaire et début holocène de la moyenne vallée de la Somme (France), in Fagnart J.-P., Thévenin A. (dir.), Le Tardiglaciaire en Europe du Nord-Ouest. Actes $d u 19^{e}$ congrès national des sociétés historiques et scientifiques, Amiens, 26-30 octobre 1994, Paris, Éditions du CTHS, p. 13-26.

Antoine P., Auguste P., Bahain J.-J., Coudret P., Depaepe P., Fagnart J.-P., Falguères C., Fontugne M., Frechen M., Hatté C., Lamotte A., Laurent M., Limondin-Lozouet N., Locht J.-L., Mercier N., Moigne A.-M., Munaut A.-V., Ponel P., Rousseau D.-D. 2003 - Paléoenvironnements pléistocènes et peuplements paléolithiques dans le bassin de la Somme (nord de la France), Bulletin de la Société préhistorique française, 100 (1), p. 5-28.

Antoine P., Bahain J.-J., Auguste P., Fagnart J.-P., LimondinLozouet N., Locht J.-L. 2011 - Quaternaire et Préhistoire de la vallée de la Somme : 150 ans d'histoire commune, in Hurel A., Coye N. (dir.), Dans l'épaisseur du temps. Archéologues et géologues inventent la préhistoire, Paris, Publications scientifiques du Muséum national d'histoire naturelle (Archives), p. $341-381$.

Antoine P., Fagnart J.-P., Auguste P., Coudret P., LimondinLozouet N., Ponel P., Munaut A.-V., Defgnée A., Gauthier A., Fritz C. (dir.) 2012 - Conty, vallée de la Selle (Somme, France) : séquence tardiglaciaire de référence et occupations préhistoriques, Paris, Quaternaire (hors-série 5), 170 p.

Antoine P., Fagnart J.-P., Limondin-Lozouet N., Munaut A.-V. 2000 - Le Tardiglaciaire du bassin de la Somme : éléments de synthèse et nouvelles données, Quaternaire, 11 (2), p. 85-98.

Antoine P., Locht J.-L., Limondin-Lozouet N., Auguste P., Bahain J.-J., Goval É., Fagnart J.-P., Debenham N., Ducrocq T. 2014 - Quaternaire et géoarchéologie de la Préhistoire. Le modèle de la vallée de la Somme et des régions avoisinantes, in Carcaud N., Arnaud-Fassetta G. (dir.), La géoarchéologie française au XXI siècle, Paris, CNRS Éditions, p. 71-87.

Argant J., Bégéot C., Marrocchi Y. 2009 - L’environnement végétal au Tardiglaciaire à partir de l'étude de trois lacs : La Thuile, Saint-Jean-de-Chevelu et Moras, in Pion G., Mevel L. (dir.), La fin du Paléolithique supérieur dans les Alpes du nord et le Jura méridional. Approches culturelles et environnementales, Paris, Société préhistorique française (Mémoire 50), p. 23-40.

Audouze F. 2006 - Essai de modélisation du cycle annuel de nomadisation des magdaléniens du Bassin parisien, Bulletin de la Société préhistorique française, 103 (4), p. 683-694.

Audouze F., Karlin C., Cahen D., Croisset E. de, Coudret P., Larrière M., Masson P., Mauger M., Olive M., Pelegrin J., Pigeot N., Plisson H., Schmider B., Taborin Y. 1988 - Taille du silex et finalité du débitage dans le Magdalénien du Bassin parisien, in Otte M. (dir.), De la Loire à l'Oder. Les civilisations du Paléolithique final dans le Nord-Ouest européen. Actes du colloque international de Liège, décembre 1985, Oxford, British Archaeological Reports (BAR Int. Ser. 444, ERAUL 25), vol. 1, p. 55-84.

Auguste P. 2012 - La grande faune de Conty : taxonomie, écologie et palethnographie, in Antoine P., Fagnart J.-P., Auguste P., Coudret P., Limondin-Lozouet N., Ponel P., Munaut A.-V., Defgnée A., Gauthier A., Fritz C. (dir.), Conty, vallée de la Selle (Somme, France) : séquence tardiglaciaire de référence et occupations préhistoriques, Paris, Quaternaire (hors-série 5), p. 95-124.

Baffier D. 1996 - Le cheval gravé, in Gaucher G. (dir.), Fouilles de Pincevent II. Le site et ses occupations récentes. L'environnement tardi et post-galciaire et les témoins postérieurs au Magdalénien, Paris, Société préhistorique française (Mémoires 23), p. 82-85.

Barbaza M. 1996 - Le Magdalénien terminal des Pyrénées françaises, in L'art préhistorique des Pyrénées, catalogue d'exposition (Musée des Antiquités nationales, 3 avril-8 juillet 1996), Paris, Éditions de la RMN, p. 124-131.

Barbaza M. 2009 - L’Azilien classique pyrénéen, L'Azilien de la grotte de Troubat dans ses divers contextes, in De Méditerranée et d'ailleurs... Mélanges offerts à Jean Guilaine, Toulouse, Archives d'écologie préhistorique, p. 31-48.

Barbaza M. 2011 - Environmental changes and cultural dynamics along the northern slope of the Pyrenees during the Younger Dryas, Quaternary International, 242 (2), p. 313-327.

Barshay-Szmidt C., Costamagno S., Henry-Gambier D., Laroulandie V., Pétillon J.-M., Boudadi-Maligne M., Kuntz D., Langlais M., Mallye J.-B. 2016 - New extensive focused AMS ${ }^{14} \mathrm{C}$ dating of the Middle and Upper Magdalenian of the Western Aquitaine/Pyrenean region of France (ca. 19-14 ka cal BP): Proposing a new model for its chronological phases and for the timing of occupation, Quaternary International, 414, p. 62-91.

Barton R. N. E. 1986a - A study of selected British and European flint assemblages of Late Devensian and Early Flandrian Age, thèse de doctorat, Université d'Oxford, inédit, 443 p.

Barton R. N. E. 1986b - Experiments with long blades from Sproughton, near Ispwish, Suffolk, in Roe D. A. (dir.), Studies in the Upper Palaeolithic of Britain and Northwest Europe, Oxford, British Archaeological Reports (BAR Int. Ser. 296), p. 129-141. 
Barton R. N. E. 1989 - The long blade technology in Southern Britain, in Bonsall C. (dir.), The Mesolithic in Europe. Proceedings of the $3^{\text {rd }}$ international symposium, Edinburgh, 31 3 March$6^{\text {th }}$ April 1985, Edinburgh, J. Donald Publishers, p. 264-271.

Barton R. N. E. 1991 - Technological innovation and continuity at the end of the Pleistocene in Britain, in Barton R.N.E., Roberts A.J., Roe D.A. (dir.), The Late Glacial in NorthWest Europe: Human adaptation and environmental change at the end of the Pleistocene, Oxford, Council for British Archaeology (Research report 77), p. 234-245.

Barton R. N. E., Jacobi R. M., Stapert D., Street M. J. 2003 - The Late-glacial reoccupation of the British Isles and the Creswellian, Journal of Quaternary Science, 18 (7), p. 631-643.

Bégeot C., Pion G., Marrocchi Y., Argant J., Birringer P., Bocherens H., Bridault A., Chaix L., Thiébault S. 2006 Environnement végétal et climatique des sociétés magdaléniennes et épipaléolithiques dans les Alpes du Nord françaises et le Jura méridional, in Miras Y., Surmely F. (dir.), Environnement et peuplement de la moyenne montagne du Tardiglaciaire à nos jours. Actes de la table ronde de Pierrefort, 19-20 juin 2003, Besançon, Presses universitaires de Franche-Comté (Annales littéraires 799, Environnement, sociétés et archéologie 9), p. 19-27.

Bémilli C., Biard M., Chaussé C., Donnart K. 2014 - Une partie de chasse à l'Aurochs il y a 10000 ans. Le Locus 28704 d'Alizay (Eure, France), in Costamagno S. (dir.), Histoire de l'alimentation humaine : entre choix et contraintes. Actes du $138^{\circ}$ congrès national des sociétés historiques et scientifiques, Rennes, 22-26 avril 2013, Paris, Éditions du CTHS, p. 170-187.

Béreiziat G. 2011 - Variabilité des comportements techniques du Dryas ancien à la fin du Bølling. Analyse techno-économique comparée du matériel lithique de cinq gisements tardiglaciaires du Jura méridional, thèse de doctorat, Université Bordeaux 1, inédit, $782 \mathrm{p}$.

Béreiziat G. 2013 - Quoi de neuf à l'Est ? - Une séquence tardiglaciaire du Jura méridional revisitée : l'abri Gay à Poncin (Ain), L'Anthropologie, 117 (1), p. 94-119.

Biard M. (dir.) 2010 - Acquigny (Eure) les Diguets-la Noé : les tailleurs de lames de l'extrême fin du Paléolithique supérieur : deux derniers locus, document final de synthèse, INRAP GrandOuest, inédit, $110 \mathrm{p}$.

Biard M., Hinguant S. (dir.) 2011 - Le bivouac préhistorique du Buhot à Calleville (Eure). Caractérisation d'un assemblage lithique lamino-lamellaire de la fin du Paléolithique supérieur, Paris, CNRS Éditions et INRAP (Recherches archéologiques 2), 158 p.

Biard M., Hinguant S. 2013 - Des grandes lames aux microlithes : unité technologique d'un assemblage lithique du Paléolithique supérieur final à Calleville (Eure), in Jaubert J., Fourment N., Depaepe P. (dir.), Transitions, ruptures et continuité en Préhistoire. Actes du $27^{e}$ congrès préhistorique de France, Bordeaux-Les Eyzies, 31 mai-5 juin 2010, Paris, Société préhistorique française, vol. 1, p. 605-621.

Biard M., Valentin B. à paraître - Belloisian know-how: Clarification on the aims and methods of flint knapping in around 9,600 BC in the Paris basin, in Montoya C., Fagnart J.-P.,
Locht J.-L. (dir.), Préhistoire de l'Europe du Nord-Ouest : mobilités, climats et identités. Actes du $28^{e}$ congrès préhistorique de France, Amiens, 30 mai-4 juin 2016, Paris, Société préhistorique française.

Bignon 0. 2008 - Chasser les chevaux à la fin du Paléolithique dans le Bassin parisien. Stratégies de subsistance et des modes de vie au Magdalénien et à l'Azilien ancien, Oxford, Archaeopress (BAR Int. Ser. 1747), 170 p.

Bintz P. (dir.) 1994 - Les grottes de Jean-Pierre 1 et 2 à SaintThibaud-de-Couz (Savoie). Paléoenvironnement et cultures du Tardiglaciaire à l'Holocène dans les Alpes du Nord, Gallia Préhistoire, 36, p. 145-266.

Bintz P., Évin J. 2002 - Événements bio-climatiques et peuplements $\mathrm{du}$ Tardiglaciaire au début de l'Holocène dans les Alpes du Nord françaises, Quaternaire, 13 (3-4), p. 279-287.

Bodu P. 1993 - Analyse typo-technologique du matériel lithique de quelques unités du site magdalénien de Pincevent (Seine-etMarne). Applications spatiales, économiques et sociales, thèse de doctorat, Université Paris 1 Panthéon-Sorbonne, inédit, 3 vol., 852 p.

Bodu P. 1995 - Le site à Federmesser du "Closeau " à RueilMalmaison (Hauts-de-Seine), Notae Prehistoricae, 15, p. 45-49.

Bodu P. (dir.) 1998a - Le Closeau. Deux années de fouille sur un gisement azilien et belloisien en bord de Seine. Rueil-Malmaison (Hauts-de-Seine), document final de synthèse de sauvetage urgent, AFAN, inédit, 3 tomes, $470 \mathrm{p}$.

Bodu P. 1998b - Magdalenians-Early Azilians in the Centre of the Paris Basin: A filiation? The example of Le Closeau (Rueil-Malmaison, France), in Miliken S. (dir.), The organization of lithic technology in Late Glacial and Early Postglacial Europe, Oxford, British Archaeological Reports (BAR Int. Ser. 700), p. 131-147.

Bodu P. 2000a - Les faciès tardiglaciaires à grandes lames rectilignes et les ensembles à pointes de Malaurie dans le sud du Bassin parisien : quelques réflexions à partir de l'exemple du Closeau (Hauts-de-Seine), in Crotti P (dir.), Épipaléolithique et Mésolithique. Actes de la table ronde de Lausanne, 21-23 novembre 1997, Lausanne, Musée cantonal d'archéologie et d'histoire (Cahiers d'archéologie romande 81), p. 9-28.

Bodu P. 2000b - Que sont devenus les Magdaléniens du Bassin parisien? Quelques éléments de réponse sur le gisement azilien du Closeau (Rueil-Malmaison, France), in Valentin B., Bodu P., Christensen M. (dir.), L'Europe centrale et septentrionale au Tardiglaciaire. Confrontation des modèles régionaux de peuplement. Actes de la table ronde internationale de Nemours, 14-16 mai 1997, Nemours, APRAIF (Mémoires du musée de Préhistoire d'Île-de-France 7), p. 315-339.

Bodu P., Debout G., Bignon O. 2006 - Variabilité des habitudes tardiglaciaires dans le Bassin parisien : l'organisation spatiale et sociale de l'Azilien ancien du Closeau, Bulletin de la Société préhistorique française, 103 (4), p. 711-728.

Bodu P., Hantaï A., Valentin B. 1997 - La Long Blade Technology au sud du Bassin parisien : découvertes récentes, in Fagnart J.-P., Thévenin A. (dir.), Le Tardiglaciaire en Europe du Nord-Ouest. 
Actes du $119^{e}$ congrès national des sociétés historiques et scientifiques, Amiens, 26-30 octobre 1994, Paris, Éditions du CTHS, p. 211-222.

Bodu P., Mevel L. 2008 - Enquête autour des lames tranchantes de l'Azilien ancien. Le cas du niveau inférieur du Closeau (RueilMalmaison, Hauts-de-Seine, France), L'Anthropologie, 112 (4-5), p. $509-543$.

Bodu P., Orliac M., Baffier D. 1996 - L'Épimagdalénien, in Gaucher G. (dir.), Fouilles de Pincevent II. Le site et ses occupations récentes. L'environnement tardi et post-galciaire et les témoins postérieurs au Magdalénien, Paris, Société préhistorique française (Mémoires 23), p. 69-94.

Bodu P., Valentin B. 1992 - L'industrie à pièces mâchurées de Donnemarie-Dontilly (Seine-et-Marne, France) : un faciès tardiglaciaire inédit dans le Bassin parisien, Préhistoire européenne, 1, p. 15-34.

Bodu P., Valentin B. 1997 - Groupes à Federmesser ou aziliens dans le Sud et l'Ouest du Bassin parisien. Propositions pour un nouveau modèle d'évolution, Bulletin de la Société préhistorique française, 94 (3), p. 341-347.

Bon F. 2009 - Préhistoire. La Fabrique de l'Homme, Paris, Éditions du Seuil (L'univers historique), 349 p.

Bordes F., Sonneville-Bordes D. de 1979 - L'azilianisation dans la vallée de la Dordogne. Les données de la Gare de Couze (Dordogne) et de l'abri du Morin (Gironde), in Sonneville-Bordes D. de (dir.), La fin des temps glaciaires en Europe : chronostratigraphie et écologie des cultures du Paléolithique final. Actes du colloque international de Talence, 24-28 mai 1977, Paris, Éditions du CNRS (Colloques internationaux du CNRS 271), p. 449-459.

Bourdier C., Man-Estier E, Paillet P. 2017 - Étude de l'art mobilier de Murat, in Langlais M., Costamagno S. (dir.), L'abri Murat (Rocamadour, Lot). Réévaluation d'une séquence-clé du Tardiglaciaire (fouilles M. Lorblanchet), opération de préparation à la publication (programme 7), inédit, p. 77-104.

Bressy C. 2009 - Approvisionnements en silex à l'Azilien récent : le site de Gerbaix (Saint-Christophe, Savoie), in Pion G., Mevel L. (dir.), La fin du Paléolithique supérieur dans les Alpes du nord, le Jura méridional et les régions limitrophes. Approches culturelles et environnementales, Paris, Société préhistorique française (Mémoire 50), p. 183-195.

Bridault A. 1993 - Les économies de chasse épipaléolithiques et mésolithiques du Nord et de l'Est de la France, thèse de doctorat, Université de Paris 10-Nanterre, inédit, 723 p., 3 vol.

Bridault A. 1997 - Chasseurs, ressources animales et milieux dans le Nord de la France de la fin du Paléolithique à la fin du Mésolithique : problématique et état de la recherche, in Fagnart J.-P., Thévenin A. (dir.), Le Tardiglaciaire en Europe $d u$ Nord-Ouest. Actes du $119^{\mathrm{e}}$ congrès national des sociétés historiques et scientifiques, Amiens, 26-30 octobre 1994, Paris, Éditions du CTHS, p. 165-176.

Brochier J.-É., Livache M. 1997 - La grotte du Taï et l'abri de Campalou à Saint-Nazaire-en-Royans. Éléments typologiques préliminaires, in Pion G. (dir.), La fin du Paléolithique supérieur dans les Alpes françaises du Nord et le Jura méridional, rapport de synthèse de PCR, inédit, [n.p.].
Bündgen B. 2002 - Évolution des comportements techniques au Magdalénien supérieur : les données de l'industrie lithique de la Madeleine (Dordogne), séries récentes, thèse de doctorat, Université Bordeaux 1, inédit, 246 p.

Cartonnet M., Naton H.-G. 2000 - Le Magdalénien de la grotte de la Chênelaz à Hostias (Ain), in Pion G. (dir.), Le Paléolithique supérieur récent. Nouvelles données sur le peuplement et l'environnement. Actes de la table ronde de Chambéry, 12-13 mars 1999, Paris, Société préhistorique française (Mémoire 28), p. $235-244$.

Cazals N. 2000 - Constantes et variations des traits techniques et économiques entre le Magdalénien inférieur et moyen : analyse des productions lithiques du Nord de la péninsule ibérique, thèse de doctorat, Université Paris 1 Panthéon-Sorbonne, inédit, 587 p.

Célérier G. 1993 - L'abri sous roche de Pont d'Ambon à Bourdeilles (Dordogne). I : Technologie de l'outillage lithique taillé; II : Inventaire et typométrie des pointes aziliennes, Gallia Préhistoire, 35, p. 1-98.

Célérier G. 1998 - L'abri sous roche du Pont d'Ambon à Bourdeilles (Dordogne, France), Perspectives synthétiques, Paléo, 10, p. 233-264.

Célérier G., Chollet A., Hantaï A. 1997 - Nouvelles observations sur l'évolution de l'Azilien dans les gisements du Bois-Ragot (Vienne) et de Pont-d'Ambon (Dordogne), Bulletin de la Société préhistorique française, 94 (3), p. 331-336.

Chaussé C. 2005 - Les horizons pédologiques tardiglaciaires du Closeau à Rueil-Malmaison (92). Premiers éléments de diagnose, in Valentin B., Bodu P, Julien M. (dir.), Habitats et peuplements tardiglaciaires dans le Bassin parisien, rapport de projet collectif de recherche, bilan des activités de 2003 à 2005, CNRS UMR 7041 et SRA Île-de-France, inédit, p. 87-93.

Chevallier A. 2015 - Chasse et traitement des mammifères durant le Magdalénien et l'Azilien dans le Sud-Ouest de la France. La place particulière du cerf, thèse de doctorat, Université Paris 1 Panthéon-Sorbonne, inédit, 745 p.

Chevallier A., Bridault A., Fagnart J.-P. 2014 - Précisions sur les fonctions d'une occupation entre Paléolithique final et Mésolithique: réexamen de la faune de Belloy-sur-Somme (Somme), in Jaubert J., Fourment N., Depaepe P. (dir.), Transitions, ruptures et continuité en Préhistoire. Actes du $27^{\circ}$ congrès préhistorique de France, Bordeaux-Les Eyzies, 31 mai-5 juin 2010, Paris, Société préhistorique française, vol. 2, p. 519-526.

Chollet A., Dujardin V. (dir.) 2005 - La grotte du Bois-Ragot à Gouex (Vienne) Magdalénien et Azilien. Essai sur les hommes et leur environnement, Paris, Société préhistorique française (Mémoire 38), 428 p.

Cochard D. 2004 - Les léporidés dans la subsistance des Paléolithiques du Sud de la France, thèse de doctorat, Université Bordeaux 1, inédit, $346 \mathrm{p}$.

Costamagno S., Barshay-Szmidt C., Kuntz D., Laroulandie V., Pétillon J.-M., Boudadi-Maligne M., Langlais M., Mallye J.-B., Chevallier A. 2016 - Reexamining the timing of reindeer disappearance in Southwestern France in the larger context of Late Glacial faunal turnover, Quaternary International, 414, p. 34-61. 
Coudret P., Fagnart J.-P. 1997 - Les industries à Federmesser dans le bassin de la Somme : chronologie et identité des groupes culturels, Bulletin de la Société préhistorique française, 94 (3), p. 349-359.

Coudret P., Fagnart J.-P. 2004 - Les fouilles du gisement paléolithique final de Saleux (Somme), Revue archéologique de Picardie, 1-2, p. 3-17.

Coudret P., Fagnart J.-P. 2006 - Données préliminaires sur les habitats des groupes de la tradition Federmesser du bassin de la Somme, Bulletin de la Société préhistorique française, 103 (4), p. $729-740$.

Coudret P., Fagnart J.-P. 2012 - Les occupations préhistoriques du 'Marais de Conty' (Somme), in Antoine P., Fagnart J.-P., Auguste P., Coudret P., Limondin-Lozouet N., Ponel P., Munaut A.-V., Defgnée A., Gauthier A., Fritz C. (dir.), Conty, vallée de la Selle (Somme, France) : séquence tardiglaciaire de référence et occupations préhistoriques, Paris, Quaternaire (hors-série 5), p. 63-90.

Coudret P., Fagnart J.-P. 2015 - Recent research on the Final Palaeolithic site of Saleux (France, Somme), in Ashton N., Harris C. (dir.), No stone unturned. Papers in honour of Roger Jacobi, Londres, Lithic Studies Society (Occasional Paper 9), p. $135-155$.

Coulonges L. 1963 - Magdalénien et Périgordien post-glaciaires : la grotte de La Borie del Rey (Lot-et-Garonne), Gallia Préhistoire, 6, p. 1-29.

Couraud C. 1985 - L'art azilien. Origine-survivance, Paris, CNRS Éditions (Suppl. Gallia Préhistoire 20), 184 p.

D'Errico F. 1994 - L'art gravé azilien. De la technique à la signification, Paris, CNRS Éditions (Suppl. Gallia Préhistoire 31), 329 p.

Dachary M. 2002 - Le Magdalénien des Pyrénées occidentales, thèse de doctorat, Université Paris 10-Nanterre, inédit, 300 p.

Debout G., Gauduchon S. 2016 - Une occupation de l'Azilien ancien, in Gauduchon S. (dir.), Les Mureaux "La Motte » (Yvelines, Île-de-France), rapport de diagnostic, SRA Île-deFrance, Service archéologique départemental des Yvelines, inédit, p. 45-61.

Debout G., Valentin B., Leesch D., Bodu P., Dumarçais G., Schoch W., Thiébault S. 2014 - Pincevent et la chronologie du Magdalénien septentrional. Nouveaux éléments au débat, in Julien M., Karlin C. (dir.), Un automne à Pincevent : le campement magdalénien du niveau IV20, Paris, Société préhistorique française (Mémoires 57), p. 49-59.

Delpech F. 1983 - Les faunes du Paléolithique supérieur dans le Sud-Ouest de la France, Paris, CNRS Éditions (Cahiers du Quaternaire 6), $453 \mathrm{p}$.

Delvigne V. 2016 - Géoressources et expressions technoculturelles dans le sud du Massif central au Paléolithique supérieur : des déterminismes et des choix, thèse de doctorat, Université de Bordeaux, inédit, 3 vol., 1287 p.

Desbrosse R. 1976 - Les civilisations du Paléolithique supérieur dans le Jura méridional et dans les Alpes, in Lumley H. de (dir.), La Préhistoire française, I : Les civilisations paléolithiques et mésolithiques de la France. Actes du $9^{e}$ congrès de l'UISPP, Nice, 13-18 septembre 1976, Paris, Éditions du CNRS, p. 1196-1213.
Desbrosse R. 1977 - L'abri Gay à Poncin (Ain), nouveau gisement azilien du Bassin rhodanien, in Congrès préhistorique de France. Compte rendu de la XXe session, Provence, 1-7 juillet 1974, Paris, Société préhistorique française, p. 123-129.

Deschodt L., Teheux E., Lantoine J., Auguste P., LimondinLozouet N. 2005 - L'enregistrement tardiglaciaire de Dourges (Nord de la France, bassin de la Deûle) : évolution d'une zone lacustre et gisements archéologiques associés, Quaternaire, 16 (3), p. 229-252.

Detrain L., Ferrie J. G., Langlais M. 2018 - Occupations de l'Épipaléolithique du site du camping du Saut à Port-de-Penne (Penne d'Agenais, Lot-et-Garonne), in Averbouh A., BonnetJacquement P., Cleyet-Merle J.-J. (dir.), L'Aquitaine à la fin des temps glaciaires : les sociétés de la transition du Paléolithique final au début du Mésolithique dans l'espace Nord aquitain. Actes de la table organisée en hommage à Guy Célérier, Les Eyzies-de-Tayac, 24-26 juin 2015, Les Eyzies-de-Tayac, Musée national de Préhistoire (nº spécial Paléo), p. 167-179.

Drucker D., Bocherens H. 2002 - Reconstitution paléoécologique de l'Azilien ancien du Closeau par l'étude des isotopes stables, Cahiers des thèmes transversaux ArScan, II : 2000/2001, Nanterre, UMR 7041 Archéologies et Sciences de l'Antiquité, p. 39-40.

Ducrocq T. à paraître - Mésolithique initial et Mésolithique ancien dans le Nord de la France à Warluis (Oise), in Montoya C., Fagnart J.-P., Locht J.-L. (dir.), Préhistoire de l'Europe du NordOuest : mobilités, climats et identités. Actes du $28^{e}$ congrès préhistorique de France, Amiens, 30 mai-4 juin 2016, Paris, Société préhistorique française.

Ducrocq T., Bridault A., Coutard S. 2008 - Le gisement de Warluis (Oise): approche préliminaire, in Fagnart J.-P., Thévenin A., Ducrocq T., Souffi B., Coudret P. (dir.), Le début du Mésolithique en Europe du Nord-Ouest. Actes de la table ronde d'Amiens, 9-10 octobre 2004, Paris, Société préhistorique française (Mémoires 45), p. 85-106.

Escalon de Fonton M., Onoratini G. 1977 - L'abri Cornille à Istres (Bouches-du-Rhône), in Congrès préhistorique de France. Compte rendu de la XX $X^{e}$ session, Provence, 1-7 juillet 1974, Paris, Société préhistorique française, p. 174-227.

Escalon de Fonton M., Onoratini G., Bonifay M.-F. 1978 - Le gisement de la Baume de Valorgues à Saint-Quentin-la-Poterie (Gard), Gallia Préhistoire, 21 (1), p. 91-142.

Evin J., Bintz P., Monjuvent G. 1994 - Human settlements and the last deglaciation in the French Alps, Radiocarbon, 36 (3), p. 345-357.

Fagnart J.-P 1988 - Les industries lithiques du Paléolithique supérieur dans le Nord de la France, Amiens, Revue archéologique de Picardie (nº spécial 7), 153 p.

Fagnart J.-P. 1993 - Le Paléolithique supérieur récent et final du Nord de la France dans son cadre paléoclimatique, thèse de doctorat, Université des sciences et technologies de Lille, inédit, 2 vol., 567 p.

Fagnart J.-P 1997 - La fin des temps glaciaires dans le Nord de la France. Approches archéologique et environnementale des occupations humaines au cours du Tardiglaciaire, Paris, Société préhistorique française (Mémoires 24), 270 p. 
Fagnart J.-P. 2009 - Les industries à grandes lames et éléments mâchurés du Paléolithique final du Nord de la France : une spécialisation fonctionnelle des sites Épi-ahrensbourgiens, in Crombé P., Van Strydonck M., Sergant J., Boudin M., Bats M. (dir.), Chronology and Evolution within the Mesolithic of North-West Europe. Proceedings of an international meeting of Brussels, 30 ${ }^{\text {th }}$ May- ${ }^{\text {st }}$ June 2007, Cambridge, Cambridge Scholars Publishing, p. 39-55.

Fagnart J.-P., Coudret P. 2000a - Données récentes sur le Tardiglaciaire du bassin de la Somme, in Pion G. (dir.), Le Paléolithique supérieur récent. Nouvelles données sur le peuplement et l'environnement. Actes de la table ronde de Chambéry, 12-13 mars 1999, Paris, Société préhistorique française (Mémoire 28), p. 113-126.

Fagnart J.-P., Coudret P. 2000b - Le Tardiglaciaire dans le Nord de la France, in Valentin B., Bodu P., Christensen M. (dir.), L'Europe centrale et septentrionale au Tardiglaciaire. Confrontation des modèles régionaux de peuplement. Actes de la table ronde internationale de Nemours, 14-16 mai 1997, Nemours, APRAIF (Mémoires du musée de Préhistoire d'Îlede-France 7), p. 111-128.

Fagnart J.-P, Plisson H. 1997 - Fonction des pièces mâchurées du Paléolithique final de la vallée de la Somme. Caractères tracéologiques et données contextuelles, in Fagnart J.-P., Thévenin A. (dir.), Le Tardiglaciaire en Europe du Nord-Ouest. Actes du $119^{e}$ congrès national des sociétés historiques et scientifiques, Amiens, 26-30 octobre 1994, Paris, Éditions du CTHS, p. 95-106.

Fat Cheung C. 2015 - L'Azilien pyrénéen parmi les sociétés du Tardiglaciaire ouest-européen : apport de l'étude des industries lithiques, thèse de doctorat, Université Toulouse 2, inédit, 2 vol., $910 \mathrm{p}$.

Fat Cheung C., Chevallier A., Bonnet-Jacquement P., Langlais M., Ferrié J.-G., Costamagno S., Kuntz D., Laroulandie V., Mallye J.-B., Valdeyron N., Ballista S. 2014 - Comparaison des séquences aziliennes entre Dordogne et Pyrénées : état des travaux en cours, in Langlais M., Naudinot N., Peresani M. (dir.), Les groupes culturels de la transition Pléistocène-Holocène entre Atlantique et Adriatique. Actes de la séance de la Société préhistorique française, Bordeaux, 24-25 mai 2012, Paris, Société préhistorique française (Séance 3), p. 17-44.

Floss H. 2000 - Le couloir Rhin-Saône-Rhône : axe de communication au tardiglaciaire ?, in Cupillard C., Richard A. (dir.), Les derniers chasseurs-cueilleurs d'Europe occidentale (13000-5500 av. J.-C.). Actes du colloque international de Besançon, 23-25 octobre 1998, Besançon, Presses universitaires de Franche-Comté (Annales littéraires 699, Environnement, sociétés et archéologie 1), p. 313-321.

Fornage-Bontemps S. 2013 - Le niveau A4 de Rochedane, l'Est de la France et la question des influences épigravettiennes à la fin du Tardiglaciaire, thèse de doctorat, Université de Franche-Comté, inédit, $555 \mathrm{p}$.

Fornage-Bontemps S. 2016 - Quand les idées franchissent les montagnes. L'Est de la France et la question de la diffusion des influences épigravettiennes au nord des Alpes entre l'Allerød et la fin du Dryas récent, in Naudinot N., Meignen L., Binder D., Querré G. (dir.), Les systèmes de mobilité de la Préhistoire au Moyen Âge. Actes des $35^{e}$ rencontres internationales d'archéologie et d'histoire d'Antibes, 14-16 octobre 2014, Nice, Éditions APDCA, p. 337-352.

Fritz C., Tosello G. 2011 - Exceptional evidence for Palaeolithic art in the Paris basin: The engraved pebble from Étiolles (Essonne), Bulletin de la Société préhistorique française, 108 (1), p. 27-46.

Fu Q., Posth C., Hajdinjak M., Petr M., Mallick S., Fernandes D., Furtwängler A., Haak W., Meyer M., Mittnik A., Nickel B., Peltzer A., Rohland N., Slon V., Talamo S., Lazaridis I., Lipson M., Mathieson I., Schiffels S., Skoglund P., Derevianko A. P., Drozdov N., Slavinsky V., Tsybankov A., Cremonesi R. G., Mallegni F., Gély B., Vaca E., Gonzáles Morales M. R., Straus L. G., Neugebauer-Maresch C., Teschler-Nicola M., Constantin S., Moldovan O. T., Benazzi S., Peresani M., Coppola D., Lari M., Ricci S., Ronchitelli A., Valentin F., Thevenet C., Wehrberger K., Grigorescu D., Rougier H., Crevecoeur I., Flas D., Semal P., Mannino M. A., Cupillard C., Bocherens H., Conard N. J., Harvati K., Moiseyev V., Drucker D. G., Svoboda J., Richards M. P., Caramelli D., Pinhasi R., Kelso J., Patterson N., Krause J., Pääbo S., Reich D. 2016 - The genetic history of Ice Age Europe, Nature, 534, p. 200-205.

Gagnière S. 1948 - XII ${ }^{\mathrm{e}}$ circonscription, Gallia, 6, p. 417-424.

Genieux G. 2015 - L'Azilien récent de l'Anse de Landroannec (Mûrde-Bretagne, Côtes-d'Armor) : entre choix techniques et adaptabilités, mémoire de master 1, Université Nice Sophia-Antipolis, inédit, $47 \mathrm{p}$.

Girardclos S., Fiore J., Rachoud-Schneider A.-M., Baster I., Wildi W. 2005 - Petit-Lac (Western Lake Geneva) environment and climate history from deglaciation to the present: A synthesis, Boreas, 34 (4), p. 417-433.

Griggo C. 2005 - Les grands mammifères de la grotte du BoisRagot, in Chollet A., Dujardin V. (dir.), La grotte du Bois-Ragot à Gouex (Vienne) Magdalénien et Azilien. Essai sur les hommes et leur environnement, Paris, Société préhistorique française (Mémoire 38), p. 289-317.

Griselin S., Koehler H., Man-Estier E. 2017 - Découverte d'un bloc gravé dans la grotte de Blénien à Wolschwiller (Haut-Rhin), in Cleyet-Merle J.-J., Geneste J.-M., Man-Estier E. (dir.), L'art au quotidien, objets ornés du Paléolithique supérieur. Actes du colloque international, Les Eyzies-de-Tayac, 16-20 juin 2014, Les Eyzies-de-Tayac, Musée national de Préhistoire $\left(\mathrm{n}^{\circ}\right.$ spécial Paléo), p. 547-551.

Guéret C. 2013 - L'outillage du Premier Mésolithique dans le Nord de la France et en Belgique. Éclairages fonctionnels, thèse de doctorat, Université Paris 1 Panthéon-Sorbonne, inédit, 472 p.

Guy E. 1993 - Enquête stylistique sur l'expression figurative épipaléolithique en France : de la forme au concept, Paléo, 5, p. 333-373.

Jacquier J. 2014 - Analyse fonctionnelle des outillages lithiques et interprétations socio-économique du statut des sites tardiglaciaires du Buhot à Calville (Eure) et de la Fosse à Villers-Charlemagne (Mayenne), in Langlais M., Naudinot N., Peresani M. (dir.), Les groupes culturels de la transition Pléistocène-Holocène entre Atlantique et Adriatique. Actes de la séance de la Société préhistorique française, Bordeaux, 24-25 mai 2012, Paris, Société préhistorique française (Séance 3), p. 221-246. 
Jacquier J. 2015 - Approche fonctionnelle de l'outillage lithique à l'aube de l'Holocène dans le Nord-Ouest de la France, thèse de doctorat, Université Rennes 1, inédit, 450 p.

Jacquier J., Naudinot N. 2015 - Socio economic significance of stone tools recycling, reuse and maintenance at the end of the Lateglacial in Northwestern France, Quaternary International, 361 , p. $269-287$.

Jallet F., Bouvier A. (dir.) 2012 - 35 rue Auguste-Isaac, tranche 1, rapport final de synthèse, INRAP Rhône-Alpes-Auvergne, inédit, 3 vol., 820 p.

Johansen L., Stapert D. 2000 - Two 'Epi-Ahrensburgian' sites in the Northern Netherlands: Oudehaske (Friesland) and Gramsbergen (Overijssel), Palaeohistoria, 39-40, p. 1-87.

Jones E. L. 2006 - Prey choice, mass collecting, and the wild European rabbit (Oryctolagus Cuniculus), Journal of Anthropological Archaeology, 25 (3), p. 275-289.

Jude P.-E. 1960 - La grotte de Rochereil, station magdalénienne et azilienne, Paris, Masson (Archives de l'Institut de paléontologie humaine, Mémoire 30), $75 \mathrm{p}$.

Julien M. 1989 - Activités saisonnières et déplacements des Magdaléniens dans le Bassin parisien, in Rigaud J.-P. (dir.), Le Magdalénien en Europe. La structuration du Magdalénien. Actes du $11^{e}$ congrès de l'UISPP, Mayence, 1987, Liège, Université de Liège (ERAUL 38), p. 177-191.

Julien M., Audouze F., Baffier D., Bodu P., Coudret P., David F., Gaucher G., Karlin C., Larriere M., Masson P., Olive M., Orliac M., Pigeot N., Rieu J.-L., Schmider B., Taborin Y. 1988 - Organisation de l'espace et fonction des habitats magdaléniens du Bassin parisien, in Otte M. (dir.), De la Loire à l'Oder. Les civilisations du Paléolithique final dans le NordOuest européen. Actes du colloque international de Liège, décembre 1985, Oxford et Liège, British Archaeological Reports (BAR Int. Ser. 444, ERAUL 25), vol. 1, p. 85-123.

Julien M., Karlin C. (dir.) 2014 - Un automne à Pincevent. Le campement magdalénien du niveau IV20, Paris, Société préhistorique française (Mémoires 57), 639 p.

Koehler H., Angevin R., Bignon-Lau O., Griselin S. 2013 Découverte de plusieurs occupations du Paléolithique supérieur récent dans le sud de l'Alsace, Bulletin de la Société préhistorique française, 110 (2), p. 356-359.

Lacombe S. 1998 - Préhistoire des groupes culturels au Tardiglaciaire dans les Pyrénées centrales. Apports de la technologie lithique, thèse de doctorat, Université Toulouse-Le Mirail, inédit, 2 vol., 385 p.

Langlais M. 2007 - Dynamiques culturelles des sociétés magdaléniennes dans leurs cadres environnementaux. Enquête sur 7000 ans d'évolution de leurs industries lithiques entre Rhône et Ebre, thèse de doctorat, Université Toulouse-Le Mirail et Université de Barcelone, inédit, 550 p.

Langlais M. 2010 - Les sociétés magdaléniennes de l'isthme pyrénéen, Paris, Éditions du CTHS (Documents préhistoriques 26), 337 p.

Langlais M. 2017 - From the social composition of a campsite to Magdalenian cultural reproduction: Studying technical expertise at Verberie (Oise, France) to better understand sites in the Aquitaine basin, in Klaric L. (dir.), The Prehistoric apprentice.
Investigating apprenticeship and expertise in Prehistoric technologies, Brno, Academy of Sciences of the Czech Republic (Dolni Vestonice Studies), p. 251-274.

Langlais M., Bonnet-Jacquement P., Detrain L., Valdeyron N. 2014a - Le Laborien : ultime sursaut technique du cycle évolutif paléolithique du Sud-Ouest de la France ?, in Jaubert J., Fourment N., Depaepe P. (dir.), Transitions, ruptures et continuité en Préhistoire. Actes du $27^{e}$ congrès préhistorique de France, Bordeaux-Les Eyzies, 31 mai-5 juin 2010, Paris, Société préhistorique française, p. 567-583.

Langlais M., Costamagno S., Laroulandie V., Pétillon J-.M., Discamps E., Mallye J.-B., Cochard D., Kuntz D. 2012 The evolution of Magdalenian societies in South-West France between 18,000 and 14,000 CalBP: Changing environments, changing tool kits, Quaternary International, 272-273, p. 138-149.

Langlais M., Delvigne V., Gibaud A., Jacquier J., Perrin T., Fernandes P., Delpuech A. 2018 - La séquence archéostratigraphique du Cuze de Sainte-Anastasie (Cantal) : nouvelle approche des industries lithiques du Paléolithique final au Mésolithique, Bulletin de la Société préhistorique française, 115 (3), p. 497-529.

Langlais M., Detrain L., Ferrié J.-G., Mallye J.-B., Marquebielle B., Rigaud S., Turq A., Bonnet-Jacquement P., Boudadi-Maligne M., Caux S., Fat Cheung C., Naudinot N., Morala A.,Valdeyron N., Chauvière F.-X. 2014b - Réévaluation des gisements de La Borie del Rey et de Port-de-Penne : nouvelles perspectives pour la transition Pléistocène-Holocène dans le Sud-Ouest de la France, in Langlais M., Naudinot N., Peresani M. (dir.), Les groupes culturels de la transition Pléistocène-Holocène entre Atlantique et Adriatique. Actes de la séance de la Société préhistorique française, Bordeaux, 24-25 mai 2012, Paris, Société préhistorique française (Séance 3), p. 83-128

Langlais M., Laroulandie V., Jacquier J., Costamagno S., Chalard P., Mallye J.-B., Pétillon J.-M., Rigaud S., Royer A., Sitzia L., Cochard D., Dayet L., Fat Cheung C., Le Gall O., Queffelec A., Lacrampe-Cuyaubère F. 2015 - Le Laborien récent de la grotteabri de Peyrazet (Creysse, Lot, France). Nouvelles données pour la fin du Tardiglaciaire en Quercy, Paleo, 26, p. 79-115.

Langlais M., Laroulandie V., Pétillon J.-M., Mallye J.-B., Costamagno S. 2014c - Évolution des sociétés magdaléniennes dans le sud-ouest de la France entre 18500 et 14000 cal BP : recomposition des environnements, reconfiguration des équipements, in Jaubert J., Fourment N., Depaepe P. (dir.), Transitions, ruptures et continuité en Préhistoire. Actes du $27^{e}$ congrès préhistorique de France, Bordeaux-Les Eyzies, 31 mai-5 juin 2010, Paris, Société préhistorique française, vol. 2, p. 417-430.

Langlais M., Naudinot N., Pasty J.-F., Marquebielle B., Fat Cheung C., Bonnet-Jacquement P., Detrain L. à paraître D'un Massif à l'autre : synthèse sur le Laborien entre France méridionale et atlantique, in Montoya C., Fagnart J.-P., Locht J.-L. (dir.), Préhistoire de l'Europe du Nord-Ouest : mobilités, climats et identités. Actes du $28^{e}$ congrès préhistorique de France, Amiens, 30 mai-4 juin 2016, Paris, Société préhistorique française.

Langlais M., Naudinot N., Peresani M. (dir.) 2014d - Les groupes culturels de la transition Pléistocène-Holocène entre Atlantique et Adriatique. Actes de la séance de la Société préhistorique française, Bordeaux, 24-25 mai 2012, Paris, Société préhistorique française (Séance 3), $246 \mathrm{p}$. 
Langlais M., Sécher A., Caux. S., Delvigne V., Gourc L., Normand C., Sánchez de la Torre M. 2016 - Lithic tool kits: A metronome of the evolution of the Magdalenian in Southwest France (19,00014,000 cal BP), Quaternary International, 414, p. 92-107.

Laroulandie V., Costamagno S., Langlais M., Pétillon J.-M. 2017 - L'œuf ou la poule ? Retour sur le projet Magdatis « Le Magdalénien de la façade atlantique face aux changements environnementaux », Quaternaire, 28 (2), p. 277-283.

Leduc C., Bridault A., Cupillard C. 2015 - Wild boar (Sus scrofa scrofa) hunting and exploitation strategies during the Mesolithic at Les Cabônes (Ranchot Jura, France), Layer 3, Journal of Archaeological Science Reports, 2, p. 473-484.

Leesch D., Cattin M.-I, Müller W. 2004 - HauteriveChampréveyres et Neuchâtel-Monruz. Témoins d'implantations magdaléniennes et aziliennes sur la rive nord du lac de Neuchâtel, Neuchâtel, Office cantonal d'archéologie (Archéologie neuchâteloise 31), 237 p.

Lefèbvre A. 2016 - Les stratégies d'adaptation des sociétés pyrénéennes entre 19 et $14 \mathrm{ka}$ cal BP : étude biométrique et technoéconomique comparée sur l'exploitation du bois de cerf et du bois de renne autour des Pyrénées au Magdalénien moyen et supérieur, thèse de doctorat, Université de Bordeaux, inédit, $422 \mathrm{p}$.

Le Tensorer J.-M. 1979 - Recherches sur le Quaternaire en Lot-etGaronne : stratigraphie, paléoclimatologie et préhistoire paléolithique, thèse de doctorat, Université Bordeaux 3, inédit, 812 p.

Leroyer C., Allenet de Ribemont G, Chaussé C. 2014 - Le paysage végétal durant le Tardiglaciaire : Bazoches-lès-Bray, une référence pour le site de Pincevent, in Chollet A., Dujardin V. (dir.), La grotte du Bois-Ragot à Gouex (Vienne) Magdalénien et Azilien. Essai sur les hommes et leur environnement, Paris, Société préhistorique française (Mémoire 38), p. 39-48.

Lorblanchet M. 1985 - Premiers résultats de nouvelles recherches à l'abri Murat (Rocamadour, Lot), Préhistoire quercynoise, 2, p. 58-94.

Lorblanchet M. 1996 - Du Magdalénien à l'Azilien en Quercy, in $L a$ Vie préhistorique, Dijon, Faton, p. 282-285.

Malgarini R. 2014 - Les gisements magdaléniens du Jura et des Alpes du nord et leurs industries osseuses, thèse de doctorat, Université de Franche-Comté, inédit, 484 et 182 p.

Mallye J.-B., Kuntz D., Langlais M., Boudadi-Maligne M., BarshaySzmidt C., Costamagno S., Pétillon J.-M., Gourichon L., Laroulandie V. 2018 - Trente ans après, que reste-t-il du modèle d'azilianisation proposé au Morin par F. Bordes et D. de Sonneville-Bordes ?, in Averbouh A., Bonnet-Jacquement P., Cleyet-Merle J.-J. (dir.), L'Aquitaine à la fin des temps glaciaires : les sociétés de la transition du Paléolithique final au début du Mésolithique dans l'espace Nord aquitain. Actes de la table organisée en hommage à Guy Célérier, Les Eyzies-deTayac, 24-26 juin 2015, Les Eyzies-de-Tayac, Musée national de Préhistoire (nº spécial Paléo), p. 153-166.

Marchand G., Arthuis R., Philibert S., Sellami F., Sicard S., collab. Forré P., Lanoë S., Nauleau J.-F., Quesnel L., Querré G. 2009 - Un habitat azilien en Anjou : les Chaloignes à Mozé-surLouet (Maine-et-Loire), Gallia Préhistoire, 51, p. 1-111.
Marchand G., Blanchet S., Chevalier G., Gallais J.-Y., Le Goffic M., Naudinot N., Yven E. 2004 - La fin du Tardiglaciaire sur le Massif armoricain : territoires et cultures matérielles, Paléo, 16, p. $137-170$.

Marchand G., Monnier J.-L., Pustoc'h F., Quesnel L. 2014 - Un visage original du Tardiglaciaire en Bretagne : les occupations aziliennes dans l'abri-sous-roche de Kerbizien à Huelgoat, Paléo, 25 , p. $125-168$.

Marchand G., Naudinot N. 2015 - Tous aux abris ! Les occupations du Paléolithique final et du Mésolithique dans les cavités naturelles du Massif armoricain, Bulletin de la Société préhistorique française, 112 (3), p. 517-543.

Marchand G., Naudinot N., Philibert S., Sicard S. 2011 - Chasse aux haltes sur un site azilien de l'Ouest de la France, P@lethnologie, 3, 271-294.

Marchand G., Sicard S., Forré P., Nauleau J.-F. 2008 - De la pelle mécanique aux remontages lithiques : espace habité et techniques au Tardiglaciaire sur l'habitat des Chaloignes (Mozésur-Louet, Maine-et-Loire), Revue archéologique de l'Ouest, 25 , p. $7-52$.

Martin Y. 2010 - La grotte de Gouy (Seine-Maritime), Bulletin Préhistoire du Sud-Ouest, 18 (1), p. 9-25.

Mevel L. 2013 - Les premières sociétés aziliennes. Nouvelle lecture de la genèse du phénomène d'azilianisation dans les Alpes du Nord à partir des deux niveaux d'occupations de l'abri de La Fru (Saint-Christophe-la-Grotte, Savoie), Bulletin de la Société préhistorique française, 110 (4), p. 657-689.

Mevel L. 2017 - Des sociétés en mouvement. Évolution des sociétés magdaléniennes et aziliennes des Alpes du nord françaises, Paris, Éditions du CTHS (Documents préhistoriques 34), 336 p.

Mevel L., Bodu P. 2018 - Le Closeau reloaded. Actualités et perspectives autour des occupations Aziliennes du Closeau (Rueil-Malmaison, Hauts-de-Seine), in Averbouh A., BonnetJacquement P., Cleyet-Merle J.-J. (dir.), L'Aquitaine à la fin des temps glaciaires : les sociétés de la transition du Paléolithique final au début du Mésolithique dans l'espace Nord aquitain. Actes de la table organisée en hommage à Guy Célérier, Les Eyzies-de-Tayac, 24-26 juin 2015, Les Eyzies-de-Tayac, Musée national de Préhistoire ( $\mathrm{n}^{\circ}$ spécial Paléo), p. 203-214.

Mevel L., Bressy C. 2009 - Comportements techniques et économiques des groupes humains du Paléolithique final dans les Alpes du nord : l'exemple de l'Azilien ancien de l'abri de La Fru (Savoie), in Pion G., Mevel L. (dir.), La fin du Paléolithique supérieur dans les Alpes du nord et le Jura méridional. Approches culturelles et environnementales, Paris, Société préhistorique française (Mémoire 50), p. 117-137.

Mevel L., Fornage-Bontemps S., Béreiziat G. 2014a - Au carrefour des influences culturelles? Les industries lithiques de la fin du Tardiglaciaire entre Alpes du Nord et Jura, 13500-9500 cal. BP, in Langlais M., Naudinot N., Peresani M. (dir.), Les groupes culturels de la transition Pléistocène-Holocène entre Atlantique et Adriatique. Actes de la séance de la Société préhistorique française, Bordeaux, 24-25 mai 2012, Paris, Société préhistorique française (Séance 3), p. 45-81. 
Mevel L., Pion G., Fornage-Bontemps S. 2014b - Changements techniques et géographie culturelle à l'extrême fin du Paléolithique dans les Alpes du nord françaises. Les stratigraphies de l'abri de La Fru (Savoie) revisitées, in Jaubert J., Fourment N., Depaepe P. (dir.), Transitions, ruptures et continuité en Préhistoire. Actes du $27^{e}$ congrès préhistorique de France, Bordeaux-Les Eyzies, 31 mai-5 juin 2010, Paris, Société préhistorique française, vol. 2, p. 527-546.

Mevel L., Weber M.-J., Berg-Hansen I.-M., Grimm S. B. à paraître - The Ahrensburgian revisited. Techno-economic variability documented by several settlements from Northernmost Germany (Teltwisch, Alt Duvenstedt, Kleine Nordende), in Montoya C., Fagnart J.-P., Locht J.-L. (dir.), Préhistoire de l'Europe du Nord-Ouest : mobilités, climats et identités. Actes du $28^{e}$ congrès préhistorique de France, Amiens, 30 mai-4 juin 2016, Paris, Société préhistorique française.

Monin G. 2000 - Apport de la technologie lithique à l'étude des séries anciennes. Les assemblages tardiglaciaires des chasseurs de marmottes des grottes Colomb et de la Passagère à Méaudre (Vercors, Isère), in Pion G. (dir.), Le Paléolithique supérieur récent. Nouvelles données sur le peuplement et l'environnement. Actes de la table ronde de Chambéry, 12-13 mars 1999, Paris, Société préhistorique française (Mémoire 28), p. 271-287.

Monjuvent G., Nicoud G. 1988 - Modalités et chronologie de la déglaciation würmienne dans l'arc alpin occidental et les massifs français : synthèse et réflexions, Bulletin de l'Association française pour l'étude du Quaternaire, 25 (2-3), p. 147-156.

Montoya C. 2004 - Les traditions techniques lithiques à l'Épigravettien : analyses de séries du Tardiglaciaire entre Alpes et Méditerranée, thèse de doctorat, Université Aix-Marseille 1, inédit, 2 vol., 477 p.

Mourre V. 2013 - Une sépulture du Paléolithique final à Cuges-lesPins, rapport d'activité, INRAP, inédit, 2 p.

Naudinot N. 2008 - Les armatures lithiques tardiglaciaires dans l'Ouest de la France (régions Bretagne et Pays de la Loire). Proposition d'organisation chrono-culturelle et chaîne opératoire de fabrication, P@lethnologie, 1, p.250-277.

Naudinot N. 2010 - Dynamiques techno-économiques et de peuplement au Tardiglaciaire dans le Grand-Ouest de la France, thèse de doctorat, Université Rennes 1, inédit, 738 p.

Naudinot N. 2012 - Anticiper ou s'adapter? Acquisition des matériaux au Tardiglaciaire dans le Massif armoricain, in Marchand G., Quérré G. (dir.), Roches et sociétés de la Préhistoire. Entre massifs cristallins et bassins sédimentaires. Actes du colloque de Rennes, 28-30 avril 2010, Rennes, Presses universitaires de Rennes, p. 93-107.

Naudinot N. 2013 - La fin du Tardiglaciaire dans le Grand-Ouest de la France, Bulletin de la Société préhistorique française, 110 (2), p. 233-255.

Naudinot N., Bourdier C., Laforge M., Paris C., Bellot-Gurlet L., Beyries S., Thery-Parisot I., Le Goffic M. 2017a - Divergence in the evolution of Paleolithic symbolic and technological systems: The shining bull and engraved tablets of Rocher de l'Impératrice, PLOS ONE, 12 (9), e 0204464.
Naudinot N., Jacquier J. 2009 - Un site tardiglaciaire en place à la Fosse (Villiers-Charlemagne, Mayenne) : premiers résultats et implications chrono-culturelles, Bulletin de la Société préhistorique française, 106 (1), p. 145-158.

Naudinot N., Jacquier J. 2011 - Le site Paléolithique final de la Fosse (Mayenne). Approche palethnologique d'une occupation de la transition Pléistocène-Holocène sur les bords de la Mayenne, rapport d'opération archéologique pluriannuelle, SRA Pays-de-la-Loire, inédit, 252 p.

Naudinot N., Jacquier J. 2014 - Socio-economic organization of Final Paleolithic societies: new perspectives from an aggregation site in Western France, Journal of Anthropological Archaeology, 35 , p. $177-189$.

Naudinot N., Le Goffic M., Bellot-Gurlet L., Bourles D., Flageul A., Guiavarc'h M., Laforge M., Jacquier J., Queré G., Quesnel L., Macphail R., Paillet E., Paillet P., Paris C., Sorin S., ThéryParisot I., Bachellerie J., Le Gueut E. 2018b - Le Rocher de l'Impératrice, Plougastel-Daoulas (Finistère), rapport intermédiaire de fouille, SRA Bretagne, inédit, $189 \mathrm{p}$.

Naudinot N., Le Goffic M., Beyries S., Bellot-Gurlet L., Bourdier C., Jacquier J., Laforge M. 2018a - Du nouveau à l'Ouest : résultats préliminaires sur l'Azilien ancien de l'abri sous roche du Rocher de l'Impératrice (Plougastel-Daoulas, Finistère), in Averbouh A., Bonnet-Jacquement P., CleyetMerle J.-J. (dir.), L'Aquitaine à la fin des temps glaciaires : les sociétés de la transition du Paléolithique final au début du Mésolithique dans l'espace Nord aquitain. Actes de la table organisée en hommage à Guy Célérier, Les Eyzies-de-Tayac, 24-26 juin 2015, Les Eyzies-de-Tayac, Musée national de Préhistoire ( ${ }^{\circ}$ spécial Paléo), p. 181-191.

Naudinot N., Michel S. dir. 2014 - SESSION G. La transition Pléistocène/Holocène dans le nord de la France : entre transferts et ruptures techniques, in Jaubert J., Fourment N., Depaepe P. (dir.), Transitions, Ruptures et Continuité en Préhistoire. Actes du $27^{e}$ congrès préhistorique de France, Bordeaux et Les Eyzies, 31 mai-5 juin 2010, Paris, Société préhistorique française, vol. 2, p. $507-639$.

Naudinot N., Tomasso A. 2012 - Le Paléolithique supérieur dans l'arc liguro-provençal, rapport d'activité du PCR ETICALP 2012, SRA Provence-Alpes-Côte-d'Azur, inédit, p. 127-140.

Naudinot N., Tomasso A., Messager E., Finsinger W., Ruffaldi P., Langlais M. 2017b - Between Atlantic and Mediterranean: Changes in technology during the Late Glacial in Western Europe and the climate hypothesis, Quaternary International, 428 (B), p. 33-49.

Olive M. 1988 - Une habitation magdalénienne d'Étiolles. L'unité P15, Paris, Société préhistorique française (Mémoire 20), 2 vol., 246 p.

Paillet P., Man-Estier E. 2014 - De nouvelles découvertes d'art mobilier laborien dans le Nord du Périgord, in Langlais M., Naudinot N., Peresani M. (dir.), Les groupes culturels de la transition Pléistocène-Holocène entre Atlantique et Adriatique. Actes de la séance de la Société préhistorique française, Bordeaux, 24-25 mai 2012, Paris, Société préhistorique française (Séance 3), p. 129-154. 
Paillet P., Man-Estier E., Baumann M. 2018 - L'art laborien et le style Pont d'Ambon, in Averbouh A., Bonnet-Jacquement P., Cleyet-Merle J.-J. (dir.), L'Aquitaine à la fin des temps glaciaires : les sociétés de la transition du Paléolithique final au début du Mésolithique dans l'espace Nord aquitain. Actes de la table organisée en hommage à Guy Célérier, Les Eyzies-deTayac, 24-26 juin 2015, Les Eyzies-de-Tayac, Musée national de Préhistoire ( ${ }^{\circ}$ spécial Paléo), p. 233-250.

Pasty J.-F. 2017 - Étude des occupations épipaléolithiques et mésolithiques, in Treffort J.-M. (dir.), Lyon $9^{e}$ (Rhône), 35 rue Auguste Isaac - tranche 3, rapport de fouilles, Inrap Auvergne-RhôneAlpes, inédit, p. 162-210.

Pasty J.-F., Alix P., Ballut C., Griggo C., Murat R. 2002 - Le gisement épipaléolithique à pointes de Malaurie de ChampChalatras (Les Martres d'Atrière, Puy-de-Dôme), Paléo, 14, p. 101-176.

Pelegrin J. 2000 - Les techniques de débitage laminaire au Tardiglaciaire: critères de diagnose et quelques réflexions, in Valentin B., Bodu P., Christensen M. (dir.), L'Europe centrale et septentrionale au Tardiglaciaire. Confrontation des modèles régionaux de peuplement. Actes de la table ronde de Nemours, 14-16 mai 1997, Nemours, APRAIF (Mémoires du musée de Préhistoire d'Île-de-France 7), p. 73-86.

Peschaux C., Debout G., Bignon-Lau O., Bodu P. 2017 - Magdalenian "beadwork time" in the Paris basin (France): Correlation between personal ornaments and the function of archaeological sites, in Bar-Yosef Mayer D. E., Bonsall C., Choyke A. M. (dir.), Not just for show. The archaeology of beads, beadwork and personal ornaments, Oxford, Oxbow Books, p. 19-38.

Pétillon J.-M. 2006 - Des Magdaléniens en armes. Technologie des armatures de projectiles en bois de cervidé du Magdalénien supérieur de la grotte d'Isturitz (Pyrénées-Atlantiques), Treignes, Éditions du CEDARC (Artefacts 10), 302 p.

Pétillon J.-M. 2016 - Technological evolution of hunting implements among Pleistocene hunter-gatherers: Osseous projectile points in the Middle and Upper Magdalenian (19-14 ka cal BP), Quaternary International, 414, p. 108-134.

Pigeot N. 1987 - Magdaléniens d'Étiolles. Économie de débitage et organisation sociale (l'unité d'habitation U5), Paris, CNRS Éditions (Suppl. Gallia Préhistoire 25), 168 p.

Pion G. 1981 - L'Azilien alpin de Gerbaix « dessus » (Savoie), Bulletin de la Société préhistorique française, 78 (5), p. 139-141.

Pion G. (dir.) 1990 - L'abri de la Fru à Saint-Christophe (Savoie), Gallia Préhistoire, 32, p. 65-123.

Pion G. 1997 - L'abri de la Fru à Saint-Christophe-la-Grotte (Savoie) : l'Azilien ancien du début de l'Alleröd, Bulletin de la Société préhistorique française, 94 (3), p. 319-326.

Pion G., Mevel L. 2005 - Nouvelles recherches sur les occupations tardiglaciaires dans les Alpes du nord françaises : premiers résultats des fouilles de l'abri des Douattes (Musièges, HauteSavoie), Antiquités nationales, 37, p. 63-68.

Pion G., Stahl-Gretsch L.-I. 2007 - Chronologie du Magdalénien dans les deux Savoie et le Jura méridional, in Évin J. (dir.), Un siècle de construction du discours scientifique en préhis- toire. Actes du $26^{e}$ congrès préhistorique de France, Avignon, 21-25 septembre 2004, vol. 1 : "Des idées d'hier 》 (*), Paris, Société préhistorique française, p. 379-397.

Pion G., Thévenin A. 2007 - Le Mésolithique de l'abri de la Fru à Saint-Christophe-la-Grotte (Savoie), Bulletin de la Société préhistorique française, 104 (3), p. 483-515.

Ploux S., Karlin C., Bodu P. 1992 - D’une chaîne l'autre : normes et variations dans le débitage magdalénien, Techniques et Culture, 17-18, p. 81-114.

Rasmussen S. O., Bigler M., Blockley S. P., Blunier T., Buchardt S. L., Clausen H. B., Cvijanovic I., Dahl-Jensen D., Johnsen S. J., Fischer H., Gkinis V., Guillevic M., Hoek W. Z., Lowe J. J., Pedro J. B., Popp T., Seierstad I. K., Steffensen J. P., Svensson A. M., Vallelonga P., Vinther B. M., Walker M. J., Wheatley J. J., Winstrup M. 2014 - A stratigraphic framework for abrupt climatic changes during the Last Glacial Period based on three synchronized Greenland ice-core records: Refining and extending the INTIMATE event stratigraphy, Quaternary Science Reviews, 106, p. 14-28.

Renssen H. 2001 - The climate in The Netherlands during the Younger Dryas and Preboreal: Means and extremes obtained with an atmospheric general circulation model, Netherlands Journal of Geosciences, 80 (2), p. 19-30.

Richard H, Bégeot C. 2000 - Le Tardiglaciaire du Massif jurassien : Bilan et perspectives de recherche, Quaternaire, 11 (2), p. 145-154.

Richard H., Bégeot C., Gauthier É., Ruffaldi P. 2000 - Évolution du couvert végétal du Tardiglaciaire et du début de l'Holocène sur la chaîne Jurassienne : nouveaux résultats, in Cupillard C., Richard A. (dir.), Les derniers chasseurs-cueilleurs d'Europe occidentale (13000-5500 av. J.-C.). Actes du colloque international de Besançon, 23-25 octobre 1998, Besançon, Presses universitaires de Franche-Comté (Annales littéraires 699, Environnement, sociétés et archéologie 1), p. 29-36.

Schmider B. (dir.) 1992 - Marsangy, un campement des derniers chasseurs magdaléniens sur les bords de l'Yonne, Liège, Université de Liège (ERAUL 55), 275 p.

Schoeneich P. 1998 - Corrélation du dernier maximum glaciaire et de la déglaciation alpine avec l'enregistrement isotopique du Groenland, Quaternaire, 9 (3), p. 203-215.

Sécher A. 2017 - Traditions techniques et paléogéographie du Magdalénien moyen ancien dans le Sud-Ouest de la France (19000-17500 cal. BP). Des groupes humains à plusieurs visages?, thèse de doctorat, Université de Bordeaux, inédit, 368 p.

Stahl-Gretsch L.-I. 2004 - Les occupations magdaléniennes de Veyrier : histoire et préhistoire des abris-sous-blocs, thèse de doctorat, Université de Genève, inédit, 2 vol., 458 p.

Stapert D. 2000 - The Late Palaeolithic in the Northern Netherlands, in Valentin B., Bodu P., Christensen M. (dir.), L'Europe centrale et septentrionale au Tardiglaciaire. Confrontation des modèles régionaux de peuplement. Actes de la table ronde internationale de Nemours, 14-16 mai 1997, Nemours, APRAIF (Mémoires du musée de Préhistoire d'Île-de-France 7), p. 175-195.

Taborin Y. 1994 - Les coquillages marins, in Taborin Y. (dir.), Environnements et habitats magdaléniens dans le centre du 
Bassin parisien, Paris, Éditions de la MSH (Documents d'archéologie française 43), p. 70-77.

Terberger T. 2006 - From the first humans to the Mesolithic hunters in the Northern German lowlands - Current results trends, in Møller Hansen K., Buck Pedersen K. (dir.), Across the Western Baltic. Proceedings of the archaeological conference in Vordingborg, 27-29 mars 2003, Vordingborg, Sydsjaellands Museums (Publikationer 1), p. 23-56.

Testart A. 2005 - Éléments de classification des sociétés, Paris, Errance, $160 \mathrm{p}$

Teyssandier N. 2000 - Un gisement belloisien sur les bords de la Seine : le Closeau à Rueil-Malmaison (Hauts-de-Seine), Bulletin de la Société préhistorique française, 97 (2), p. 211-228.

Thévenin A. 1982 - Rochedane. L'Épipaléolithique de l'Est de la France et les civilisations épipaléolithiques de l'Europe occidentale, Strasbourg, Université des sciences humaines (Mémoire de la faculté des sciences sociales 1), 2 vol., 845 p.

Tomasso A. 2014 - Territoires, systèmes de mobilités et systèmes de production. La fin du Paléolithique supérieur dans l'arc liguroprovençal, thèse de doctorat, Université Nice Sophia-Antipolis et Université de Pise, inédit, 1070 p.

Tomasso A., Fat Cheung C., Fornage-Bontemps S., Langlais M., Naudinot N. 2018 - Winter is coming: What happened in Western European mountains between 12.9 and 12.6 ka cal. BP (beginning of the GS1), Quaternary International, 465 (B), p. $210-221$

Tomasso A., Naudinot N., Binder D., Grimaldi S. 2014 - Unité et diversité dans l'Épigravettien récent de l'arc liguro-provençal, in Langlais M., Naudinot N., Peresani M. (dir.), Les groupes culturels de la transition Pléistocène-Holocène entre Atlantique et Adriatique. Actes de la séance de la Société préhistorique française, Bordeaux, 24-25 mai 2012, Paris, Société préhistorique française (Séance 3), p. 155-184.

Tosello G. 2008 - L'art paléolithique en Bassin parisien, in Leclerc A.-S. (dir.), Préhistoire en Île-de-France. Les collections du musée départemental de Préhistoire d'Île-de-France, Nemours, APRAIF, p. 129-134

Valdeyron N., Detrain L. 2009 - La fin du Tardiglaciaire en Agenais, Périgord et Quercy. État de la question, perspectives, in Fullola J. M., Valdeyron N., Langlais M. (dir.), Els Pirineus $i$ Les Àrees Circumdants durant el Tardiglacial. Mutacions $i$ Filiacions Tecnoculturals, Evolució Paleoambiental (1600010000 BP). Actas XIV Col.loqui Internacional d'Arqueologia de Puigcerdà. Puigcerdà-10-12 de novembre de 2006, Puigcerdà, Institut d'estudio Ceretans, p. 493-517.

Valentin B. 1995 - Les groupes humains et leurs traditions au Tardiglaciaire dans le Bassin parisien. Apports de la technologie lithique comparée, thèse de doctorat, Université Paris 1, inédit, 3 vol., 834 p.

Valentin B. 2000 - L'usage des percuteurs en pierre tendre pour le débitage des lames. Circonstances de quelques innovations au cours du Tardiglaciaire dans le Bassin parisien, in Pion G. (dir.), Le Paléolithique supérieur récent. Nouvelles données sur le peuplement et l'environnement. Actes de la table ronde de Chambéry, 12-13 mars 1999, Paris, Société préhistorique française (Mémoire 28), p. 253-260.

Valentin B., collab. Hantaï A. 2005 - Transformations de l'industrie lithique pendant l'Azilien. Étude des niveaux 3 et 4 du BoisRagot, in Chollet A., Dujardin V. (dir.), La grotte du Bois-Ragot à Gouex (Vienne) Magdalénien et Azilien. Essai sur les hommes et leur environnement, Paris, Société préhistorique française (Mémoire 38), p. 89-182.

Valentin B. 2008a - Jalons pour une paléohistoire des derniers chasseurs (XIV $-V I^{e}$ millénaire avant J.-C.), Paris, Publications de la Sorbonne (Cahiers archéologiques de Paris 1-1), 325 p.

Valentin B. 2008b - Productions lithiques magdaléniennes et aziliennes : disparition d'une économie programmée, The Arkeotek Journal,2 (3) [URL: http://thearkeotekjournal.org/tdm/Arkeotek/ fr/archives/2008/3Valentin.xml].

Valentin B. 2009 - Éléments de paléohistoire autour du basculement Pléistocène-Holocène, in Crombé P., Van Strydonck M., Sergant J., Boudin M., Bats M. (dir.), Chronology and Evolution within the Mesolithic of North-West Europe. Proceedings of the International Meeting of Brussels, 30 ${ }^{\text {th }}$ May-1 ${ }^{\text {st }}$ June 2007, Cambridge, Cambridge Scholars Publishing, p. 23-38.

Valentin B., Fagnart J.-P., Coudret P., Pelegrin J. 2006 L'azilianisation et ses rythmes dans le Bassin parisien. Nouvelles observations sur Hangest III.1 (Somme), in Valentin B. (dir.), Habitats et peuplements tardiglaciaires dans le Bassin parisien, rapport de projet collectif de recherche, rapport d'activités pour 2006, CNRS UMR 7041 et SRA Île-de-France, inédit, p. $83-92$.

Valentin B., Fosse G., Billard C. 2004 - Aspects et rythmes de l'azilianisation dans le Bassin parisien. Caractérisation de l'industrie lithique recueillie au Cornet (locus 33) à Ambenay (Eure), Gallia Préhistoire, 46, p. 171-209.

Valentin B., Pétillon J.-M. 2018 - Autour de Lascaux : dialogue avec Alain Testart, in Karadimas D., Lécrivain V., Rostain S. (dir.), De l'ethnologie à la préhistoire. En hommage à Alain Testart, Paris, L'Herne (Cahiers d'anthropologie sociale 16), Paris, p. 107-120.

Valentin B., Weber M.-J., Bodu P. 2014 - Initialisation and progression of the core reduction process at Donnemarie-Dontilly (Seine-et-Marne, France), site of the Belloisian tradition. New interpretative key for comparisons with contemporaneous industries and Federmesser-Gruppen assemblages, Bulletin de la Société préhistorique française, 111 (4), p. 659-678.

Waelbroeck C., Duplessy J.-C., Michel E., Labeyrie L., Paillard D., Duprat J. 2001 - The timing of the last deglaciation in North Atlantic climate records, Nature, 412, p. 724-727.

Weber M.-J. 2012 - From technology to tradition: Re-evaluating the Hamburgian-Magdalenian relationship, Neumünster, Wachholtz Verlag (Untersuchungen und Materialien zur Steinzeit in Schleswig-Holstein und im Ostseeraum 5), 252 p. 